National Highway

Traffic Safety

Administration

\title{
Assessment of Insurance Incentives for Safety Belt Use
}

Philip S. Coonley

Carol Gurvitz

DOT/Transportation Systems Center

Kendall Square

Cambridge, MA 02142

This document is available to the U.S. public through the National Technical Information Service, Springfield, Virginia 22161 
This document is disseminated under the sponsorship of the Department of Transportation in the interest of information exchange. The United States Government assumes no liability for 1 ts contents or use thereof. 


\begin{tabular}{|c|c|}
\hline $\begin{array}{l}\text { 1. Rerpor No. } \\
\text { DOT HSS-806 } 474 \quad \text { 2. Converimenent Accession No. }\end{array}$ & 3. Recipient's Cotalog No. \\
\hline $\begin{array}{l}\text { Assessment of Insurance Incentives for Safety } \\
\text { Belt Usage }\end{array}$ & $\begin{array}{l}\text { 5. Report Date } \\
\text { May } 12,1983 \\
\text { 6. Perlorming Organization Code } \\
\text { DTS-45 }\end{array}$ \\
\hline $\begin{array}{l}\text { 7. Author's) } \\
\text { Coonley, P.S., Gurvitz, C.E. }\end{array}$ & $\begin{array}{l}\text { 8. Pertorming Orgonization Report No. } \\
\text {. }\end{array}$ \\
\hline $\begin{array}{l}\text { 9. Performing Organization Name and Address } \\
\text { D0T/Transportation Sys tems Center } \\
\text { Kendall Square } \\
\text { Cambridge, MA } 02142\end{array}$ & $\begin{array}{l}\text { 10. Work Unit No. (TRAIS) } \\
\text { 11. Controct or Grant No. } \\
\text { HS-399 } \\
\end{array}$ \\
\hline $\begin{array}{l}\text { 12. Sponsoring Agency Name and Address } \\
\text { DOT/National Highway Traffic Safety Administration } \\
\text { Office of Driver and Pedestrian Research }\end{array}$ & $\begin{array}{l}\text { 13. Type of Report and Period Covered } \\
\text { Fina1 Report } \\
\text { May, } 1982 \text { - May, } 1983\end{array}$ \\
\hline $\begin{array}{l}4007 \text { th Street, S.W. } \\
\text { Washington, DC } 20590\end{array}$ & $\begin{array}{l}\text { 14. Sponsoring Agency Code } \\
\text { NRD-40 }\end{array}$ \\
\hline
\end{tabular}

15. Supplomentary Notes

16. Abstrac

This study assesses the feasibility of insurance companies to offer incentives, in the form of premium reductions or additional benefits, which would be effective in increasing safety belt usage. The insurance types considered in this report are auto, health, life, and workers' compensation. The research findings on auto insurance, workers' compensation, and 1 ife insurance rely on discussions with about 20 insurance firms. The health insurance industry findings rely on contacts with industry associations, including the Health Insurance Association of America, and, in particular, the Group Health Association of America. This report concludes that:

0 The best prospect for insurance incentives to influence safety belt usage lies with efforts by employers to achieve extra insurance benefits or premium reductions as supplements to other strong employer safety belt efforts.

- Insurers have a substantial financial incentive in attracting customers who wear safety belts but precise estimates of these savings need to be developed with actual insurance claim data.

o It is unlikely that any insurance company will offer substantial up-front incentives for those who claim to be belt wearers because there are serious problems with trusting the insured's to wear belts and with denying payments to insureds who are injured while not wearing belts.

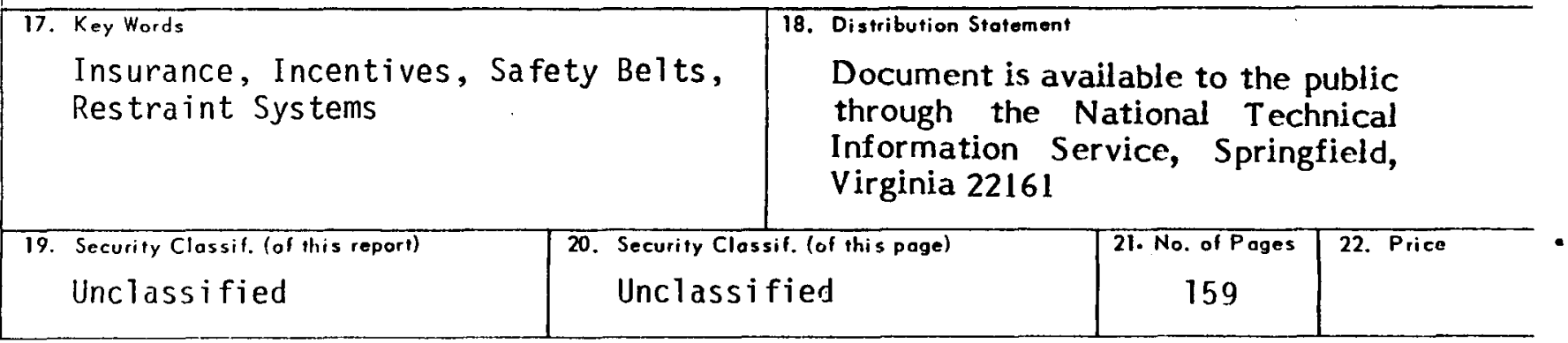




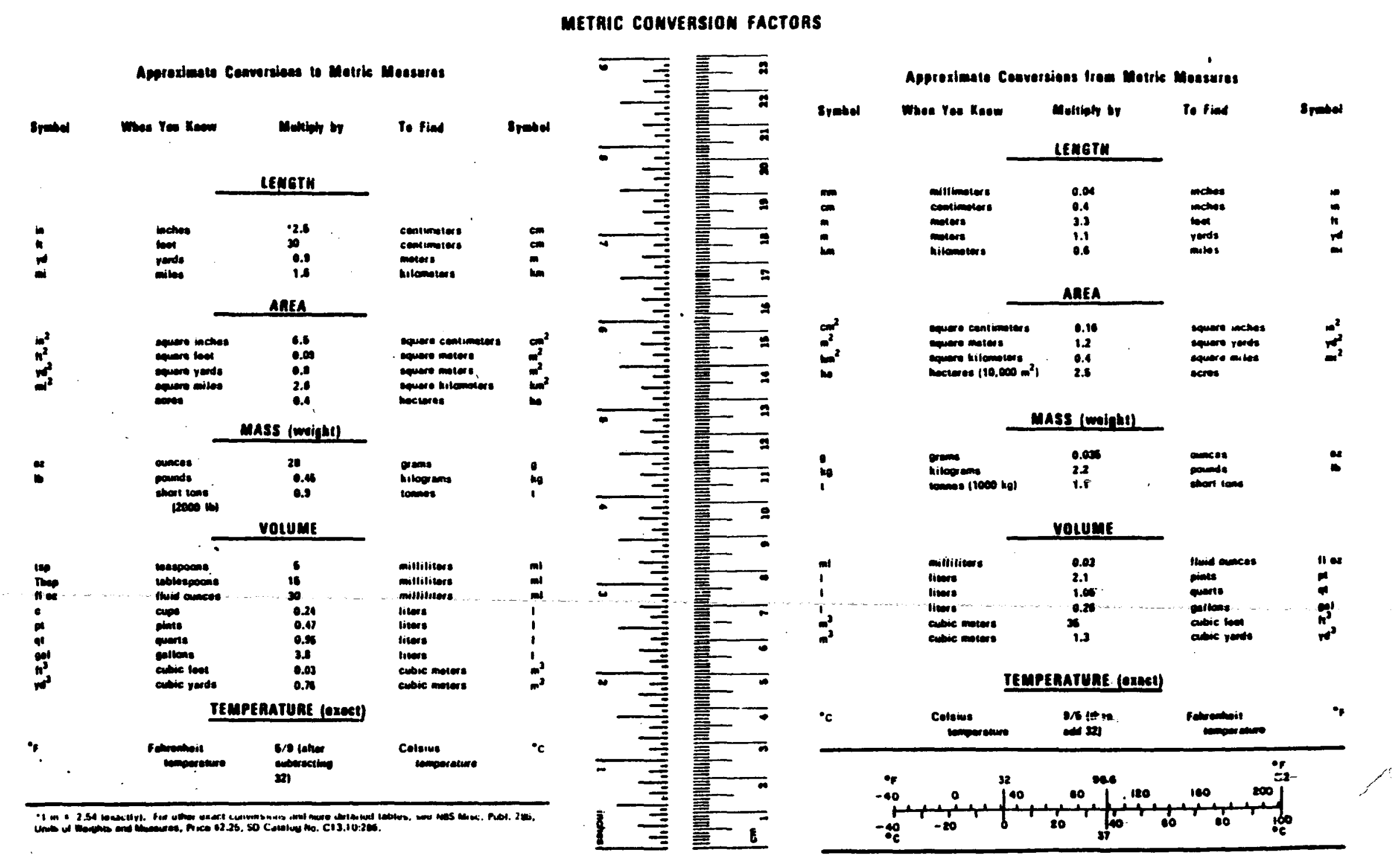




\section{ACKNOWLEDGEMENTS}

Many people have contributed to this study. The joint authors gratefully acknowledge the contributions of Raymond Shih (Operator/Vehicle Systems Division, TSC) for the life insurance chapter; Garry Prowe (Raytheon Service Co.) for the chapters on health insurance and health maintenance organizations; and J.K. Pollard and Mary Stearns (Operator/Vehicle Systems Division, TSC) for portions of the chapter on the general case for insurance incentives.

Dr. John Eberhard of the National Highway Traffic Safety Administration's Office of Driver and Pedestrian Research has supported this study from its inception through its completion.

Among the insurance industry officials who were particularly generous with their time and insights were Doug Fergusson, Nationwide Insurance Co.; Lyle Prause, Safeco; Daniel Ershoff, Maxicare, Inc.; Jim Saalberg, League General; Bill Quinn, Robert Heglund, and John Elliott, Liberty Mutual Insurance Co.; John Appleby, Automobile Club of Southern California; Ray Jackson, Travelers Insurance Co.; Garnett Brown, J.C. Penney; Richard Jewell, National Association of Independent Insurers; and Hal Hunter, Group Health A ssociation of America.

$V$ aluable editorial and substantive review of this study was performed by Simon Prensky and E. Donald Sussman of TSC's Operator/Vehicle Systems Division and by Herschel Hawley of NHTSA. Carol Arlington provided many hours of secretarial support. 
Acknowledgements

Table of Contents

List of Tables and Exhibits

vi

Executive Summary

viii

Chapter 1: Introduction

1.1 Purpose and Scope

$1-1$

1.2 Organization of the Report

Chapter 2: $\quad$ The General Case for Insurance Incentives

2.0 Summary 2-1

2.1 Efficacy of Safety Belts in Reducing Injury and Death 2-1

2.2 Costs of Motor Vehicle Accidents

2.3 Insurance Loss Reductions from Safety Belt Usage

2.4 Potential for Incentives to Increase Safety Belt Usage

Chapter 3: The Automobile Insurance Industry

3.0 Summary 3-1

3.1 General Description 3-2

3.2 Structure of the Industry 3-3

3.3 Types of Automobile Insurance, Premiums, and Benefits 3-4

3.4 Auto Insurance Coverage Characteristics Influencing the 3-6

Potential for Safety Belt Incentives
3.5 Estimating the Auto Insurance Loss Reduction Associated with 3-11

Safety Belt Wearers

3.6 Regulatory Environment

3.7 Experience with Incentives

3.8 Model Automobile Insurance Incentives

Chapter 4: Health Maintenance Organizations

$4-1$

4.1 General Description

4.2 HMO Experience with Insurance Incentives

$4-1$

4-4

4.3 HMOs and Safety Belt Incentives

4-6

Chapter 5: The Health Insurance Industry

5.0 Summary

5.1 Hexalth Insurance Types and Purposes 5-2

5.2 An Example of Typical Health Insurance Policies: Federal Plans 5-10

5.3 Industry Experience with Insurance Incentives 5-11

5.4 Conclusions 
Chapter 6: The Life Insurance Industry

6.0 Summary 6-1

6.1 General Description: Life Insurance Types 6-2

6.2 Life Insurance Industry 6-4

6.3 Existing Life Insurance Incentives: Non-Smoking 6-9

6.4 Existing Life Insurance Incentives: Physical Fitness 6-18

6.5 Potential Life Insurance Incentives for Encouraging 6-21

6.6 Recommendations $\quad$ 6-26

A ppendix 6-1 Percentage of Business Issued to Non-Smokers by State 6-29

Mutual Life, Phoenix Mutual Life, and Home Life

Insurance Companies

Appendix 6-2 Urity Mutual's "Fit Person" Discount Plan

A ppendix 6-3 Premi.jms for a Safety Belt-Related Accidental Death Benefit

$\begin{array}{cl}\text { Chapter 7: } & \text { Workers' Compensation Insurance } \\ 7.0 & \text { Summary } \\ 7.1 & \text { Background } \\ 7.2 & \text { Analysis of Typical Policy and Benefits } \\ 7.3 & \text { Rate Determination } \\ 7.4 & \text { Financial Indicators } \\ 7.5 & \text { Competitive Factors } \\ 7.6 & \text { Regulatory Environment } \\ 7.7 & \text { Major Public Policy Concerns } \\ 7.8 & \text { General Industry View of Insurance Incentives } \\ 7.9 & \text { Workers' Compensation Cost Reductions: Motor Carriers } \\ 7.10 & \text { Reduction of Workers' Compensation Benefits Due to Failure } \\ & \text { to Wear Safety Belts } \\ 7.11 & \text { Recommendations for Safety Belt Incentive Program }\end{array}$




\section{LIST OF TABLES, EXHIBITS, AND APPENDICES}

\section{TABLES}

Page

2-1 Injuries to Automotive Occupants in Tow-A way Accidents, by

Restraint Use: NASS Data, 1979-80

2-2 Injuries to Automotive Occupants in Tow-A way Accidents, by

Restraint Use: NCSS Data

2-3 Economic Loss from Traffic Accidents in the Urited States, 1960-1980

2-4 Societal Costs of Motor Vehicle Accidents

2-5 Relative Contribution of Reimbursement Sources

2-6 Derived Distribution of Insurance Payments to Persons Injured

3-1 1981 Automobile Insurance Premiums

3-2 Top 15 U.S. Auto Insurance Firms In 1981

3-3 Examples of Auto Insurance Premiums and Coverage

3-4 Auto Insurance Coverage as Reported by U.S. Car Owners, 1981

3-5 Example of 1982 Massachusetts Surcharge Table

3-6 Summary of Insurance Company Responses to Congressman James C. Cleveland's Letters

3-7 Premium Discounts for Airbag as of March, 1978

5-1 Types of Health Insurance

5-2 The Providers of Heal th Insurance

5-3 Market Shares of Leading Commercial Health Insurance Companies

5-4 The Major Commercial Health Insurance Firms

5-5 Annual Premium Costs for Various Health Insurance Plans

6-1 1981 Rankings of U.S. Life Insurance Companies by Premium Income (Top 15) and Insurance in Force

6-2 Premium Receipts: U.S. Life Insurance Companies

6-3 U.S. Life Insurance Company Dollar, 1980

6-4 State Mutual Mortality Experience by Age at Issue 
6-5 Comparison of Sinoker and Nonsmoker Premiums: State Niutual Life 6-13

6-6 Comparison of Initial Preiniums between Nonsmokers and 5 mokers 6-14

6-7 Cornparison of Premiums between Standard and HA/PFI Plans 6-20

7-1 1981 Workers' Compensation Insurance Market $\quad 7-4$

7-2 Leading Writers of Workers' Compensation Insurance, 1931 7-5

7-3 Estimates of Workers' Compensation Payments by Typé benefits, 7-12 1979 and 1978

7-4 Workers' Compensation Claims of Six Motor Carrier Fleets 7-18

\section{EXHIBITS}

5-1 Oregon Health Chec 5-14

\section{APPENDICES}

2-1 Estimating the Annual Savings in Direct Insurance Claims 2-18 Payments from Increased Safety Belt Use

6-1 Percentage of Business Issued to Nonsmokers by State Mutual Life, Phoenix Mutual Life, and Home Life Insurance Companies

6-2 Unity Mutual's "Fit Person" Discount Plan

6-3 Premiums for a Safety Belt-Related Accidental Death Benefit 


\section{EXECUTIVE SUMMARY}

This study, sponsored by NHTSA's Dffice of Driver and Pedestrian Research, assesses the feasibility of insurance companies to offer incentives, in the form of premiurn reductions or additional benefits, which would be effective in increasing safety belt use. This idea has intuitive appeal because individuals usually respond to financial incentives, and because insurance companies could substantially reduce their motor vehicle injury-related loss payments if belt use increased.

The insurance types considered in this report are auto, health, life, and workers' compensation. The research findings on auto insurance, workers' compensation, and life insurance rely primarily on discussions with about 20 insurance firms. The health insurance industry findings rely more heavily on contacts with industry assoriations, including the Health Insurance Association of America, and, in particular, the Group Health Association of America.

\section{Findings}

General

- The insurance industries have a large stake in reducing the costs of motor vehicle accident-related injuries and deaths. On the basis of very incomplete data, we estimate that $\$ 12.8$ billion was paid out by private insurers as compensation for motor vehicle injuries in 1980, including:

o $\$ 9.2$ billion by auto insurers (or 22 percent of total premium value);

- $\$ 3.0$ billion in health insurance (four percent of total premium value); and

- $\$ 0.5$ billion in workers' compensation insurance (two percent of total premium value).

- A recent NHTSA study indicates that belt wearers have about 44 percent the incidence of fatal or serious auto injuries as do unbelted occupants. While the efficacy of the safety belt is indisputable, financial data on the expected loss reductions associated even with current belt users are lacking. However, it is estimated that the 
savings in direct insurance claims to be realized by converting all currently unbelted motor vehicle occupants to regular belt use is about $\$ 5.8$ billion annually.

- The various insurance industries are regulated primarily by state insurance commissions, whose mandate is to oversee the financial viability, marketing behavior, and claims settlement process of insurance firms. They generally are more concerned about the potential of incentives to confuse consumers than about their potential to change driver behavior.

o No insurance companies currently provide incentives in the form of premium reductions based solely on regular beit usage, although there are many auto insurance firms that offer additional benefits. No insurance company-provided incentive has been evaluated with respect to its effectiveness in increasing belt usage by insuredi. There is widespread belief in the industry that incentives would be ineffective in changing the level of safety belt usage. Incentives are seen by insurers as a way to influence a company's share of those in the population already wearing belts, rather than as a way of increasing the overall number of belt wearers. Without an increase in the general level of belt usage, the overall premium levels cannot be reduced, only shifted from belt wearers to non-users.

- Employers are in a much stronger bargaining position (because of their group purchasing power and negotiating abilities) than individuals in negotiating changes in insurance premiums and benefits that would recognize the lower risks associated with belt use. Employers may be interested in obtaining insurance incentives for safety belt use because other types of financial incentives have proven effective when of fered by employers. (This is probably because employers are in a unique position to use daily face-to-face education, promotion, peer pressure, financial incentives, and direct observation to encourage safety belt use.) Moreover, employers are in a strong position to capture a portion of the financial benefits from increased safety belt usage, including lower insurance premiums. 


\section{Auto Insurance.}

- Less than 20 percent of the total automobile coverage arid premium lends itself to reduction due to an individual insured's safety belt wearing. Of the six types of auto insurance coverage - bodily injury liability, property damage liability, comprehensive (fire, theft, etc.), medical payments (personal injury protection in no-fault states), collision, and uninsured motorist - two types, the medical payments and uninsured motorist coverages, directly relate to the injury severity of the occupants of the insured's vehicle. A third category, bodily injury liability, can relate to injury severity in jurisdictions where occupants are permitted to sue the owner/driver of the vehicle in which they are passengers.

- The estimated potential annual average reduction in loss payout per insured safety belt user ranges from about $\$ 11.00$ up to $\$ 42.00$. The potential reduction is greatest in no-fault states with high limits on medical payments and wage coverage. Thus, there is a significant incentive for insurance companies to attract belt-using customers. However, this estimate is not verifiable with actual claims data because these data do not differentiate between belt wearers and nonusers.

- "Although premium reductions for safety belt use would be desirable both for attracting customers and for increasing belt usage, the auto insurance industry's reluctance to offer up-front premium reductions is based on the problems associated with either completely trusting the insured's commitment to wear safety belts or in denying a portion of coverage to those insureds who are injured while not wearing a safety belt.

- Extra benefits for safety belt usage, in the form of an additional 50 to 100 percent in medical payments coverage for those injured in motor vehicle accidents while belted, have been offered by several auto insurance firms for over a decade. These incentives were offered primarily as a marketing strategy, but also reflected a belief that safety belt wearers were a "better class" of risk. However, until 
recently no firm has inarketed these safety helt benefits aggressively, evaluated their impact, or had any reason to believe that they had been effective in increasing their market share of the belt-wearing population. No firm believes that the extra benefits are effective in changing safety belt usage. However, at least one firm, the Travelers Insurance Company, was enthusiastic about the idea of coupling incentives for belt wearing with employer-based safety belt efforts.

o Recently, safety belt benefits have been increased or newly offered by several of the nation's leading auto insurers. For example, Nationwide recently announced a doubling of medical payments coverage, a special $\$ 10,000$ death benefit, and increased family compensation coverage for those insured who are injured while wearing safety belts. These additional benefits are estimated to increase the claims liability per insured belt wearer by less than one dollar per year.

\section{Heal th Insurance}

- Of the civilian non-institutional population, 85 percent is protected by at least one type of private health insurance.' Group policies represent 84 percent of total premium dollars. Major employers typically pay between 70 and 100 percent of health insurance premiums for their employees. Annual premiurns for family policies range from $\$ 1,600$ to $\$ 2,700$, depending on the carrier and the services covered. Our estimate is that losses attributable to motor vehicle accidents equal four percent of the premium. Given that serious injuries and fatalities are about 44 percent as likely for safety belt wearers, a belt-wearing family with a comprehensive family health insurance policy may save the insurer from $\$ 32$ to $\$ 54$ annually in medical claims.

o Although it is estimated that health insurers are spending $\$ 3.0$ billion annually on motor vehicle injuries, the health insurance industry itself has no estimate of the aggregate medical costs associated with motor vehicle injuries, let alone those related to the failure to wear safety belts. 
o Since preiniums typically are based on the experience of either the group or the community, and since health insurers generally may not set discriminatory premiums based on policyholder behavior (including smoking), neither premium reductions nor extra benefits based on an insured's preventive behavior are provided by health insurers.

- Health maintenance organizations (HMOs) have been extremely active in counseling related to child restraint usage; some have offered discounts, gifts, or loans of child safety seats. While HMOs generally are committed to promoting child restraints, they are increasingly concerned that their loaner programs are not cost-beneficial to the HMO itself.

- Health insurers have extensive experience in providing preventive health services, such as inoculations and counseling, but almost no experience in offering incentives for preventive health behavior. One of the few exceptions is Health Chec, an experimental program initiated in Oregon by an insurance firm for its employees during 1982. This program returns part of the health insurance premium contributions to the program participants after one year if they are absent from work less than the average of all employees and accumulate a certain number of "wellness points" for certain good heal th practices. Some of these points may be achieved by committing to safety belt usage. The program has been successful in reducing medical insurance payments and lọst time. However, no data have been collected on the program's impact on the belt-wearing habits of its participants.

\section{Workers' Compensation Insurance}

- Workers' compensation insurance is designed to provide for the expenses of medical care, rehabilitation, and lost wages for injured employees, and death benefits for the dependents of persons killed in work-related accidents. In 1979, 89 percent of all wage and salary workers were covered by workers' compensation insurance. 
Since workers' compensation is a mandatory, state-regulated employer responsibility, there is no way that workers' compensation insurers can provide incentives directly to individuals. Reducing workers' ability to claim workers' compensation if injured while not wearing safety belts has been the announced policy of the State of Vermont for state workers since early 1982. However, this policy has not been enforced.

- Workers' compensation premiums are based on historical claims loss data for major firms, and on industry-wide norms for smaller firms. Thus, larger firms have a direct interest in reducing their motor vehicle accident-related losses, since these reductions will be reflected in lower future premiums.

- Workers' compensation insurers offer loss prevention services and are constantly stressing the direct relationship between worker safety, workers' compensation premiums, and overall company profitability. They also are in an excellent position to monitor the costs of on-the-job motor vehicle injuries for specific industries.

- Depending on the industry, workers' compensation claims costs for motor vehicle injuries can be substantial; for example, insurance data derived from a representative group of companies shows that motor carriers have an average of $\$ 322$ per driver per year in such claims.

\section{Life Insurance}

- Life insurers have not offered discounts or benefit increases to belt wearers because the mortality data is not highly credible, the potential market currently is only 11 percent of the driving population, and existing discounts for non-smokers already favor the less accidentprone drivers.

- The life insurance industry is accustomed to setting premiums based on age, sex, health, and risk-related behavior. Premium discounts of up to 50 percent have been offered for non-smoker's term insurance in recent years. These discounts are offered to attract customers with substantially lower expected mortality rates, but are not intended (or thought to be effective) in changing behavior. 
- Based on recent NHTSA data, the probability of death from a motor vehicle injury for a belted driver is 0.44 that of an unbelted driver. In other words, where the expected loss payout for an unbelted driver is about $\$ 14.00$ on a $\$ 100,000$ life insurance policy, the expected payout for a belted driver is only about $\$ 6.00$. A belt wearer with $\$ 100,000$ of life insurance could pay $\$ 8.00$ less on the annual premium than a nonbelt wearer (or receive an additional special accidental death benefit of more than $\$ 130,000$ if killed in an automobile accident while wearing a belt).

- Recognizing the very low likelihood that a belt wearer will die in a motor vehicle accident, several auto insurers recently have added special accidental death benefits to their automobile policies at little or no charge.

- Many employers either contribute directly to life insurance premiums for employees or offer group life insurance through a payroll deduction plan. A large employer who was successful in increasing safety beit usage by its employees would have a good case for a modest reduction in the employees' life insurance premiums.

\section{Conclusions}

- The best prospect for insurance incentives to influence safety belt usage lies with efforts by employers to achieve extra group insurance benefits or premium reductions as supplements to other strong employer safety belt efforts.

- Employers have a concentrated financial interest in increased safety belt usage, both on-the-job and off-the-job, because they commonly pay most of the health insurance premiums, some life insurance premiums, and for workers' compensation, sick time, and trauma-associated productivity losses.

- Employers are in a strong bargaining position with respect to insurers since they are direct and large customers, are informed about insurance policies and premiums, and are experienced at negotiation. 
- Employers are in a unique position to influence employee belt usage because of their daily control over the employees' environment, faceto-face education and promotion, opportunities for peer testimonials and peer pressure, the capability to fund and administer lottery-type incentive programs, and the ability to impose sanctions for the failure to use safety belts while on-the-job.

- Insurers have a substantial financial incentive in attracting customers who wear safety belts. The size of this incentive depends on the type of insurance, the age of the insured, and the type of employment. Examples of these annual loss claims savings include a potential $\$ 11.00$ to $\$ 42.00$ savings in private auto insurance, $\$ 200$ savings in workers' compensation per truck driver, approximately $\$ 3.00$ on an average life insurance policy, and $\$ 32$ to $\$ 54$ on a comprehensive family health insurance premium. More precise estimates of these savings need to be developed with actual insurance claim data that differentiate between belt wearers and non-belt wearers.

o It is unlikely that insurance companies will offer substantial up-front incentives, such as premium discounts, for those who claim to be belt wearers. Although premium reductions for safety belt usage would be desirable both in terms of attracting customers and increasing belt use, there are serious problems associated with trusting an insured's commitment to wear belts and denying claims settlements to those insureds who are injured while not wearing belts.

- Insurance incentives alone are unlikely to change belt-wearing behavior, but may influence the choice of insurer by those already committed to regular belt usage.

- Important safety belt-related data are lacking in the following areas:

- The distribution of motor vehicle injury and mortality costs among the various types of insurers;

- Loss claims data for belt wearers and non-belt wearers by demographic characteristics;

- Employer costs of motor vehicle injuries and fatalities both at work and off-the-job, and the ability of safety belt programs to reduce these costs; and

- Mortality data for belt wearers as opposed to non-belt wearers. 


\section{Recommendations}

- The important safety belt-related data identified above should be collected in cooperation with major insurers and employers, and should be widely disseminated so employers will better appreciate the substantial potential econornic benefits of safe driving and belt use.

- Existing insurance incentives and initiatives relating to safety belts and child restraints should be evaluated for their effectiveness in increasing restraint usage, attracting belt-wearing customers, and reducing loss claims. In particular, the following programs should be evaluated:

o The offering by Nationwide's auto insurance of additional death benefits/medical payments/family compensation to belt wearers;

- The Health Chec "wellness" and cash rebate program offered by Blue Cross/Blue Shield of Oregon; and

- Vermont's "policy" of denying workers' compensation benefits to state employees who are killed or injured without safety belts while on-thejob.

- NHTSA should evaluate a selected health insurance child restraint/parental safety belt education and safety seat loaner/giveaway program because: 1), health insurers have been most active in the use of incentives (in the form of safety seat loans, discounts, and giveaways) to promote child restraint use; 2), there may be a strong relationship between child restraint use and adult safety belt wearing; and 3), the heal th insurers are concerned about the costeffectiveness of the child safety seat programs.

- NHTSA should encourage employers to increase the safety belt use by employees and their families through active involvement with group insurers. Such encouragement may take two forms: the development of data that demonstrates the economic benefits to both employers and employees of participating in safety belt programs, and the development of guidelines and techniques which facilitate the implementation of such programs. 


\section{CHAPTER 1: INTRODUCTION}

\subsection{PURPOSE AND SCOPE}

The purpose of this study is to gain an understanding of the potential for U.S. automobile, health, life, and workers' compensation insurance to offer incentives which would increase safety belt use. The report is intended to be used by the National Highway Traffic Safety Administration (NHTSA), insurance companies, employers, and other organizations and individuals interested in increasing safety belt use. Because this report concerns the potential role of insurance companies in providing financial incentives to individuals, it focuses on the dollar costs of motor vehicle injuries. While the economic benefits of increased safety belt use are substantial and may motivate individuals to increase belt use, the reduction in the pain and suffering associated with motor vehicle injuries and fatalities would be an even greater benefit.

\subsection{ORGANIZATION OF THE REPORT}

The second chapter reviews the following:

- The data demonstrating that wearing safety belts greatly reduces the risk of serious injury and fatality, and their associated costs;

- The data suggesting that insurance companies are reasonable institutions through which to make the cost savings from safety belt use more evident to motorists;

- The data relevant to the effectiveness of financial incentives in increasing safety belt use; and

- Information suggesting that employers are especially well-situated to both initiate insurance incentives and to use them in a way that may be most effective in increasing safety belt usage. 
world accident data demonstrates that motor vehicle occupants wearing safety belts have less than half the incidence of fatality and serious injury as those not wearing belts.

For the years 1979 and 1980, NASS supplies extremely detailed records of about 3,000 accidents per year. Investigation teams spend about 50 hours on each accident interviewing victims, police officers, medical personnel, and others, as well as gathering physical data and making about 75 photographs of the site, vehicles, and overall accident environment. The accidents included in NASS are selected according to a probability sampling scheme which allows results to be expanded to the total population.

Table 2-1 shows NASS data on the restraint use and injury severity of accident victims in 1979-80. Restraint effectiveness is defined as the relative decrease in injuries (or fatalities) to restrained versus unrestrained vehicle occupants. In equation form,

$$
\text { Effectiveness }=\frac{\text { Unrestrained rate }- \text { Restrained Rate }}{\text { Unrestrained rate, }}
$$

Where "unrestrained rate" is the rate of injury or fatality to unrestrained occupants, and "restrained rate" is the equivalent rate for restrained occupants.

Injury severity is rated according to the Abbreviated Injury Scale (A.I.S.), an injury severity rating system first developed by the American Association for Automotive Medicine in 1971 and most recently updated as AIS-80. This comprehensive system for rating tissue damage due to trauma is used world-wide. Scale values range from 1 reflecting a minor injury to 6 for a maximum injury which is virtually unsurvivable.1 "Maximum AIS" refers to the most severe injury sustained by an accident victim when more than one injury is sustained. 
The NASS data show that among unrestrained occupants, 8.0 percent sustained maximum injuries of AIS three or higher 2.9 only 1.7 percent of the restrained occupants did so. The effectiveness of safety belts in reducing injuries is therefore 64 percent $((8.0-2.9) / 8.0)$. Similialy, 0.38 percent of those wearing belts were fatally injured, as opposed to one percent of those not wearing safety belts. Thus, the NASS data show that the effectiveness of belts in reducing fatalities is 60 percent.

\section{TABLE 2-1}

INJURIES TO AUTOMOTIVE OCCUPANTS IN TOW-AWAY ACCIDENTS, BY RESTRAINT USE: NASS DATA, 1979-1980

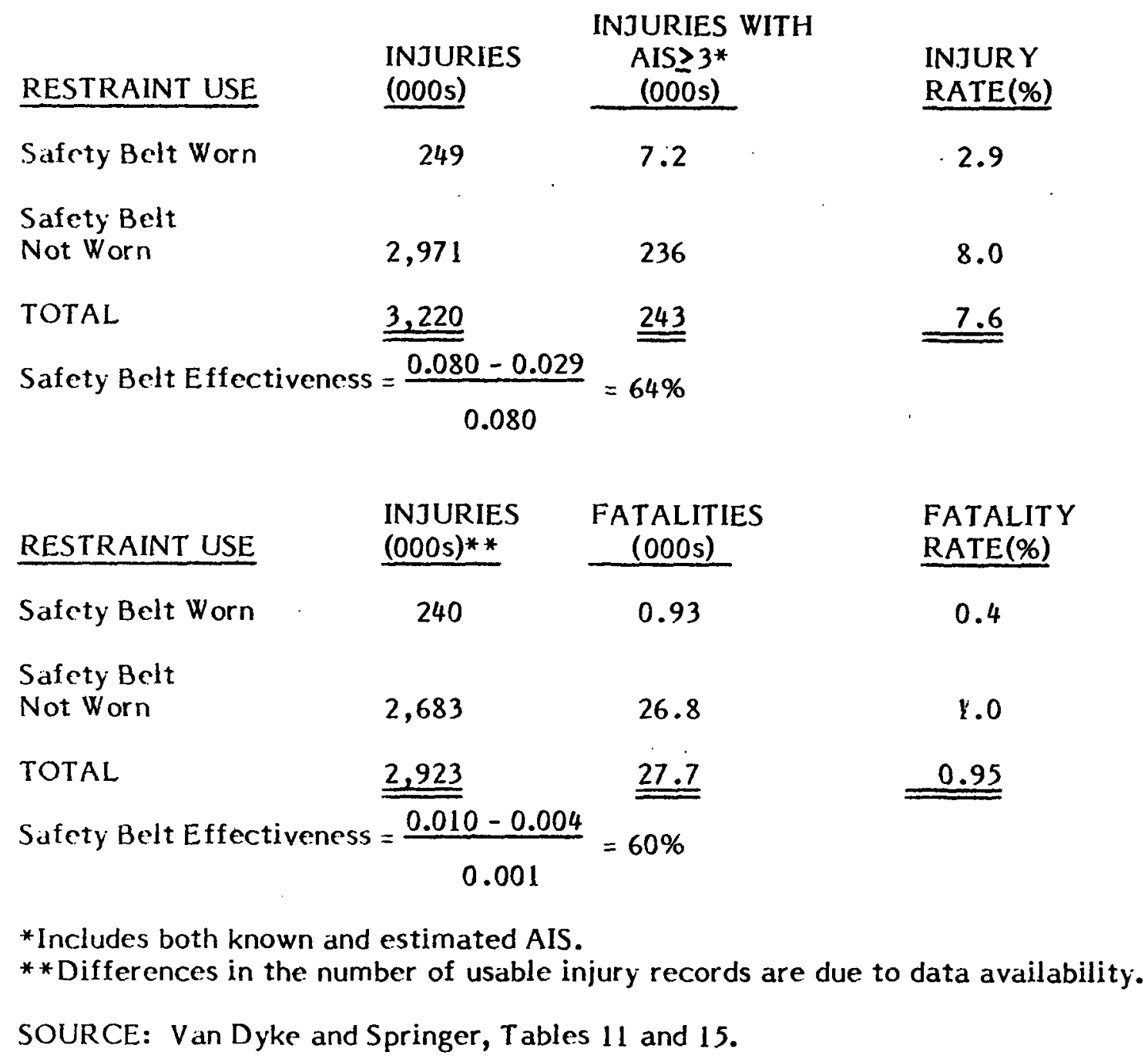


The National Crash Severity Study (NCSS) is a one-time data collection consisting of information on 25,000 occupants of automobiles involved in police-reported towaway accidents. Because serious accidents were sampled at a higher rate than were less serious accidents, the number of accident cases of each type must be weighted to produce an unbiased national sample of injury severity. When weighted, the number of injured vehicle occupants increases to approximately $106,000.2$ The study was designed specifically to link vehicle damage to occupant injury scverity. Accident investigation teams, similar to those used for NASS, collected information from seven sites selected to match the national distribution of central city, suburban, small town, and rural populations.

A nalysis of NCSS data in Table 2-2 shows that about 2.2 percent of belted automobile occupants had an Overall AIS (equivalent to the NASS Maximum AIS) greater than or equal to three, while 4.3 percent of those not wearing safety belts sustained an equivalent injury. The effectiveness of safety belts in reducing serious injuries, as derived from these data, is approximately 50 percent. A similar Calculation using NCSS data on fatalities shows that the effectiveness of safety belts in reducing fatalities is 49 percent.

The average effectiveness of safety belts in reducing serious injuries and fatalities thus ranges between 50 and 60 percent. NHTSA uses an estimated effectiveness figure of 56 percent, which has been adopted for use in this report.

These estimates of safety belt effectiveness do not imply that belt use by itself reduces injuries and/or deaths by a factor of two. There is evidence that safety belt-using drivers tend to have somewhat less severe crashes than non-users. ${ }^{3}$ Since changing a non-user into a user may not affect other aspects of driving behavior, the reduction in risk of injury or death may be somewhat smaller than that suggested by the data on present users and non-users. At the margin, however, individuals who can be induced to become belt users through insurance incentives are probably fairly similar to current belt users in other aspects of their driving behavior. Moreover, the first impact of special incentives for safety belt wearing 
is likely to be that those alrcady wearing belts choose the policy offering special benefits. Thus, the data in Tables $2-1$ and 2-2 provide a reasonably satisfactory estimate of the relative injury severity reduction associated with occupants who wear belts, or are likely to become belt wearers through incentives.

TABLE 2-2

INJURIES TO PASSENGER CAR OCCUPANTS IN TOW-A WAY ACCIDENTS, BY RESTRAINT USE: NCSS DATA

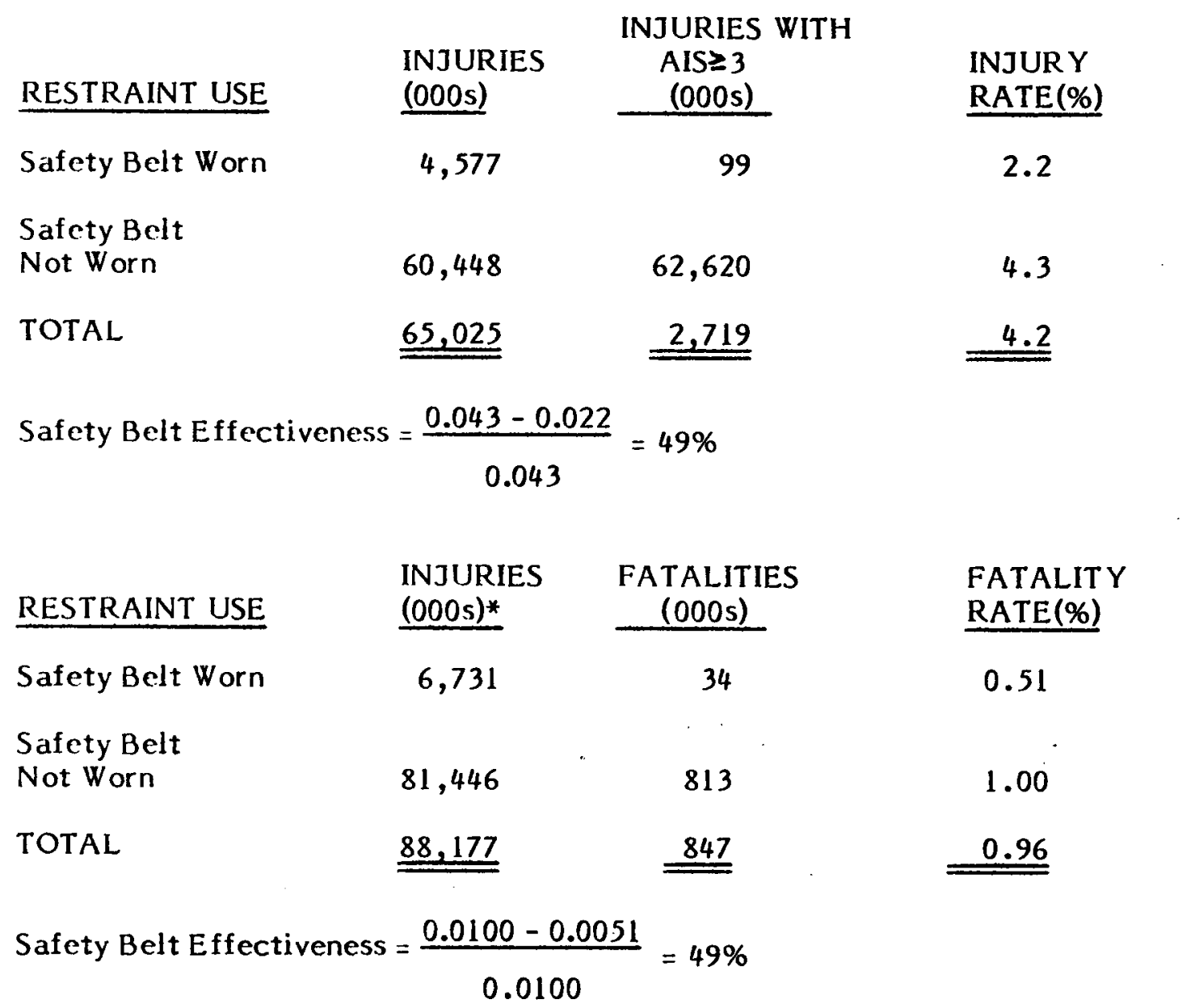

* Differences in the number of usable injury records are due to data availability.

SOURCE: Van Dyke and Springer, Tables 12 and 16. 


\subsection{COSTS OF MOTOR VEIHCLE ACCIDENTS}

A nother factor to be considered in making the general case for insurance incentives is the magnitude of potential financial savings from increasing belt use. The general estimate can be developed from data on the overall costs of motor vehicle accident injuries and fatalities, and on the compensation of these injuries by social institutions including insurance companies.

The economic losses associated with motor vehicle accidents inclucie lost wages and salaries; legal, medical, hospital, and funeral expenses; insurance. administration costs; and property darnage. Some components, such as medical and auto repair costs, can be estimated with reasonable accuracy because they are immediate and are accompanied by actual cash payments. On the other hand, wage losses represent the net present value of. future earnings streams which are subject to much greater uncertainty with regard to factors such as magnitude, pattern over time, and discount rate. Table 2-3 shows the estimates of the Insurance Information Institute (I.I.I.) for the total economic loss associated with motor vehicle accidents for the past two decades. The rapid rise of the current dollar total of economic losses since 1970 is due almost entirely to inflation.

Table 2-4 identifies the costs of motor vehicle accidents in 1980 as estimated by NHTSA in a 1983 study, The Economic Cost to Society of Motor Vehicle Accidents. The $\$ 57.2$ billion total is close to the Insurance Information Institute estimate of $\$ 57.5$ billion. Of particular interest to this study are the $\$ 14.2$ billion attributable to lost productivity, the $\$ 3.3$ billion in medical costs, and the $\$ 7.5$ billion in "other losses" related to injury or death. These "other losses" include insurance administration expenses, legal and court costs, emergency services, coroner/medical examiner costs, and the administrative costs of public assistance programs. In other words, motor vehicle injuries and deaths cost the U.S. about $\$ 25$ billion in 1980; these costs would be reduced substantially by increased safety belt use. The majority of the total economic loss is spread among motorists through automobile insurance premiums, including both liability and property damage componentś. 
TABLE 2-3

ECONOMIC LOSS FROM TRAFFIC ACCIDENTS IN THE UNITED STATES, 1960-1980

\begin{tabular}{|c|c|c|c|c|}
\hline YEAR & ACCIDENTS $^{* *}$ & DEATHS* & INJURIES ${ }^{*}$ & CONOMIC LOSS $* * *$ \\
\hline 1960 & $11,429,000$ & 38,137 & $3,078,000$ & $\$ 10,211,000,000$ \\
\hline 1965 & $14,733,000$ & 49,163 & $3,982,000$ & $14,177,000,000$ \\
\hline 1970 & $22,116,000$ & 54,633 & $4,983,030$ & $23,549,000,000$ \\
\hline 1975 & $24,887,000$ & 45,853 & $4,978,000$ & $40,889,000,000$ \\
\hline 1976 & $25,439,000$ & 47,038 & $5,269,000$ & $40,889,000,000$ \\
\hline 1977 & $26,716,000$ & 49,510 & $5,575,000$ & $47,710,000,000$ \\
\hline 1978 & $27,742,000$ & 52,411 & $5,798,000$ & $52,622,000,000$ \\
\hline 1979 & $26,669,000$ & 52,800 & $5,681,000$ & $56,371,000,000$ \\
\hline 1980 & $24,100,000$ & 52,600 & $5,230,000$ & $57,519,000,000$ \\
\hline
\end{tabular}

SOURCES:

* National Safety Council.

* Insurance Information Institute. (Injury estimates prior to 1965 are those of the Travelers Insurance Companies). Estimates by the Insurance Information Institute of accident and injury totals are based on official reports from a representative cross-section of states. The Institute's estimates are higher than those of the National Safety Council, which do not include a factor for unreported accidents and include only injuries which result in death, permanent disability, or some degree of temporary total disability.

***Dollar loss data take into account wage losses; legal, medical, hospital and funeral expenses; insurance administrative costs, and property damage. The projection factors were adjusted in 1972 on the basis of a study by the National Highway Traffic Safety Administration of the social costs of motor vehicle accidents, and are recomputed monthly to track with government cost indices. 
Given the NHTSA estimate of $\$ 57.2$ billion in total losses for 1980 , then the $\$ 39$ billion in premiums which flowed into the auto insurance system comprised 68 percent of the total losses. The iemaining $\$ 18$ billion was spread among other types of insurers, employers, the government, and uncompensated losses. Data for estimating which institutions bore the $\$ 18$ billion loss are extremely weak, and the NHTSA cost study does not focus on who bears the costs. Industry associations of life insurers, health insurers, and HMOs were unable to provide usable information.

A data source which sheds some light on how the burden of motor vehicle injury compensation is distributed among various segments of the insurance industry is a survey conducted by the insurance industry's All-Industry Research Advisory Committee (AIRAC) in 1975-1977. These data, based on interviews with 1,849 injured persons, include the frequency of claims and dollar amounts falling upon various categories of insurers (see Table 2-5), excluding property damage coverage. Of the 1,849 injured persons, only 1,117 were counted in the data, since the others did not have claims which were closed with payment. The data suggest that health insurance is a major source of motor vehicle accident injury reimbursement, especially in more serious injury cases.

This is one of several indications that health insurance is playing a much larger role in motor vehicle injury compensation than is commonly realized (see Chapter 5). However, given the absence of comprehensive data on motor vehicle injury compensation, this finding cannot be verified. The AIRAC-derived estimate of 22 percent health insurance-paid compensation is used here. However, a detailed study of which institutions in society are bearing the costs of motor vehicle accidents is needed because many institutions, especially employers and health insurers, seem to have little awareness of their economic stake in reducing motor vehicle injuries. 
TABLE 2-4

SOCIETAL COSTS OF MOTOR VEHICLE ACCIDENTS

(\$ in Millions)

INJURY LEVEL (AIS)

\begin{tabular}{|c|c|c|c|c|c|c|c|c|c|}
\hline & $\begin{array}{l}\text { PROPERTY } \\
\text { DAMAGE } \\
\text { ONLY }\end{array}$ & 1 & 2 & 3 & 4 & 5 & $\begin{array}{l}\text { FATAL- } \\
\text { ITY }\end{array}$ & $\begin{array}{l}\text { LOSSES } \\
\text { ATTRIBU- } \\
\text { TABLE } \\
\text { TO } \\
\text { DEATH } \\
\text { AND } \\
\text { INJURIES }\end{array}$ & $\begin{array}{l}\text { TOTAL } \\
\text { LOSSES }\end{array}$ \\
\hline $\begin{array}{l}\text { MEDICAL } \\
\text { COSTS }\end{array}$ & & 543 & 622 & 631 & 335 & 1,125 & 70 & 3.3 & 3,326 \\
\hline $\begin{array}{l}\text { PRODUCT- } \\
\text { IVITY } \\
\text { LOSSES }\end{array}$ & & 319 & 251 & 313 & 451 & 801 & 12,102 & 14.2 & 14,237 \\
\hline $\begin{array}{l}\text { PROPERTY } \\
\text { LOSS }\end{array}$ & 16,984 & 2,656 & 612 & 424 & 100 & 33 & 174 & -- & 20,983 \\
\hline $\begin{array}{l}\text { OTHER } \\
\text { LOSSES }\end{array}$ & 4,127 & 3,933 & 590 & 684 & 640 & 245 & 306 & 7.5 & $18,653^{*}$ \\
\hline TOTAL & 21,111 & 7,451 & 2,075 & 2,052 & 1,526 & 2,204 & 13,730 & 25.0 & $57,199 *$ \\
\hline
\end{tabular}

* Includes $\$ 7,050$ million in other costs borne by owners of all motor vehicles which were not involved in accidents.

\section{NOTES:}

1. Government costs are not included in this table as they are not additive with the other cost categories.

2. Injury level represents the maximum AIS level of survivors. All fatalities are shown in the Fatality category, no matter what the injury level.

SOURCE: U.S. DOT/NHTSA, The Economic Cost to Society of Motor Vehicle Accidents (DOTHS-806-342: J anuary, 1983), Table I-J, p.1-4. 
By applying the percentages from Table 2-5 to data on the paid losses by auto insurers for bodily injury and personal injury protection, it is possible to make a rough estimate of insurance payments for motor vehicle injuries. About 65 to 75 percent of auto insurance premiums goes towards loss compensation. ${ }^{4}$ In 1980, the premium total was $\$ 39.1$ billion, so total losses paid out are estimated at $\$ 25.4$ billion. About 36 percent of auto insurance losses relate to bodily injury or personal injury protection coverage. 5 In 1980, therefore, it is estimated that auto insurance payments for motor vehicle injury were approximately $\$ 9.2$ billion $(0.36$ times $\$ 25.4$ billion). Table $2-5$ indicates that this sum constitutes 67.5 percent of the total compensation, thus implying the absolute values of payments shown below in Table 2-6.

TABLE 2-5

\section{RELATIVE CONTRIBUTION OF REIMBURSEMENT SOURCES}

(Closed With Payment Claims)

(1975-1977)

\begin{tabular}{|c|c|c|c|c|c|c|}
\hline $\begin{array}{l}\text { SIZE OF } \\
\text { ECON. } \\
\text { LOSS }\end{array}$ & $\begin{array}{l}\text { GROUP } \\
\text { HEALTH } \\
\end{array}$ & $\begin{array}{l}\text { WORKERS } \\
\text { COMP. }\end{array}$ & $\begin{array}{l}\text { AUTOMOBILE } \\
\text { INSURANCE }\end{array}$ & $\begin{array}{l}\text { GOV'T } \\
\text { SOURCES }\end{array}$ & $\begin{array}{l}\text { OTHER } \\
\text { INSURANCE }\end{array}$ & TOTAL \\
\hline $1-100$ & $12.6 \%$ & $1.2 \%$ & $81.4 \%$ & $3.3 \%$ & $1.5 \%$ & $100.0 \%$ \\
\hline $101-300$ & 11.2 & .2 & 86.5 & 1.3 & 0.8 & 100.0 \\
\hline $301-500$ & 9.0 & .9 & 88.6 & .1 & 1.3 & 100.0 \\
\hline $501-1000$ & 8.4 & .4 & 90.6 & .5 & .2 & 100.0 \\
\hline $1001-2500$ & 9.2 & 1.6 & 86.5 & 2.2 & .5 & 100.0 \\
\hline $250-5000$ & 21.8 & 8.2 & 63.3 & 4.5 & 2.2 & 100.0 \\
\hline $5001-10000$ & 24.0 & 9.3 & 63.6 & 2.0 & .9 & 100.0 \\
\hline $10001-25000$ & & 26.9 & 3.2 & 46.8 & 20.9 & 2.1 \\
\hline $\begin{array}{l}\text { ALL } \\
\text { CLAIMS }\end{array}$ & $23.3 \%$ & $3.5 \%$ & $67.5 \%$ & $5.6 \%$ & $1.1 \%$ & $100.0 \%$ \\
\hline
\end{tabular}

* The contribution of reimbursement sources for claims over $\$ 25,000$ cannot be reliably estimated because of the small sample size.

SOURCE: All-Industry Research Advisory Committee. 
TABLE 2-6

DERIVED DISTRIBUTION OF INSURANCE PAYMENTS TO

PERSONS INJURED IN MOTOR VEHICLE ACCIDENTS, 1980

\begin{tabular}{lrc}
\multicolumn{1}{c}{ TYPE } & PERCENTAGE* & BILLIONS OF \$ \\
${$\cline { 2 - 2 }$} }$ & 22.3 & 3.0 \\
Worker's Compensation & 3.5 & 0.5 \\
Auto & 67.5 & 9.2 \\
Government & 5.6 & 0.8 \\
Other Insurance & $\underline{1.1}$ & $\underline{0.1}$ \\
TOTAL & 100.0 & 13.6
\end{tabular}

*Based on 1975-1977 AIRAC survey data.

As the methodology suggests, Table 2-6 provides only a broad estimate of the distribution and magnitude of insurance payments to persons injured in automobile accidents. The difference between the $\$ 13.6$ billion total from Table 2-6 and the $\$ 25$ billion in total monetary costs of motor vehicle injuries and deaths in 1980 represents overhead costs for insurance companies, losses borne directly by employers through sick leave and productivity losses, and uncompensated losses.

While the estimate of $\$ 13.6$ billion paid by insurance to those injured or killed in automobile accidents is not precise, its magnitude clearly indicates why insurance companies have been identified as institutions with a great financial stake in reducing automobile injuries and fatalities.

\subsection{INSURANCE LOSS REDUCTIONS FROM SAFETY BELT USAGE}

This section provides an estimate of the amount by which insurance claim losses could be reduced with increased safety belt usage. The estimated $\$ 13.6$ billion for insurance compensation in 1980 for motor vehicle injuries and deaths includes 
compensation to people who were not occupants of safety belt-equipped vehicles. A downward adjustment of 20 percent (from $\$ 13.6$ billion to $\$ 10.9$ billion) has been used to allow for losses where safety belt use is irrelevant. This is to account for the fact that 30 percent of those injured and 20 percent of those killed were pedestrians, motorcyclists, and pedalcy'clists.

The portion of this $\$ 10.9$ billion in insurance company payments to occupants of motor vehicles that could be reduced given more widespread use of safety belts depends on the effectiveness of safety belts and on safety belt use rates. The data in Tables 2-1 and 2-2 indicate that the effectiveness of safety belts in reducing serious injury and fatalities is about 56 percent. It is estimated that the annual savings in direct insurance claims payments that may be realized from converting all currently unbelted motor vehicle occupants to regular safety belt use is approximately $\$ 5.8$ billion. (For a detailed derivation of this estimate, see Appendix 2-1.)

\subsection{POTENTIAL FOR INCENTIVES TO INCREASE SAFET Y BELT USAGE}

\subsubsection{BACKGROUND}

There appears to be an inconsistency between attitudes towards safety belts and belt-wearing behavior that influences the potential effectiveness of incentives. On the one hand, the overwhelming majority of American drivers believe that belt use enhances safety. A 1982 Illinois survey found that 85.5 percent of the respondents believe that safety belts were somewhat effective or very effective in reducing injuries while fewer than nine percent felt they were ineffective. 6 Other surveys have reported similar statistics. 7,8 Of course, attitudes as expressed on surveys do not directly predict behavior. Nevertheless, it is surprising that actual belt usage, as determined by observation, currently is only about 11 percent. 9

One study that examined the reluctance to use belts from a psychological perspective concluded that this reluctance was consistent with observed human behavior in other instances in which the probability of an adverse outcome is extremely remote for any particular trip. 10 A number of experiments and field 
surveys have demonstrated the human tendency of failing to undertake an optimal degree of precaution when the probability of an unfavorable outcome is very low. 11,12

The probability of being killed on an average automobile trip is on the order of one in 10,000,000, while the probability of disabling injury is about 1 in $112,000.13,14$ Given these extremely low probabilities of circumstances arising in which belt use will yield benefits, it is perhaps not surprising that most people find safety belt use to be unworthy of the time, effort, and possible discomfort involved.

Incentives represent a way to develop an immediate or near-term payoff for safety belt use. The public has positive attitudes towards the safety belt and recognizes that they can contribute to injury reduction. To be effective, safety belt promotions must focus on motivating people to wear safety belts. Incentive schemes must try to make the perceived payoff more immediate and to balance the equation between behavior (safety belt use) and reward. 15

A nother study used a general safety belt questionnaire and follow-up focus groups to explore the efficacy of insurance incentives. In response to the question, "Would you wear safety belts if offered a reduced rate on your insurance," 80 percent of those queried in a national survey said yes. However, follow-up focus groups revealed respondents would perform this behavior only for a price which was subjectively identified to be in the range of at least $\$ 100$ per year. When the focus group members were told that auto insurance companies would most likely provide increased medical liability coverage, one group's members translated the change to quarterly premium savings. Quarterly savings of $\$ 5$ to $\$ 10$ were deemed irrelevant by the focus group. At a minimum, they would expect at least $\$ 20$ to $\$ 30$ per quarter before changing their belt-wearing behavior. 16

Positive incentives have been tried in the U.S. with considerable success in increasing safety belt use. A recerit survey by Dr. Scott Geller of employer incentive programs aimed at of $f$-the-job safety belt wearing found that post- 
treatment use rates averaged about 44 percent (as measured at the plant parking lot entrances and exits). 17 In one extreme calse, more than two out of three white collar workers became users. These figures surpass the usage rates in many mandatory-use jurisdictions around the world.

The successful incentive programs studied by Geller were all multifaceted approaches that included all or nearly all of the following elements:

- They were conducted or sanctioned by large employers and carried out at the work place.

- The probability of being rewarded for belt use was relatively high. Reward rates ranged from 100 percent for low-value items like discount coupons donated by fast food chains to one percent for more valuable prizes worth $\$ 100$ or inore. Occasionally, much more expensive prizes, such as new cars, were awarded, through lotteries where safety belt use was the requirement for eligibility.

o Rewards were often a function of both individual and group performance so as to encourage the development of peer pressure to use belts. For example, the values of prizes have been a function of the group belt-use rate, or the scheduling of drawings could have been contingent upon the achievement of specified belt-use rates for the group.

- The rewards were applied repeatedly (usually daily) for a period of time, typically a few weeks, followed by a period of intermittent reinforcement. Occasional "refresher" sessions are planned for future years.

- The implementation plans were developed by employees of the participating institutions. The programs received lots of publicity, both within the sponsoring organizations and in their local communities. Contest winners were given considerable recognition, as well as prizes. 
- Promises to wcar safety belts, usually in the form of signed pledge cards, of ten were used, but rewards were based on actual observed safety belt use whenever possible, such as by observers posted at employee parking lot entrances or exits.

From the foregoing list of the characteristics of successful programs, it is evident that there is more to thern than the simple provision of financial incentives. Employers are well-positioned to implement incentive programs for several reasons. The employer is a unique type of intermediary who is close to the employee in terms of ability to observe and reward the use of safety belts on a daily basis. The employer also fosters a group norm regarding behavior. Because safety belt use is positively rewarded, the behavior becomes socially acceptable, and all employees mutually reinforct the requirement for this behavior. The acceptance and social reinforcement provided by fellow workers is as important as the employer's incentive scheme.

Depending on nature of the employer work site and characteristics of the employee population (e.g. amount of on-the-job driving, extent of employer benefit contribution, accident history), the costs to employers of employee motor vehicle accidents exceed several hundred dollars. Thus, there may be a substantial economic incentive for employers to undertake safety belt incentive programs and for their insurers to support and encourage the activity. The safety belt incentive programs studied by Geller had average direct costs for prizes and publicity of less than $\$ 10$ per year per employee. For large organizations, administrative costs probably added no more than $\$ 10$ per employee. The success rates of these programs were on the order of 40 percent (i.e., about 40 percent of the non-users become long-term belt users). Thus, the effective cost per worker converted to belt use was about $\$ 50$. At this overall cost, the programs are probably costeffective to society, and to the employers. Furthermore, the societal cost savings are most likely understated because of induced safety belt usage by employees' families. 


\subsubsection{CONCLUSIONS}

It may be in the best interest of corporate clients to work with and through their insurance companies to develop incentive programs for safety belt usage for the following reasons:

- Employers have a larger economic incentive to implement belt use programs than insurers have. Whereas large employers with extended sick leave policies and comprehensive medical benefits stand to achieve substantial economic savings for each employee converted to belt use, individual insurance companies can gain only a small fraction of that amount because each type of company shares only a portion of the total cost of motor vehicle accidents.

- Employers have the daily contact with policyholders that is required to provide the frequent rewards most effective in developing habitual belt use.

- Employers can reward actual belt use.

- Incentive schemes based on extra payoffs to belt users in the event of accident or reduced payoffs to non-users are probably relatively ineffective options. If the prospect of saving one's life or avoiding serious injury is not a sufficient incentive to use belts, it is difficult to imagine that extra insurance benefits could change behavior substantially. 
APPENDIX 2-1

ESTIMATING THE ANNUAL SAVINGS IN DIRECT INSURANCE CLAIMS PAYMENTS FROM INCREASED SAFETY BELT USE

It is estimated that the annual savings in direct insurance claims payments that may be realized from converting all currently unbelted motor vehicle occupants to regular safety belt use is approximately $\$ 5.8$ billion. This is calculated as follows:

- The average annual cost per auto occupant is equal to the average claims cost of unbelted occupants times the proportion of unbelted occupants, plus the claims cost of belted occupants times the proportion of belted occupants.

$$
C / N=U \cdot X+B(1-E) X
$$

Where:

$\mathrm{C}=$ average claims cost per motor vehicle occupant;

$N=$ total number of insured motor vehicle occupants;

$U=$ proportion of unbelted occupants

$B=$ proportion of belted occupants;

$X=$ direct claims cost of an unbelted occupant;

$E=$ effectiveness of safety belts;

$(1-E) X=$ cost of a belted occupant; and

$\mathrm{X} \cdot \mathrm{E}=$ cost savings of converting one motor vehicle occupant to regular belt use.

- Given that 89 percent of motor vehicle occupants do not wear safety belts and that safety belts are estimated to be 56 percent effective, the average cost savings per unbelted driver is calculated as:

$$
10.9 / N=0.89 X+0.11(0.44) X ;
$$

Where:

$$
X=11.6 / N
$$


- The insurance claims savings expected to be realized by converting all motor vehicle occupants to regular safety belt use is equal to the effectiveness of belts times the number of converted non-belt wearers, times the insurance claims cost per unbelted motor vehicle occupant:

$$
\begin{aligned}
& \text { S }=\mathrm{E} \cdot(\mathrm{U} \cdot \mathrm{N}) \cdot \mathrm{X}, \\
& \begin{aligned}
\text { where: } \\
\mathrm{S}=\text { total insurance claims savings given } 100 \text { percent motor vehicle } \\
\text { belt use; and } \\
\mathrm{U} \cdot \mathrm{N}=\text { total number of insured non-belt wearers. } \\
\text { So, } \quad \mathrm{S}=0.56 \cdot(0.89 \mathrm{~N}) \cdot(11.6 / \mathrm{N}) \\
\mathrm{S}=5.8
\end{aligned}
\end{aligned}
$$$$
\mathrm{U} \cdot \mathrm{N}=\text { total number of insured non-belt wearers. }
$$

Thus, the fact that 89 percent of motor vehicle accidents currently do not wear belts may be costing U.S. insurers about $\$ 5.8$ billion annually in insurance loss payments. 


\section{NOTES AND REFERENCES TO CHAPTER' 2}

1. The Abbreviated Injury Scale 1980 Revision, Committee on Injury Scaling, American Association for Automotive Medicine, 1980.

2. Partyka, S. "NCSS - The Analyst's Companion," DOT-HS-805-871, National Highway Traffic Safety Administration, Washington, DC, October, 1981.

3. See "A Statistical Analysis of Seat Belt Effectiveness in 1973-75 Model Year Cars," September, 1976, U.S. DOT Report \#HS 802035.

4. "Final Assessment of the Bumper Standard," DOT-HS-804-718, June 1979, in U.S. Department of Transportation, National Highway Traffic Safety Administration, The Economic Cost to Society of Motor Vehicle Accidents, (DOT) HS 806342: January, 1983), P. VII-34.

Appleby, Michael R., et al. "Insurance Losses in Relation to the Safety Characteristics of Automobiles Demonstrated by an Automatic vs. Manual Seat Belt Study," (SAE: 1981), No. 810216.

5. Jewell, R.L. Jr., Vice President, National Association of Independent Insurers, personal communication.

6. The Illinois Poll. Survey Research Laboratory, University of Illinois at Urbana-Champaign, 1982.

7. Knapper, C.K.; Cropley, A.J.; and Moore, R.J. "Attitudinal Factors in the Non-Use of Seat Belts," Accident Analysis and Prevention, Vol. 8, 1976, pp. 241-246.

8. Marzoni, P. Motivating Factors in the Use of Restraint Systems. National Analysts, Philadelphia, DOT Report 非HS 800 585, 1971.

9. "19 City Survey" op. cit.

10. Slovic, P.; Fischhoff, B.; and Lichtenstein, S. "Accident Probabilities and Seat Belt Usage: A Psychological Perspective." Accident Analysis and Prevention, Vol. 10, 1978, pp. 281-285.

11. Anderson, D., "The National Flood Insurance Program -- Problems and Potential," Journal of Risk and Insurance, Vol. 41, 1974, pp 579-599.

12. Slovic, P.; Fischhoff, B; Lichtenstein, S.; Corrigan, B.; and Combs, B. "Preference for Insuring Against Probable Small Losses: Implications for the Theory and Practice of Insurance," Journal of Risk and Insurance, Vol. 44, 1977, pp. 237-258. 
13. Total travel in cars and trucks in 1980 amounted to 1.496 trillion vehicle miles (Source: FHWA, Highway Statistics, 1980, Table VM-1). A verage oneway trip length for personal travel is about 8.3 miles (Source: FHWA, 1977 Nationwide Personal Transportation Study: Purposes of Vehicle Trips and Travel, p. 10) Average occupancy is about 1.87 persons per vehicle mile (Source: NPTS: Vehicle Occupancy, p. 1). Thus the total number of person trips by car or truck in 1980 can be calculated as:

\section{$\frac{1.496 \times 10^{12} \mathrm{VMT} \times 1.87 \text { persons }}{8.3 \mathrm{VMT} / \mathrm{trip}}=337.2$ billion person trips}

Since only 35,477 persons were killed as occupants of a car or truck, the probability of being killed on an average trip was $1.05 \times 10^{-7}$ or about one chance in ten million.

A bout 3.0 million occupants of cars or trucks are injured each year (Source: NHTSA/NCSA, Report on Traffic Accidents and Injuries for 1979-80, p. 7). Thus, the probability of being injured on an average trip is $8.91 \times 10^{-6}$ or about one chance in 112,000

14. Slovic, P., B. Fischoff, and S. Lichtenstein. "Accident Probabilities and Seat Belt Usage: A Psychological Perspective," Accident A nalysis and Prevention, Vol. 10, 1978, pp. 281-285.

There is an alternative way to conceptualize the risk/reward relationship between autcmobile accidents and safety belt protection from injury. Slovic et. al. suggest that people are more influenced by the possibility of a driving lifetime free of injury rather than the risk they incur per trip. This concept of a lifetime of risk is drawn from the insurance industry's experience convincing people to insure for low probability, high loss events.

Slovic et al. tested the significance of viewing automobile injury risk cumulatively over a lifetime on attitudes towards safety belt suage using experimental and control groups and a before and after design. The experimental group was told that in a driving lifetime, a driver faces about a 30 percent chance of incurring at least one disabling injury. This information on cumulative risk caused the experimental group to have much stronger positive attitudes towards the effectiveness of safety belts, and to believe that their usage should be mandatory. Although this study did not measure subsequent behavioral change, it documents that the cumulative risk concept can cause significant at titude change.

It is interesting to speculate that defining risk of injury in cumulative or lifetime terms makes people perceive automobile accident injury in a health maintenance framework. People engage in many health behaviors to prevent relatively low risk types of illness; for example, toothbrushing and flossing, and taking vitamin pills. Perhaps safety belt usage could be better encouraged using a preventive medicine orientation. 
15. To counteract a human tendency to discount the probability of rare adverse events to zero, many approaches have been explored. Some of these use financial incentives and disincentives. For example, in Germany there is a firmly established policy of reducing benefit payments to victims of motor vehicle accidents who neglect to wear their safety belts. This policy arose not from legislation or insurance company initiatives, but rather from a decision of the Supreme Court of the Federal Republic in 1965, in which a motorcyclist who wore no helmet was denied a portion of the benefits to which he was otherwise entitled, even though he was not at fault in causing the accident. This decision was soon applied to safety belt cases throughout the country. Reduced payments to non-belt users are now automatic. Dissatisfied beneficiaries may contest these payments, but the courts tend to support the insurance adjusters' judgments. It should be recognized, however, that even though no legislation has ever been enacted to establish this policy, Germany does have statutes which make safety belt use mandatory, al though non-use is not punishable.

16. Telephone conversation with Dr. Steve Benson, Tarrance and Associates, Vienna, VA.

17. Geller, E.S. Corporate Incentives for Promoting Safety Belt Use: Rationale, Guidelines, and Examples, Final Report for NHTSA Contract DTNH22-82-P$05552,1982$. 


\section{CHAPTER 3: THE AUTOMOBILE INSURANCE INDUSTRY}

\subsection{SUMMARY}

This chapter explores the potential for automobile insurance companies to offer incentives that will be effective in promoting safety belt usage. It considers the coverages included in automobile insurance, the regulatory environment, and existing policies offering special additional benefits for those injured or killed while wearing safety belts. Since the annual loss reduction potential of the insured safety belt user ranges from about $\$ 11.00$ up to $\$ 42.00$, the potential to translate this lower risk into increased benefits is substantial. Although premium reductions for safety belt use would be desirable from a behavior modification perspective, the industry's reluctance to offer "up-front" premium reductions seem reasonable in light of problems associated with either completely trusting the insured's commitment to wear safety belts, or in actually denying a portion of coverage to those insured who are injured while not wearing a safety belt.

Nationwide's announcement that, at no premium charge, it is doubling medical payments coverage and providing a $\$ 10,000$ death benefit for those insureds who dre injured or killed while wearirg belts is a major step forward in insurance incentives, and provides a unique opportunity to evaluate the impact on insureds' belt use and claims experience. Evaluation of this effort would be valuable. This evaluation ideally also would address regulatory concerns about the potential for special safety belt benefits to confuse consumers, increase phony claims, and cause some drivers to underinsure.

In some states employer-offered automobile insurance is not allowed. However, in other states the insurance commissioners believe that employer-negotiated insurance policies require less oversight, since employers are much more informed in dealing with insurance companies than is the average individual consumer. While automobile insurance is not generally allowed as a non-taxable employer-provided benefit, many major employers do provide payroll deduction plans for automobile 
insurance. Employers traditionally have selected an auto insurer on the basis of price competition, with little or no attention to particular coverage. However, employers interested in supplementing their own safety belt programs might be able to secure supplemental safety belt benefits from insurers.

\subsection{GENERAL DESCRIPTION}

This insurance indistry is built around the substantial individual and societal risks associated with tire ownership and use of the automobile. The costs are considerable, as evidenced by the $\$ 41.3$ billion in U.S. auto insurance premiums during 1981 (up from $\$ 39.1$ billion in 1980). While automobile insurance policies typically include some medical (and sometimes, even death) benefits, auto insurance is considered primarily a property and casualty insurance, rather than a health or life insurance. The industry categorizes its business by type of customer (private or commercial) and by general area of coverage (passenger liability or automobile physical damage liability). (See Table 3-1 below.) The private customers dominate, with about 80 percent of all premiums. Passenger liability (private and commercial) comprises about 60 percent of the total premiums, compared to about 40 percent for physical damage.

TABLE 3-1

1981 AUTOMOBILE INSURANCE PREMIUMS

( $\$$ in Billions)

\begin{tabular}{|c|c|c|c|c|c|c|}
\hline & \multicolumn{2}{|c|}{ PASSENGER LIABILIT Y } & \multicolumn{2}{|c|}{$\begin{array}{l}\text { PHYSICAL } \\
\text { DAMAGE } \\
\text { LIABILITY }\end{array}$} & \multicolumn{2}{|c|}{ TOTAL } \\
\hline & $\$$ & (\%) & $\$$ & $(\%)$ & $\$$ & (\%) \\
\hline PRIVATE & 19.6 & $(47.5)$ & 14.1 & (34) & 33.7 & $(81.5)$ \\
\hline COMMERCIAL & 4.9 & (12) & 2.7 & (6.5) & 7.6 & (18.5) \\
\hline TOTALS & 24.5 & $(59.5)$ & 16.8 & $(40.5)$ & 41.3 & $(100)$ \\
\hline
\end{tabular}




\subsection{STRUCTURE OF THE INDUSTRY}

Over half ( 52 percent) of the auto insurance business in the United States is written by the top 15 companies (see Table 3-2). The two largest auto insurers are State Farm (14.5 percent of the market) and Allstate (9.1 percent). State Farm has nearly $\$ 6$ billion in premiums and is the leading company in 33 of the 50 states and District of Columbia. Still, in no state does State Farm, or any other firm, have significantly more than a quarter of the market (GEICO has 25.2 percent of the market in the District of Columbia, State Farm has 25.1 percent in W. Virginia, and 24.2 percent in Alabama, and the Auto Club of Michigan has 24.3 percent in Michigan). 1 There is competition in every state by a variety of firms and types, with the result that underwriting costs (which include claims paid, claims adjustrnent costs, sales commissions, state premium taxes, and general administrative expenses) were equal to 107.4 percent of the premiums collected in $1981 .^{2}$

TABLE 3-2

TOP 15 U.S. AUTO INSURANCE FIRMS IN 1981

RANK

IN

PRE- COMPANY

MIUMS$$
1
$$

2

3

4

5

6

State Farm

Allstate

Farmers Group

Actna L\&C

Nationwide

Travelers

Liberty Mutual

Continental

Hartford

USAA

INA

U.S.F.\&G.

GEICO

Fireman's F und

Auto Club, S. Calif.

TOTAL ALL FIRMS:
DIRECT PREMIUMS

( $\$$ in Millions)

$\%$ TOTAL

MARKET

$$
\$
$$

5,977

3,749

1,840

1,409

1,316

1,039

888

803

714

696

648

647

612

549

525

21,412

41,328
14.5

9.1

4.5

3.4

3.2

2.5

2.1

1.9

1.7

1.7

1.6

1.6

1.5

1.3

1.3

SOURCE: Bests Review, "Auto Insurance 1981," August, 1982, p. 13. 
The auto insurance industry inarkets its product through agencies or direct writers. In general, the direct writers, led by State Farm, are increasing their majority share (up to 53.5 percent in 1981 from 50.3 percent in 1977) of auto insurance premiums. The only national agency company among the top 10 commercial auto insurers is Liberty Mutual, a firm that ranked seventh in 1981.

The big states in auto insurance premiums are California, with 12.6 percent of the premium volume, New York with 7.4 percent, Texas with 6.2 percent, Pennsylvania with 5.5 percent, and New Jersey with 5.0 percent. ${ }^{3}$

One characteristic which distinguishes competition in the auto insurance industry is that most large firms are not trying to sell their policies to everyone," but rather are attempting to attract customers who are "preferred risks" whlle avoiding customers with high expected losses. The analogy to fire insurance, where problems of discriminatory availability of coverage or "red-lining" are a prevailing regulatory concern, is close indeed. Many, if not all, insurance "incentives" are designed to attract a category of risks with especially low expected losses. In most states, assigned risk pools, or some combination of "mandatory offer" insurance requirements, attempt to assure that the least desirable risks are insurable.

\subsection{TYPES OF AUTOMOBILE INSURANCE, PREMIUMS, AND BENEFITS}

There are six typical coverage categories of automobile insurance policies: bodily injury liability, property damage liability, medical payments, uninsured or underinsured motorist coverage, comprehensive, and collision. Each category of coverage is described briefly below. In general, it is the insured's car which is insured; if the insured is driving scmeone else's car, then the insurance of the person owning the car has the primary responsibility to cover liabilities resulting from any accident. However, if the car is not insured, but the driver is, the driver's insurance applies. 
- Bodily injury liability coverage pays damages associated with the bodily injury or death of others harmed when the insured is responsible for causing the accident. Most states have a "guest" clause which limits the applicability of this coverage in paying for injuries to occupants of the insured's car. 4 The cost of this coverage may constitute 25 percent, or $\$ 125$, of a $\$ 500$ policy's overall annual premium. This coverage is compulsory in many states. Since this coverage seldom compensates injury victims who are occupants of the insured's car, and since the insured can influence belt usage only in his/her own car, it does not lend itself to individual incentives for safety belt use. However, payments (and premiums) under this coverage could be expected to decline if there were a significant general increase in safety belt usage, since. the chances that the other car's occupants were belted would be higher.

- Medical payments coverage (and personal injury payments in no-fault states) pays all occupants of the insured's auto for medical expenses up to a certain limit, and a portion of lost wages associated with the motor vehicle accident-related injury. This coverage also includes pedestrians hit by the insured's car and other drivers who are using the insured's car with the insured's consent. Payments to any one person usually are limited to $\$ 2,000$ or less; this limitation may keep the premium cost to between two and seven percent, or between $\$ 10$ and $\$ 35$, of a typical $\$ 500$ policy premium. However, in those few no-fault states where there are unlimited medical payments under the personal injury protection policy, this coverage may represent 20 percent of the policy's total annual premium.

- Uninsured motorist coverage pays the occupants of the insured's car limited medical payments and wage losses for injuries suffered in accident caused by someone else who is uninsured, underinsured, or unidentified. The cost of this coverage represents about four or five percent of a typical policy. 
- Comprehensive coverage pays for damage or loss to the insured's car due to fire, theft, or vandalism. The coverage accounts on average for 13 percent of total premium cost, but can be a much higher proportion of the total for certain model cars or in certain urban locations where car theft is common.

- Collision coverage compensates for repair of all damage due to the driver's car (less a deductible, such as $\$ 200$ per accident) whether or not the accident is caused by the insured. In the typical $\$ 500$ policy, this coverage is the most expensive, costing about $\$ 175$, or 35 percent of the total. Many older cars are not covered by this form of insurance.

- Property Damage Liability coverage compensates victims of motor vehicle accidents, caused by the driver of the insured's car, for property damage resulting from the accident. This damage is not limited to the vehicles struck but may include other types of property including fences, buildings, and lawns. This coverage is also relatively costly, $\$ 125$, or 25 percent of the typical $\$ 500$ policy.

\subsection{AUTO INSURANCE COVERAGE CHARACTERISTICS INFLUENCING THE POTENTIAL FOR SAFETY BELT INCENTIVES}

Four major characteristics of auto insurance coverage that bear directly on the potential for safety belt incentives are as follows:

- Only a small portion of the total coverage (and premium) lends itself to decrease due to an individual insured's safety belt wearing.

- In no-fault states, the relevant coverage (and premiums) are higher than in fault states. This is especially true in those no-fault states with the highest limits on medical payment and wage coverage.

- Many people are "underinsured" in the areas where safety beit incentives might be applied.

o Young drivers are often uninsured, so that safety belt incentives may be least likely to reach this higher risk, low belt-usage group. 


\subsubsection{COVERAGE (AND PREMIUMS) RELEVANT TO SAFETY BELT INCENTIVES}

Of the six basic auto insurance coverages, only two - medical payments coverage (or personal injury protection in no-fault states) and uninsured motorist coverage are appropriate for belt use incentives. These two coverages are the only ones that generally pay the injury costs of those in the insured's car when the insured is at fault. (In no-fault states, the "fault" of the insured is irrelevant to some limit of loss so that his/her insurer must pay the losses.) The collision and property liability coverage are not relevant since safety belts have not been proven to significantly reduce vehicle damage (through accident avoidance or through reducing damage caused by unrestrained humans hitting a car's interior). Bodily injury liability coverage is of little relevance since the insured can influence belt use only in his/her own car; the insured has no influence on the likelihood that occupants of a car may be hit will be wearing belts. In addition, most states have "guest laws" prohibiting passengers from suing the driver of the car in which they are riding.

From a societal point of view, there is some logic in including the bodily injury liability portion of automobile insurance among those coverages relevant to safety belt insurance incentives. If every person wore safety belts, the expected payout for bodily injury liability would be greatly reduced; no matter who the insured hit with his/her vehicle, the other vehicle's occupants would be belted and could be expected to sustain considerably less injury. Everyone's expected claims under bodily injury liability coverage could be reduced, and premiums could be made less expensive. Unfortunately, we now have a situation where only 11 . percent of auto occupants wear belts. Therefore, an auto insurance company wishing to influence belt-wearing behavior through insurance incentives including bodily injury coverage would find itself without any way to capture most of the benefits of increased policyholder usage. This is true except in the instance when the insured hits someone's vehicle that is also insured by the same company and in which the occupants are wearing belts. (Note that this suggests that those insurers having a substantial (e.g., 25 percent) share of a state's market would have a larger interest in promoting safety belt usage than would a firm with a rather small share.) 


\subsection{2 "NO-FAULT" AND POTENTIAL FOR SAFETY BELTS INCENTIVES}

Coverage and premiums vary tremendously depending on the age, sex, and driving history of the insured; on the vehicle type and price; on the vehicle's accident, repair, and theft history; on the vehicle's use and neighborhood parking characteristics; and on the particular state's loss experiencie, regulatory procedures, and method of settling personal injury claims (i.e., whether the state is a no-fault state). This last variable is especially relevant to the potential size of safety belt incentives, since in a no-fault state the insured's own insurer pays for medical and wage losses up to some specific limit regardless of who is at fault.

In no-fault states where there is unlimited medical coverage (e.g., Pennsylvania, New Jersey, and Michigan), a much larger portion of the insurance premium may be linked to safety belt wearing by the insured and occupants of his/her vehicie. This is evident in Table 3-3, which compares a tort state (California) to a no-fault state with unlimited medical coverage (Michigan) and a no-fault state with a rather low limit under no-fault coverage (Massachusetts). From a safety belt incentives perspective, the extent of no-fault coverage is more important than the tort/nofault distinction.

\subsubsection{UNDERINSURED MOTORISTS}

A second fact about auto coverage that bears on the potential for, and social desirability, of safety belt incentives is that medical payments coverage levels typically are quite modest compared to the potential maximum losses. Since the auto insurance coverage for medical payments and wage losses suffered when the insured is at fault already usually is limited to $\$ 2,000$ or less, and the most common 
TABLE 3-3

EXAMPLES OF AUTO INSURANCE PREMIUMS AND COVERAGE

\begin{tabular}{|c|c|c|c|c|c|c|}
\hline COVERAGE & \multicolumn{2}{|c|}{$\begin{array}{l}\text { CALIFORNIA } 1 \\
\text { Premium } \%\end{array}$} & \multicolumn{2}{|c|}{$\begin{array}{l}\text { MICHIGAN2 } \\
\text { Premium \% }\end{array}$} & \multicolumn{2}{|c|}{$\begin{array}{l}\text { MASSACHUSETTS } \\
\text { Premium } \%\end{array}$} \\
\hline $\begin{array}{l}\text { Bodily Injury } \\
\text { Liability }\end{array}$ & 125 & 25 & 53 & 15 & 155 & 26 \\
\hline $\begin{array}{l}\text { Property } \\
\text { Damage Lia- } \\
\text { bility }\end{array}$ & 75 & 15 & 7 & 2 & 130 & 22 \\
\hline $\begin{array}{l}\text { Medical } \\
\text { Payments }\end{array}$ & 35 & 7 & 70 & 20 & 20 & 3 \\
\hline $\begin{array}{l}\text { Uninsured } \\
\text { Motorist }\end{array}$ & 25 & 5 & -- & -- & 10 & 2 \\
\hline Comprehensive & 65 & 13 & 60 & 17 & 85 & 14 \\
\hline Collision & 175 & 35 & 150 & 43 & 200 & 33 \\
\hline TOTAL & 500 & 100 & 350 & $100^{*}$ & 600 & 100 \\
\hline
\end{tabular}

*Includes Property Potential Insurance, $\$ 12$ or three percent.

PIP = Personal Injury Protection

SOURCES:

1. Appleby, Michael R., et al. "Insurance Losses in Relation to the Safety characteristics of Automobiles Demonstrated by an Automatic vs Manual Seat Belt Study," (SAE: 1981), No. 810216, and conversation with Michael Appleby.

2. National Association of Independent Insurers. PIP includes Unlimited Medical; wage loss maximum about $\$ 150,000$, but adjusted annually for cost of living.

3. Policy of 30 -year-old male with 1980 Honda Civic.

coverage is $\$ 1,000$, the provision of extra benefits for those wearing safety belts is attractive. However, if some insureds choose to reduce their regular coverage because of the extra safety belt-wearing benefits, they would find themselves with large uncompensated losses in the event that they failed to wear their belts in an 
coverage is $\$ 1,000$, the provision of extra benefits for those wearing safety belts is attractive. However, if some insureds choose to reduce their regular coverage because of the extra safety belt-wearing benefits, they would find themselves with large uncompensated losses in the event that they failed to wear their belts in an accident where they were at fault. (See Section 3.7.2.) Thus, it could prove foolish to encourage safety belt wearers to opt for lower basic coverage because of a provision increasing coverage in accidents where the insured's occupants are belted.

\subsubsection{UNINSURED MOTORISTS}

A third characteristic of automobile insurance coverage relevant to the potential for effective safety belt incentives is that the young driver is the least likely to be insured at all. The Insurance Information Institute national survey in March, 1981 found that while only eight percent of all car owners do not have automobile insurance, 14 percent of the 18-29 age group are uninsured (see Table 3-2). It is quite likely that the survey exaggerates the proportion of drivers covered by automobile insurance. Since in half of the states motorists are required by law to carry automobile liability insurance (or to provide some other form of surety), those without insurance are probably quite reluctant to admit it. Finance companies or banks lending money for automobile purchases usually require evidence of insurance coverage as a condition of the loan. Evidence that the uninsured driving population is underreported is provided by a recent study by the state of Illinois, which estimated that only 40 percent of registered cars were insured in the years 1972-1976.5

TABLE 3-4

AUTO INSURANCE COVERAGE AS REPORTED BY U.S. CAR OWNERS, 1981

$\begin{array}{llllll}\text { BY AGE GROUP } & 18-29 & 30-39 & 40-49 & 50-59 & 60+\end{array}$

Do Not Have

Insurance

$14 \%$

$7 \%$

$3 \%$

$5 \%$

$5 \% \quad 8 \%$ 
The fact that young drivers are the least likely to be insured is especially important in evaluating the overall effectiveness of safety belt incentives since this sarne group is known to have a disproportionate high number of accidents and of severe and fatal injuries. Although persons aged 25 years or less constitute only 22 percent of all licensed drivers, they represent about 42 percent 6 of all accidentinvolved drivers, about 46 percent $^{7}$ of all motor vehicle fatalities, and about 45 percent 8 of all drivers with incapacitating injuries.

Since the young driver is also thought to have a much lower-than-average safety belt usage rate, 9 it appears that the drivers who could most benefit from safety belt use are precisely those least likely to be reached by automobile insurance incentives for safety belt usage.

\subsection{ESTIMATING THE AUTO INSURANCE LOSS REDUCTION ASSOCIATED WITH SAFETY BELT WEARERS}

Estimating the difference between the expected losses of insureds wearing belts and those without belts can be accomplished by applying the methodology employed by Michael Appleby et al. in a recent Society of Automotive Engineers Paper. Table 3-3 indicates that the portion of insurance premiums subject to reduction as a result of an insured's safety belt use (i.e., medical payments or personal injury protection and underinsured motorist) varies from five percent (in Massachusetts) to 20 percent (in Michigan). Only about 75 percent of the premium dollar is used to cover loss and loss adjustment expenses; the rest covers administrative expenses, premium taxes, commissions, and general claims handling costs. The portion of premiums tied to loss reduction thus ranges from four percent to 15 percent $(0.75$ times 5 to 20 percent) of total premiums.

If safety belts can reduce injuries by 56 percent, then the portion of total premium that theoretically could be saved by the belt wearer is 2.2 to 8.4 percent of total premium value ( 0.56 times four to 15 percent). On a $\$ 500$ policy the annual premium reduction potential could thus vary from about $\$ 11.00$ to $\$ 42.00$. However, the upper range of this estimate is applicable only in one or two states, 
where there is both unlimited no-fault medical coverage and where the premiums for that coverage depend on age and neighborhood. In most states, the premiums for medical coverage are much more modest, so the potential insurance cost saving attributable to seat belt use would be closer to the lower estimates (c.g., about $\$ 11.00)$.

These estimates assume that claims insurance reductions are proportional to the reduction in the number injured at each severity level. If so, then the estimates developed in Chapter 2 of safety belt effectiveness suggest that loss claims for belt wearers would be less than half that of non-wearers. The information on actual loss reduction from the experience in one Canadian province indicates that insurance loss claims reductions and increases in safety belt use may be roughly proportional.10 Factors that might influence the relationship between loss reductions and safety belt use include the amount of coordination between automobile benefits and health insurance benefits, the extent to which insureds have low limits on medical coverage, and the degree to which safety belts are less effective in reducing injuries in minor accidents.

\subsection{REGULATORY ENVIRONMENT}

Since safety belt incentives would acknowledge the lower risk of injury to belt wearers, and might even induce increased belt ysage, why aren't auto insurers required to offer them? The states have a tradition of primacy in the regulation of insurance. By 1919, 36 states already had permanent administrative agencies for insurance regulation. In 1944, the U.S. Congress passed the McCarran-Ferguson Act in response to a Supreme Court decision which found that the insurance industry was "not wholly" beyond the regulatory power of Congress under the Commerce Clause. The McCarran-Ferguson Act declared that "the continued regulation and taxation by the several states of the business of insurance is in the public interest." The act basically exempted the insurance industry from the Federal antitrust laws (the Sherman Act, the Clayton Act, and the Federal Trade 
Commission Act) so long as the states were regulating the industry. Since then, especially during the late 1970s, the Congress has questioned the adequacy of state insur ance regulation. :

In response to Congressional inquiries, in 1978-79 the GAO's Comptroller General did an extensive study of the effectiveness of insurance regulation by state insurance departments. This report to Congress, Issues and Needed Improvements in State Regulation of the Insurance Business (hereinafter referred to as the GAO report), focused on automobile insurance regulation, and particularly on regulatory issues such as price regulation, risk classifications, and insurance availability. The finding of the GAO report most relevant to the potential for insurance incentives is that "most states apparently have only a passive position on merit rating and safe driver incentive plans." 11

State insurance departments have many responsibilities that have priority over the promotion of highway safety. According to the National Association of Insurance Commissioners, the basic functions undertaken by state insurance departments are as follows:

- Licensing insurance companies and agents. The licensing function requires that a depariment enforce state law with regard to the formation of companies, financial standards, qualifications as to character of management, and suspension or revocation of license;

- Examining the financial condition and claims practices;

- Implementing statutory standards. This entails making sure that rates are not excessive, inadequate, or unfairly discriminatory and that policies meet standards requiring benefits to be reasonable in relation to premiums;

- Administering a complaint-handling office;

- Enforcing unfair trade practices laws;

- Regulating residual market mechanisms designed to provide insurance for risks rejected by the voluntary insurance market; and 
- Applyinys for a court urder of liquidation, rehabilitation, or conservation of comfanies because of insolvency or other reasons. 12

The resources, staffs, organizations, and activities of the individual state insurance commissions vary widely, but the primary focus is almost always on the financial condition of companies and secondarily on market conduct and the handling of claims. The wide variations among states is especially evident in the regulation of rates (premiums). The spectrum ranges from rates set by states (e.g., Texas) through six lesser types of state rate-making powers to California where there is not even a requirement to file rates. Of the 17 states examined in depth by the: GAO, only Texas and Massachusetts conducted empirical actuarial analysis which would enable them to independently determine the appropriate level of insurance rates.

The fact that state insurance commissions cannot always devote sufficient actuarial staff time and effort to analyze the potential impact of innovative incentives is only one barrier to the adoption of novel programs. Another is that the rating law in most states provides that "no insurer shall be required to record or report its loss experience on a classification basis that is inconsistent with the rating system used by it." 13 It is difficult to argue for another classification basis without data relevant to the alternate system. Another barrier to rate classification initiatives by commissioners is the prevailing philosophical and political environment surrounding automobile insurance, especially in the area of risk classification.

State insurance commissioners are charged with making sure that rates are neither inadequate, excessive, or unfairly discriminatory. Credible statistical justification of classification schemes by the insurers generally is sufficient for classification approvals. Such "credible" statistical justification must show only that there were enough cases for data to be statistically valid in predicting the class average of a definable primary driver class or territory. In other words, if there is a mathematical basis for grouping people by characteristics that are correlated with variations in hazards (and therefore in expected claims payments), then the rates (or premiums) can vary accordingly. By maintaining some degree of competition, 
the state commission is in a position to select the more reasonable choices presented to it by the companies. However, the initiative and the information needed for innovation was and is primarily in the hands of the competing duto insurers.

Most of the controversary about rating classifications has surrounded age, sex, marital status, and territory (urban/rural neighborhood ratings, such as those associated with "red-lining"). The alternative to these traditional risk classification variables involves so-called "merit rating" schemes that attempt to place a much greater weight on the individual driver's own behavior. Generally, the public has supported the idea that those individuals responsible for most accidents should pay more for insurance than others. Accident history, conviction history, and unsafe driving experience arc examples of variables applicable to this merit rating approach. By emphasizing individual accountability, "merit rating" also adds incentives (and disincentives) for safer driving. These can be substantial, as indicated by recent developments in the state of Massachusetts (see Table 3-5), where a driver who is convicted twice for driving under the influence of alcohol faces a surcharge on his/her annual auto insurance premium of up to $\$ 1,000$.

The merit rating approach also has some drawbacks. First, the data on which to base merit ratings typically are more difficult to collect. Secondly, the more predictive of individual claims that rate classification analysis becomes, the greater the premium disparities that can be expected. With very high rates for some, affordability becomes a critical issue for higher risks.

Those facing the higher rates under merit rating classification raise questions of "equity" and "fairuess" arguing that the purpose of insurance is to cushion catastrophe's impacts, not to create barriers to auto ownership or incentives to become uninsured. If a purpose of insurance is to share the costs of catastrophe, then a classification system that spreads risks over large groups may be socially preferable. This argument is buttressed by reminders that there will always be 


\section{IMPORTANT NOTICE}

The Surcharge Table below replaces the Surcharge Table shown in the brochure entitled "Information About Merit Rating". The new rates apply to incidents occurring on or after March 8, 1982.

\section{Surcharge Table}

\section{Maximum Cost of Each Surcharge (Billable first full year)}

\begin{tabular}{lccc} 
Surcharge Table & Number Per Operator & $\begin{array}{c}\text { Incidents Occurring } \\
\text { Prior to March 8, 1982 }\end{array}$ & $\begin{array}{c}\text { Incidents Occurring on } \\
\text { or After March 8, 1982 }\end{array}$ \\
\hline At-Fault Accident & First & 50 & 50 \\
(AC) & Second & 150 & 225 \\
& Third & 300 & 450 \\
\hline Driving Under the & First & 200 & 200 \\
Influence (DI) & Second & 425 & 1000 \\
& Third & 675 & 1000 \\
\hline Conviction for Driving & First & 100 & 100 \\
to Endanger or Reckless & Second & 225 & 340 \\
Driving (DE) & Third & 375 & 560 \\
\hline Conviction for Certain & First & 25 & 25 \\
Other Traffic Violations & Second & 75 & 115 \\
(OT) & Third & 150 & 220 \\
\hline
\end{tabular}

The surcharge amounts you are billed may not correspond with any amounts shown above. The exact amounts billed will depend on the amounts already collected on other policies, and the length of time your current policy is in effect. If the policy is written for less than 12 months, the above amounts will be reduced proportionally.

SOURCE: Standard attachment to al1 1982 autu insurance policies in the state of Massachusetts. 
classification crrors: it is unclear whether the errors should be the type that improperly overcharge a small number of drivers by several hundred dollars, or the type that overcharge a larger number of drivers by $\$ 10$ to $\$ 20.14$

In reality, either a merit or an age/sex/neighborhood system can result in large premium discrepancies and individual rating inequities. In Virginia, for example, the unmarried 20-year-old male with no claims record in 1978 typically would face a premium of $\$ 600$, two to three times as high as a 45 -year-old married male (who pays \$207), and nearly twice as high as an unmarried 20 -year-old female (who pays \$355).15 An 18-yedr-otd male in Brooklyn using his car to commute to work pays $\$ 2,500$ for the sam coverage purchased for $\$ 700$ by a 40 -year-old male who uses his car primarily for pleasure driving. 16

The vast majority of state insurance commissioners have implicitly agreed that while statistical convenience may not be equivalent to statistical or social fairness, they cannot be expected to throw out a working system in favor of unproven experiments which are inherently controversial. In considering the outlook for safety belt incentives, the difference in claims losses typically is about $\$ 15$. This size problem is dwarfed by premium disparities of well over $\$ 500$ per year. If a respectable insurance company thinks it makes actuarial sense to offer extra benefits for safety belt wearers, most state commissioners will approve the firm's filings. Nevertheless, many state insurance commissioners are quite skeptical about the value of safety belt incentives provided by automobile insurers. Some suspect they may even do more harm than good. 17

The major misgivings of state insurance commissioners include the following:

o It is hard for them to believe that extra benefits will really change safety belt-wearing behavior. Indeed, there is doubt that any voluntary approach can increase safety belt usage significantly. The National Association of Insurance Regulators has endorsed mandatory passive restraints, and many individual insurance commissioners have been 
leaders in the fight for mandatory belt use laws. Currently, several state insurance commissioners and legislative committees are interested in pursuing a legislative requirement that young drivers wear safety belts, and on March 1, 1983, New York State implemented a mandatory belt use requirement for drivers holding learner's permits.

- They are afraid that some people will capitalize on "extra benefits" by reducing their basic coverage only to be injured in an accident in which they are unbelted and for which the coverage they need is unavailable.

- They fear that safety belt incentives may promote more "cheating" than safety belt wearing; this creates rewards for undesirable behavior, causing the honest clients to pay a higher average premium.

- They believe that safety belt benefits may distract customers from more imporiant considerations in choosing an insurer, such as premiums and claims service.

- They suspect that companies may provide knowledge of safety belt incentives to customers in a selective manner, thus strengthening their ability to engage in discriminatory marketing. This potential is evidenced in the very low-profile way in which existing safety belt incentives have been marketed.

- Given the absence of good claims experience data, they are not sure that the extra benefits are fair to the non-safety belt wearing insured.

- They fear that a more widespread introduction of safety belt incentives may further complicate claims settlement procedures.

- They are afraid that extra benefits for wearing safety belts may confuse and intimidate some of the more timid non-belt wearing claimants into failing to vigorously press their legimate claims.

\subsection{EXPERIENCE WITH INCENTIVES}

The automobile insurance industry has extensive "incentives" experience with premium discounts and benefit increases based on the behavior of its insureds. In general, the industry sees the rate discounts and premium credits primarily as a 
means of competing for preferred customers, not as a way of changing the behavior of autorrobile users. Auto insurance discounts have been compared to the practice that sorne banks employ of giving their lowest interest rate loans to preferred customers. 18 From the industry's perspective, "Discounts won't reduce an insurer's total losses, or the amount it must pay for claims...Since the total losses remain the same, the reduced rate given any 仍oup must be of fset by raising the rates for those outside the group." 19 In other words, insurance discounts are primarily marketing devices which, if successful, will attract new custorners whose expected losses are low enough to justify the cost of any discount or benefit increases offered. Auto insurance discounts are available in some states for the following types of driver or vehicle characteristics:

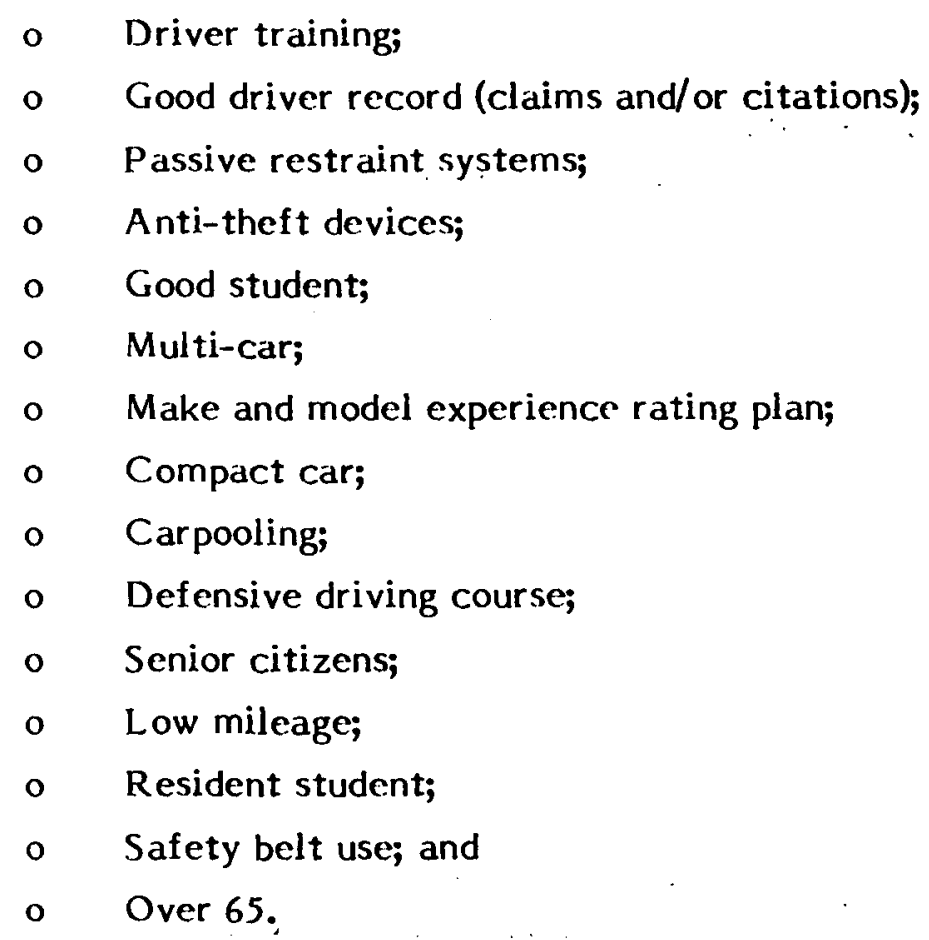

While automobile insurers would prefer credible actuarial evidence in evaluating insurance discounts, there are many instances where marketing judgement has been sufficient for offering premium reduction or special additional benefits. 


\subsubsection{EXAMPLES OF AUTOMOBILE INSURANCE INCENTIVES}

In considering the actual experience of insurance companies offering "incentives" relevant to safety belt usage, we have relied primarily on the following sources of information:

- Conversations with officials of automobile insurance companies that are offering or have offered safety belt incentives. These firms include State Farm, Safeco, J.C. Penney, Motors Insurance, Nationwide, and Travelers. In general, these officials were very cooperative, but were unable to give quantitative information useful in evaluating the extent of customers use of the incentives, changes in loss experience, or claims. Any evaluation of the incentives by the firm was subjective. Without exception, most were doubtful that the availability of benefit increases for wearing safety belts actually influenced safety belt use in any significant way. However, one firm believed their benefit increases were useful "talking points" that had won them new customers.

- Conversations with officials of automobile insurance firms not currently offering safety belt incentives but quite interested in developing such offerings if practical. These firms included GEICO, USAA, and League General; all three firms are active in marketing to safety-conscious drivers.

- Conversations with firms that, while quite sympathetic to increasing safety belt use, did not yet see any practical way to employ discounts or benefit increases for safety belt usage. These firms included Allstate, Liberty Mutual, Insurance Company of British Columbia, and the Automobile Club of Southern California.

- A summary of 11 U.S. auto insurance company responses to a 1977 inquiry into safety belt incentives by U.S. Congressman James Cleveland (R., New Hampshire), then a member of the House Public Works Committee. 
The GAO Summary of responses to a March, 1977 questionnaire distributed to 20 of the largest U.S. automobile insurance companies concerning their plans to offer discounts in 1981 to owners of cars equipped with air bags or passive safety belts. 20 These responses provide useful perspectives on the different potentials for safety belt incentives, especially between tort and no-fault states.

o The 1981 SAE paper by staff of the Automobile Club of Southern California titled, "Insurance Losses in Relation to the Safety Characteristics of Automobiles Demonstrated by an Automatic U.S. Mannual Seat Belt Study," which provides a simplified discussion of the non-marketing factors weighed by an insurer who is considering offering insurance discounts.

o The insurance consulting experience of Chang and Company supplemented the above sources, as did the firm's preliminary findings about insurance commissioner attitudes toward automobile insurance incentives.

In 1978, Representative James C. Cleveland, then the ranking minority member on the Public Works Committee, asked automobile insurance companies why they were not offering incentives for safety belt use. Their confidential responses were summarized by the Committee (see Table 3-6). It is evident that all the insurers were favorable to safety belts, but only one, (No. 4) actually was providing a special benefit increase to safety belt wearers. The barriers to safety belt incentives mentioned in the letters are as follows:

- Insufficient Incentives: The possible incentives would not be sufficient encouragement (No. 1, No. 3, and No. 5);

- Policing: Knowing who uses safety belts is impractical, so incentives are unenforcable (No. 2, No. 6, No., 8, No. 10);

- Courts Unsupportive: Courts will not sustain disincentives (No. 6, No. 11 ), and these would have to be part of effective incentives. 
TABLE 3-6

SUMMARY OF INSURANCE COMPANY RESPONSES

TO CONGRESSMAN JAMES C. CLEVELAND'S LETTERS

No. 1. Most effective means to reduce fatals and infuries is improved construction of autos and highways. Can motivate seat belt use by 1) mandatory law; 2) persuasion; 3) incentives and disincentives. For insurers $10 \%$ or $20 \%$ discount on $\$ 10$ medical payment coverage not an encouragement. Support passive restraints. Will cooperate with any seat belt use encouragement program which shows promise.

NO. 2. No practica: way to reward belt users but will put workable 1deas into effect. Only mandat:ory use has been successful. Will participate in any effort to develop programs to increase belt use. Endorse passive restraints.

No. 3. Have examined financial incentives and not convinced would have any effect. No adequate data from companies which tried incentives. Disincentives must be permitted by legal, regulatory or judicial authorlzation but attempt by our company to initiate would appear self-serving. Our greatest efforts will focus on passive restraints.

NO. 4. Now provide double medical payments for insured wearers. Passive restraints are best ultimate solution.

No. 5. Attempts to encourage belt use disappointing. Studies of mandatory law countries showed some good inftial results but later drop-off in use, per Insurance Institute statistics. Passive restraints most effective answer. Incentives and disincentives have practical problems. Will continue to explore possibilities.

No. 6. Believe Incentive and disincentive standards cannot be enforced by insurance companies. To accomplish increased use would need legislation at State level such as mandatory use laws and authorization of introduction of evidence concerning lack of belt use in any tort action. Belleve passive restraints may prove more effective in long run.

No. 7. In full accord with your views. Investigating use of incentives and disIncentives to promote safety belt usage.

NO. 8. Considered financial rewards for passive restraint device and now offer in one State. Financial incentive for seat belt use tried but not successful. Most difficult problem is proof of use. Disincentives equally difficult to administer. Strongly support NHTSA efforts to increase seat belt use.

No. 9. Have discussed incentives and disincentives and one approach being considered is to double medical payment benefits.

No. 10 . Have $15 \%$ credit for passive restraints. Believe incentives and disincentives idea worthwhile but no practical way to police.

NO. 11. Have been interested in financlal rewards and have reviewed reduced prenium approach. Verification is a concern but incentive is a live possibility. Disincentives almost ruled out in Michigan since courts take position failure to use is not contributory negligence and that it is an effor for trial judge to permit evidence of use or non-use by plaintiff before jury. Also considering premium advantage for passive restraints.

SOURCE: U.S. House of Representatives, committee on Public Works (Provided by Paul Yates of the Minority Staff) 
The companies' objections are similar to those raised by most ato insurers today, including many who have offered increased benefits for safety belt use. These responses also show an overwhelming preference for passive restraints.

\subsubsection{EXAMPLES OF AUTOMOBILE INSURANCE INCENTIVES}

Nationwide: Nationwide (Nationwide Mutual Insurance Company) ranks fifth in size of auto insurance premiums collected in 1981. It is a direct writer with a long interest in the promotion of automobile safety and of restraint system use. On January 5, 1983, Nationwide introduced the most significant benefit increases for safety belt use ever offered.

In 1962, Nationwide began offering a 50 percent increase in medical payments benefits for any insured (claiming under first party medical) who is wearing at least a lap belt at the time of the accident. Nationwide began this plan after deciding that premium discounts for safety belt use were fraught with problems, primarily in the policing of compliance and in the up-front costs of any substantial premium reduction given to everyone solely on the basis of their word. Nationwide has "never invested heavily" in advertising the policy and would not be surprised if most of its insureds did not even know about the additional coverage. Nationwide has never done a qualitative evaluation of the policy and did not have accessible records as to the history of claims under this policy benefit. The company's claims adjusters regularly note the availability of belts and the insured's statements about belt usage in each accident since they are aware the extra benefit might be invoked. Until now, Nationwide has not been successful in implementing the safety belt benefit in a way that highlights the firm's commitment to increasing safety belt use.

On January 5, 1983, Nationwide began a new effort to promote identification of the company with the provision of unprecedented extra benefits for safety belt wearers. Nationwide has offered an amendatory endorsement which provides three additional benefits to insureds who are injured or killed while wearing a safety belt. 
The first benefit amends the medical payments and family compensation coverage to provide a 100 percent increase in medical benefits if the insured is using a safety belt or child restraint systern at the time of the accident. The second benefit increases the family compensation coverage confinement benefits to provide for 360 days instead of 270 days when a safety belt is worn or a child restraint systern is used. The last benefit adds a $\$ 10,000$ death benefit that is payable for the death of an insured who is wearing a safety belt or using a child restraint at the time of an accident. There is no additional charge for this coverage, and it will be extended automatically to all policyholders within the company's regulatory jurisdiction.

The initial endorsement of this policy is being sought in the state of Ohio. Eventually, the company expects to attempt implementation of this policy in every state and the District of Columbia. In the 23 "file and use" states, few problems in gaining regulatory approval are anticipated. In some "prior approval" states, especially those that have highly specific legislation related to the creation of nofault coverage, some delays and difficulties in obtaining regulatory approval are expected. Where necessary, Nationwide will consider adapting the benefits to meet local regulatory requirements. In providing the special death benefits, the benefit package includes something of value even in those states with unlimited medical payments coverage.

This new safety belt benefits package will be marketed much more aggressively than the earlier 50 percent medical payments benefit increase, since the company hopes to gain new safety-conscious customers. By improving Nationwide's "safety image," as well as encouraging safety belt usage, the company expects to appeal to a better class of risk.

Nationwide embarked on this new initiative after considering the following:

- Recent data on the efficacy of safety belts; 
Their 1962 decision to offer increased benefits rather than premium discounts;

- The administrative costs of trying to charge extra for the additional benefits (in charging extra, it was determined that the administrative costs would be several times the additional claims losses on a per policy basis);

o

The importance of being "out front" with a "safety" image in the markets they serve; and

- The problems and extra losses associated with determining whether the insured was belted at the time of the accident. (In resolving this problem, the company has assumed the burden of proof and expects that it would have to find a "flagrant contradiction" between the insured's claim and the facts before it would, even administratively, challenge a claim.)

The potential for evaluation of this safety belt initiative is high, both because the company recently has computerized its policy and claims processing and because the company would like to demonstrate to the industry that promoting safety belts by providing extra benefits makes good business sense. There appears to be a real possibility that NHTSA could be provided a role in this evaluation.

State Farm Mutual Automobile Insurance Company: State Farm, the nation's largest automobile insurer with 14.5 percent of total direct premiums, introduced its first safety belt benefit early in 1983. This special benefit relates to an optional "dismemberment" coverage offered by State Farm to its automobile policy holders. This optional coverage provides a schedule of payments related to accidental death or dismemberment (loss of limbs or eyesight). The new safety belt benefit will double all dollar values on the schedule if the injured person was belted. For example, the typical $\$ 5,000$ coverage for accidental death will now be increased to $\$ 10,000$ for those wearing belts. There is no charge for this additional coverage. About four million of State Farm's 22 million customers currently carry the optional "dismemberment" coverage. 
State Farm intends to offer this coverage in every state, except for a very few (c.g., Texas, North Carolina, and Massachusetts) where regulatory considerations, such as a requirement for "uniform policy," will not permit it. As of March 1, 1983, the safety belt benefit was approved in Ohio, California, Colorado, Idaho, and Louisiana. State Farm has received much more attention from major national media than had been anticipated. The attention has been welcomed and additional marketing is planned. Plans for evaluation of the new coverage's impacts on the company are not yet formalized, but claims records will be coded to identify the instances where the additional safety belt benefits are paid out to insureds.

Travelers Insurance Coinpany: The Travelers Insurance Company, the nation's sixth largest in terms of 1981 auto premiums, was one of the first to offer extra benefits for safety belt wearing. A doubling of medical coverage for those injured while wearing belts was introduced in May, 1963, and eventually was offered in 43 states. Over the years, the benefits have been discontinued in those states that adopted no-fault, so it is now offered in about 20 states.

Travelers was impressed with early studies on the efficacy of safety belts by the Air Force and by the University of Michigan, and saw a great potential for safety belt to save lives, reduce injuries, and to greatly lower bodily injury claims. Initially, Travelers considered offering premium discounts to those insureds with cars that had belts installed, but decided that it vias better to adopt extra benefits, given that every new car soon would have belts and that the belts would only be effective if used. Travelers hoped that extra medical coverage would "serve as a minor incentive to wear safety belts." However, they doubt "that it has had any effect at all."

Opinions about the Travelers experience with incentives must suffice, since there has been no recordkeeping or systematic evaluation. The claims department was never asked to code, or otherwise identify, claims settlements under this special policy. Over the years, only a "handful" of safety belt-related claims have been paid. 
Marketing of the'se benefits has been practically nonexistent over the last ten years. In courses for the agents, the benefits are only briefly discussed when talking about selling points. A bout 5,000 brochures, "Buckle Up and Double Your Medical Payments Limi:," are distributed annually, but otherwise it is not featured in promotions. Because marketing has not been extensive, none of the company's marketing questionnaires to customers have asked specifically about the impact of the safety belt benefits on policy selection. In any event, "liking the agent" and "price" are considered much more dominant marketing considerations than coverage. Increasingly, the company finds that the lowest-cost coverage, not the implications of a specific coverage offered, decides sales.

This emphasis on price is especially prevalent in "mass marketing", including the 2,000 firms with which Travelers has arranged payroll deduction plans for payment of automobile insurance. When asked about the potential for employers to couple auto insurance coverage with their own employee safety belt programs, the Travelers' spokesinan was quite enthusiastic. "E mployers have real clout with auto insurers," and the competition is intense. Traditionally, the competition has been almost totally on price, but the idea that safety belt benefits could become an effective incentive for belt wearing if coupled with employer programs seemed to make some sense to Travelers.

Safeco: Over a decade ago, Safeco developed a double medical payments benefit for those policyholders wearing safety belts. It was one of the "many small extra benefits, not costing much, but useful as "talking points," or "sales points." It was not an actuarially based benefit but the company was confident it would not cost too much given safety belt effectiveness. Without experience data, some states did not permit the benefit, but it is currently available in nine states. The company has paid the double benefits on occasion and has never contested a claim on this benefit. "We take their word for it, but there's usually some obvious evidence. The claimants are mighty sore when the belts were worn." The company has not evaluated the program and says they have "no statistics, no experience data." 
When asked about the marketing advantages of the benefits, Safeco's chief automobile underwriter was not enthusiastic. The policy may have won "a few sales," but "probably the average salesman didn't know about it anyway." Safeco did not want the nine states in which the company offers tie policy to be listed in this report, since they are in the process of phasing out these and other seldom used minor benefits. It is believed by the company that today's market competition favors the least cost policy, and that this means all special extra benefits eventually will be eliminated. This development is said to be due, in part, to the fact that state insurance commissions are increasingly requiring "readable policies" (i.e., a policy explained in simple, straightforward terms understandable to most consumers) and their publishing of consumer information bulletins that downplay the importance of an individual company's special benefits. At any rate, the company notes, as personal injury protection gains ground (in no-fault states), medical limits are getting higher so that additional medical coverage is not as widely needed. At Safeco, safety belt incentives are seen more as an experiment that failed, rather than as the wave of the future.

J.C. Penney: J.C. Penney Auto Insurance provides a 50 percent increase in A uto Medical Payments Coverage for those insureds wearing belts while in an accident. The company actively advertises this benefit. Like the other extra medical payment benefits of Nationwide and Safeco, no extra premium is charged. The benefit was developed by the Educator and Executive Insurance Co. (E.E.I.) several years before the company was acquired by J.C. Penney in 1973. The special safety belt benefit was developed as a marketing tool useful for the state teacher and education affinity groups in which E.E.I. specialized. Such associations were always looking for something special, something extra, for their members. The company believed that safety belt usage would be more attractive to affinity groups whose members were highly educated and thus more likely to believe in safety belts. In any event, such groups' members were deemed to be a better class of risk. 
The introduction of this benefit was not based on an actuarial study but did use the findings of an early study on safety belts by the state of Indiana. The company has not had trouble getting state approval for the benefit since it does not effect the reasonableness and adequacy of the premiums, nor is it discriminatory. Since typical policies of ten include low medical coverage limits (e.g., $\$ 500, \$ 1,000$, or $\$ 2,000)$, it is thought likely that some safety belt wearers used the extra benefit to gain coverage without paying extra premiums. In other words, for some insureds the extra benefit may have been perceived as equivalent to a premium discount.

According to the Director of Product Development and Customer Research, the benefit is still advertised by J.C. Penney and is promoted by use of envelope stuffers during renewal billings and quarterlies, in other advertising, by their salaried insurance sales people in J.C. Penney stores, and in J.C. Penney auto insurance advertising. Claims have been paid under this benefit coverage, but J.C. Penney has not kept records or made a careful evaluation of the impact on sales or on loss payout. Claims settlement has not been a problem; the claims people have said that "we take their word for it." While licensed to operate in several no-fault states, J.C. Penney does not of fer the safety belt benefits in those environments. For example, when Pennsylvania became an unlimited no-fault state, they stopped offering the benefit since the extra coverage was redundant. In summary, J.C. Penney considers its program of extra medical payment benefits for safety belts to be successful, and has every intention of continuing it in the approximately 20 tor $t$ states in which they are now actively selling auto insurance.

Motors Insurance Company: Motors Insurance Co., a subsidiary of GMAC, began in 1982 to offer its customers, GM employees in Ohio and Indiana, the option of purchasing for $\$ 2$ per year a rider to their auto insurance providing $\$ 10,000$ in accidental death coverage payable if the insured is killed in an automobile while belted. Since this special safety belt coverage is as much a life insurance incentive as an auto insurance incentive, it is discussed in the next chapter. 


\subsubsection{ESTIMATING THE VALUE AND COST OF SAFETY BELT INCENTIVES}

While the above examples may not include every safety belt benefit plan offered in the U.S., they are the major examples of the type of coverage the industry is providing. At least two major automobile insurers (GEICO and USAA) and one smaller insurer (Progressive) currently are considering some spácific safety belt benefits of the general types noted above. These benefits provlde extra medical payments coverage or a death benefit if the insureds are wearing the belt, and result in a relatively low increase in expected claims losses. There is no evidence regarding the perceived value to consumers of these extra benefits, but none of the insurers contacted suggested safety belt wearing consumers would pay more than $\$ 5$ for the additional benefits.

Estimates of the "cost" of these extra benefits can be compared to both the potential for insurers to profit from the initiative, and for confirmed safety belt wearers to capitalize on the benefit increases by choosing lower medical coverage. In Ohio, for example, most people have $\$ 1,000$ medical payments coverage, and the premium for this coverage does not vary by the age of the driver. J.C. Penney's annual premiums for medical payments insurance (single-car) are as follows: $\$ 12.00$ for a $\$ 5,000$ coverage, $\$ 9.00$ for $\$ 2,000$ coverage, and $\$ 7.00$ for $\$ 1,000$ coverage.

The annual premium difference between $\$ 1,000$ and $\$ 2,000$ coverage is $\$ 2.00$ for one car. In going from $\$ 2,000$ to $\$ 5,000$, the premium increases by $\$ 1$ per thousand. The 50 percent increase in coverage for the safety belt benefit would allow the insured who is covered by a $\$ 1,000$ policy to save the equivalent of $\$ 1$ in premiums annually (half of the $\$ 200 / \$ 100$ premium). The belt wearer with $\$ 2,000$ coverage, who gains an extra $\$ 1,000$ in safety belt coverage, also saves about $\$ 1.00$ in annual premiums. As suggested in Chapter 2, premium reductions of this size cannot by themselves be expected to increase safety belt use significantly. 
Using this same example, if safety belts are effective in reducing expected medical payment losses by 56 percent, and $i:$ the average payment normally is 75 percent of premiums, then the expected extra claims costs per policy that could be anticipated by the insurer woulc be only $\$ 0.42$ annually. Using the same methodology, it is estimated that the safety belt wearer in Ohio would annually have an expected loss at least $\$ 10$ lower than the non-belt wearer. If safety belt incentives are successful in attracting safety belt wearers to the company, the net reduction in loss claims per driver would be substantial, perhaps 40 times the cost of the incentive (\$10 divided by $\$ 0.42)$. In addition, new customers presumably would generate additional profits.

The differences in Nationwide's premiums for medical payments coverage in the state of Indiana provides another example of the "premium reduction value" of their extra safety belt benefits. Nationwide's annual premium for $\$ 1,000$ coverage is $\$ 5.20$; for $\$ 2,000$ coverage, $\$ 7.80$; and for a $\$ 5,000$ policy, $\$ 9.20$. The 100 percent additional benefit for the safety belt wearer, with $\$ 1,000$ tiasic coverage, thus provides additional coverage with a premium value of $\$ 2.60$. For a belt wearer with $\$ 2,000$ basic coverage, the extra benefit might be worth $\$ 0.92$ in premium savings. The premium savings associated with the $\$ 10,000$ extra death benefit could be estimated at an additional $\$ 2.00$ using the premium charged by Motors Insurance Corporation for this benefit as a benchmark. Thus, the total premium value of Nationwide's safety belt benefits approaches $\$ 4.60$ for the person who always uses safety belts. As in the J.C. Penney case, however, the expected costs of the additional benefits to Nationwide are a small fraction of the potential premium value.

Since there certainly is more evidence that safety belts when worn are at least as effective as passive restraints, it is interesting to compare the less than $\$ 1.00$ cost of extra safety belt benefits against the premium discounts offered for air bags, as reported in 1978 in the GAO report (see Table 3-7). 21 
TABLE 3-7

PREMIUM DISCOUNTS FOR AIRBAGS AS OF MARCH, 1978

\begin{tabular}{lcr} 
Company & $\begin{array}{c}\text { Michigan } \\
\text { (no-fault) }\end{array}$ & $\begin{array}{r}\text { Illinois } \\
\text { (fault) }\end{array}$ \\
\cline { 2 - 3 } Hartford & $\$ 17.08$ & $\$ 6.83$ \\
Nationwide & 10.74 & 2.17 \\
Liberty & 12.00 & 3.20 \\
Allstate & 14.61 & 3.83 \\
Travelers & 16.48 & 1.60 \\
GEICO & 9.78 & 5.18
\end{tabular}

The value of these premium discounts for passive restraints in the fault state of Illinois was two to seven times greatter than the extra losses that could be expected to accrue from consumers' safety belt benefit packages. In the no-fault state of Michigan (where the discount ranged from $\$ 9.75$ to $\$ 17.08$ ), the premium reduction was 10 to 17 times as costly. Reasons for the much lower value of safety belt use incentives probably include the following:

- The "air-bag" premium discount is more of a symbolic incentive, aimed at policymakers than at customers. To show their confidence in passive. restraints, the discount needed to be high in terms of percentage ( 15 to 30 percent).

- The "air-bag" incentive could afford to be high since few customers initially could avail themselves of the discount. It could be revised downward if passive restraints became more common on new cars without the expected decrease in claims losses.

o The "safety belt" extra benefit could not be made proportionately as high without inviting substantial cheating on claims.

\subsection{MODEL AUTOMOBILE INSURANCE INCENTIVES}

In the current competitive and regulatory environment, Nationwide's new "nocharge safety belt users benefit increases" represents a model program. Informal discussions are underway with Nationwide about the potential cooperation with DOT in evaluation of the program. Data bearing on safety belt use changes and on 
the role played by the benefits in the customer's choice of Nationwide probably could be gathered only by periodic survey of Nationwide's customers. However, changes in claims experience data could be documented relatively easily, given Nationwide's cooperation, because the company has computerized their operations and is committed to coding safety belt usage in accident claims handling. Data on how many insureds translate Nationwide's extra benefits into reduced basic coverage might also be a product of this evaluation. 


\section{NOTES TO CHAPTER 3}

1. Bests Review, "Auto Insurance 1981," August, 1982, pp. 13-16.

2. Ibid.

3. Ibid.

4. Mr. R.L. Jewell, Vice President, National Association of Independent Insurers, personal contact.

5. The Illinois Poll. Survey Research Laboratory, University of Illinois at Urbana-Champaign, 1982

6. NHTSA/NCSA, Report on Traffic Accidents and Injuries for 1979-80

7. Ibid, Fatal Accident Reporting System 1980, p. 8 (interpolated).

8. TSC staff analysis of NASS data for 1979.

9. "19 City Safety Belt Usage Summary Report," NHTSA Memo, dated August 23, 1983.

10. There exists one study of the average medical costs of a ranitom sample of 526 vehicle occupants injured in Saskatchewan between July 1, 1977 and June 3, 1978 which supplies some evidence that substantial loss reductions due to safety belt use are possible. The study found average injury treatment costs of $\$ 199$ for those who were unbelted, $\$ 96$ (50 percent reduction) for those using lap belts only, and \$59 (a 70 percent reduction) for persons who used lap and shoulder harnesses. The weighted average of lap belt only and of lap/shoulder belt wearers was $\$ 77$, about 61 percent less than the non-belt wearing average cost. This latter figure corresponds rather closely to NHTSA's more modest claim that safety belts are 56 percent effective in reducing moderate to critical injuries (AIS-3-6).

Shiels, Carl A., "The Effects of Seat Belt Legislation, The Saskatchewan Experience," Presentation to Canada Safety Council, 10th Annual Safety Conference, October 16-18, 1978, Addendum.

11. Issues and Needed Improvements in State Régulation of the Insurance Industry, GAO Comptroller General's Report, PAD-79-72, 1979, p. 130.

12. John Hanson, "An Overview--State Insurance Regulation," 31 CLU Journal, pp. 20-31 (April, 1977), cited in Issues and Needed Improvements in State Regulation of the Insurance Industry. 
13. Ibid., p. 140.

14. Ibid., p. 124.

15. Ibid., p. 229.

16. Executive Summary, Issues and Needed Improvements in State Regulation of the Insurance Industry, p. 40.

17. Chang and Company, "Regulatory and Legislative Barriers to Insurance Incentive Programs for Automobile Safety Devices and Proposed Remedies."

18. "How to Save With Insurance Discounts," Journal of American Insurance, Spring 1981, r. 14.

19. Ibid.

20. Comptroller General; GAO, Report to the Congress of the United States on Passive Restraints for Automobile Occupants -- A Closer Look.

21. Neither the additional safety belt benefit nor the passive restraint discounts have been supported by credible actuarial data. 


\section{CHAPTER 4: HEALTH MAINTENANCE ORGANIZATIONS}

\subsection{SIJMMARY}

This chapter summarizes the findings of a TSC/NHTSA-sponsored study by the Group Health Association of America on the potential for safety belt incentives in HMOs. It describes the many reasons HMOs have to encourage safety belt (and child restraint) usage, their experience in infant seat use incentives and several safety belt incentive programs that might be implemented on an experimental basis. The most promising experiment would relate a theoretically cost-effective approach to child safety seat incentives to parents' commitment to wear safety belts. A higher risk experiment would have an HMO use prizes to enhance safety belt promotion and gain safety belt use commitments from its enrollees. These experiments avoid legal prohibitions against HMO premium reductions or benefit increases keyed to individual behavior. If these experiments were successful, this approach could be extended to other HMO preventive health problems and to safety belt incentive programs involving more traditional insurers. While HMO safety belt incentives have a reasonable chance to develop independent of employer initiatives, the participation of employers would greatly increase the likelihood of an ongoing and successful safety belt incentive program.

\subsection{GENERAL DESCRIPTION}

Health Maintenance Organizations (HMOs) provide comprehensive health care services to their members for fixed periodic payments. In these plans a group of physicians, surgeons, dentists and/or optometrists provide both inpatient and outpatient health services as specified in a contract with subscribers. Since the HMO guarantees comprehensive health services for a fixed monthly premium, an incentive exists for the HMO to keep its enrollees healthy.

The idea of HMOs is not new. Prepaid group medical practice has existed in its current form since 1929, relying on the concept of an enrolled population, periodic payment of premiums, group practice, and integration of a broad spectrum of 
health services. However, until the carly 1970s, restrictive state laws prevented the establishment and development of HMOs in 35 states.

The term "Health Maintenance Organization" was first used in 1970 to promote government sponsorship of these plans. The word "maintenance" was used to imply a commitment to preventive medicine.

The HMO Act of 1973 was designed as a demonstration effort to attract private support for HMOs and to show that they could succeed in many new areas of the country. The act provided grants, loans, loan guarantees, and access to the health insurance market through mandatory dual choice: in accordance with the Fair Labor Standards Act, employers with more than 25 employees in an HMO's service area must offer, if requested, a choice of coverage by a federally-qualified HMO along with traditional health insurance.

The HMO is becoming increasingly accepted by health care consumers as a means of containing costs, in part by introducing incentives to prevent serious illness. In 1970 there were 35 HMOs with a total of approximately four million members. Today, most metropolitan areas have at least one HMO in operation. There are 11 million people currently enrolled in a total of $240 \mathrm{HMOs}$ at an average annual cost of $\$ 720$ per person, for a total of approximately $\$ 8.0$ billion in premiums in 1980 . The majority of these premiums are paid by the member's employer. For example, the Federal government assumes up to 75 percent of the cost of an HMO for its employees. Many key manufacturing employers, such as steel and automobiles, pay 100 percent of the cost. 1

Until recently, HMOs were required by law to set their rates by a "community rating" system. Under this system, rates are determined on a per person or per family basis and may vary with the number of persons in a family. The rates were required to be equivalent for all individuals and for all families of similar composition. Rates were not allowed to vary due to actual or anticipated utilization of services by individuals associated with any particular group of subscribers. 
The 1981 HMO Act made possible a "class rating" option for determining premium rates. Under this rating option, rates are fixed for individuals and families by groups. The rates are required to be cqual for all individuals in the same group and for all families oi similar composition in the same group. The rates are determined according to the HMO's revenue requirements for providing services to members of the different classes. The classes are based on factors which the HMO sees as determining the differences in the use of health services. Age, sex, income, and marital status have been established as reasonable factors for determining utilization.

During the past decade the growth of the HMO movement has been impressive. HMOs now are beginning to suffer some growing pains, and a few major obstacles must be overcome to insure continued success. Currently, there are three major obstacles to be overcome: a lack of sufficient management depth to handle daily operational problems, a need for considerable amounts of capital for expansion, and a continuing effort to increase the HMO share of the competitive rate-conscious health insurance market.

In marketing to the very large employers, HMOs emphasize the total coverage provided and their interest in keeping people well. HMO's competitive rates depend largely on cost containment measures including outpatient treatment, greater use of non-physician health professionals, emphasis on early diagnosis and disease detection, and incentives for the medical staff that reward cost containment. Preventive medical practices also are financially attractive and feasible for the HMOs, but these practices probably contribute much less to cost reductions than HMOs would like to admit. Nevertheless, "preventive medicine" is much more appealing to potential customers than "cost containment," since people would presumably rather avoid a disease than receive (even .cost-effective) treatment. 
The key to success for HMOs is whether they call capitalize on their competitive advantage over the fec-for-service insurers in marketing to the major employer groups. Acceptance by the major employers would dramatically increase membership and bring in badly-needed funds for management and expansion.

The principal association representing the interests of HMOs is the Group Health Association of America (GHAA). This association of prepaid group practice HMOs represents member plans which cover 85 percent of all HMO enrollees. In the course of this study, a close working relationship has been established with the GHAA. The GHAA has conducted a survey of the interest and current involvement of GHAA-member HMOs in child safety seat and adult safety belt education and promotion activities which resulted in a 74-page report with a 250-page appendix. Most of the findings and recommendations contained here are drawn from the GHAA study. 2

\subsection{HMO EXPERIENCE WITH INSURANCE INCENTIVES}

There are no cases where an HMO offers an insurance discount for participation in a particular activity. Until 1982, differential premium rates were prohibited by the "community rating" system. The current "class rating" option of rate setting allows more flexibility in determining rates, but it is unclear whether life-style indicators would be acceptable as bases for establishing classes. Such considerations are new to HMOs, and for this reason there are no programs utilizing insurance discounts at this time. However, many HMOs have offered additional health promotion benefits. Except in the case of child restraint loaner or giveaway programs, these counseling services have not utilized tangible incentives to achieve a desired behavior change.

HMOs have bcen mandated to educate their members in the contribution each one can make to maintaining their own health. The primary method used by HMOs to encourage particular forms of behavior is the provision of health education and 
promotion programs. A wide variety of activities has been organized including the distribution of relevant literature, individual counseling prior to delivery, "well baby" visits, newsletter articles, child safety seat education programs, posters and displays in the health center, films, and group counseling. Various members of the health center staff participate in these activities including pediatricians, obstetricians, nurses, and health educators.

The activities pursued by HMOs to encourage child restraint use are similar to other forms of healthy behavior promotion efforts, except for the incentive element present in many HMO child restraint programs. A survey of $52 \mathrm{HMO}$ by GHAA revealed that one-third of the programs either lend infant seats; provide them at no cost; or have a program in conjunction with a community group, a contracting hospital, or some other organization to provide enrollees with access to infant seats. ${ }^{3}$ In these cases, the incentive for utilization is the easy availability of the child restraint seats. In addition, health center staff members have lobbied community and state legislatures regarding the use of child restraints.

Half of the HMOs reviewed attempted some evaluation of the effectiveness of their child safety seat programs through interviews, observations, or other survey techniques. However, there has been only one comprehensive cost-benefit analysis of the effects of an HMO child restraint program. An evaluation of a comprehensive Prenatal Health Education Program was performed by Maxicare, an HMO based in Southern California. 4 The behavior of members who participated in three integrated prenatal programs - individual nutrition counseling, smoking cessation, and individual infant car safety counseling (including a free car seat) was compared to that of a control group. The major results of the infant car seat evaluation were as follows:

"From the standpoint of behavioral outcomes, the prenatal infant car safety program achieved great success with regard to its goal of promoting proper use of infant restraint devices among program participants. Both self-report and observational data indicated that a significantly greater percentage of Intervention Group women were using car seats than was found for Control women..." 
"Although differences in infant car seat use between groups was large, an estimation procedure using national incidence and cost datc pertaining to infantinvolved automobile accidents revealed that the program did not yicld a favorable cost-benefit ratio. The program was estimated to cost approximately $\$ 40,000$ a year, yet in the absence of data on (the) potential secondary benefit which may have accrued to the program...annual treatment cost savings (to Maxicare) were projected to be less than $\$ 5,000$. Given the problem of disenrollment of health plan members, and major questions regarding the long-term stability of behavioral differences between groups, it was determined that a less costly intervention would be required in order to make the infant car safety program economically viable".5

The major cost of the safety seat program was the salary of a health educator. If the health educator could increase the number of clients seen per hour by changing from an individual to a group counseling format, the labor cost per treatment could be significantly reduced. In addition, it is probably too costly for HMOs to provide infant seats free of charge. Both low-cost and free loaner programs appear to be more cost-effective, especially if they use convertible child safety seats which provide protection for children up to four years of age (vs. anly one year of use for infant-only seats). Such cost-reducing measures would probably not reduce the effectiveness of the program but would result in a much more favorable costbenefit ratio. 6

\subsection{HMOS AND SAFET Y BELT INCENTIVES}

Over half of the HMOs interviewed by GHAA expressed interest in developing incentive programs for automobile safety beit use, but few had any formal safety belt programs. Several HMOs keep records of safety belt use in auto accidents which result in hospitalization. However, quite often, accident victims are seen first outside of HMO facilities, usually in emergency rooms which bill the HMO for care without providing details on the cause of the injury requiring treatment. Therefore, few HMO clinical staff know the full circumstances of auto accidents involving their enrollees. Auto accident treatment costs, when hospitalization is not involved, are seldom identified systematically. In addition, although some HMOs subrogate the medical costs of auto accidents (i.e., they transfer charges to other insurers, especially the enrollee's automobile insurer), this information remains in the finance department, and the amount of auto accident-related 
medical costs actually paid by HMOs often is unknown. One surprising finding of the GHAA study was that many HMOs pay little attention to opportunities for subrogation. A task force has been created by GHAA to further study the pay'ment subrogation issue.

Despite their lack of automobile accident cost information, HMOs are concerned that they are paying for services for which other insurers should be responsible. While systems are being developed to confront this problem, HMOs are limited to attempting to reduce the costs of automobile accidents; encouraging the use of safety belts is one method currently being pursued. Unfortunately, most HMOs have found that safety belt programs are even more difficult to implement than child restraint programs because there is less internal staff support for safety belts and less access to enrollees on a regular basis. Regular prenatal and postnatal visits build strong relationships between patients and health care personnel. The effectiveness of counseling and the susceptibility of new parents to advice concerning protection of their infants combine to produce very high usage rates (correct habitual use of the car seat was reported by 56.3 percent of new parents in the Maxicare study).

Many of the same types of activities are used to encourage safety belt usage as were used to encourage the use of child restraints. These activities include individual counseling, films, literature, newsletters, posters, and recommendations. However, a difference between the two types of programs (child restraints and safety belts) is a lack of any tangible incentive for encouraging safety belt use. In the child restraint program, HMOs make safety seats easily available to parents as an incentive. There is no comparable incentive for safety belts.

Several HMOs have indicated their interest in changing the premium and benefit structure to encourage accident injury prevention through the use of safety belts and motorcycle helmets. As noted above, differentiated benefits clearly were not allowed under the traditional "community rating" system. Under the new "class rating" option it is unclear whether lifestyle indicators such as wearing or not 
wearing safety belts, using or not using motorcycle helmets, smoking or not smoking, or exercising or not exercising are factors, which may be used to determine a class. If these factors are acceptable then a composite class rate could be established which would include the beneficial rating characteristics of the good lifestyle class.

A nother option is to reduce or dismiss copayment for good lifestyle characteristics. While previously not possible, with a "class rating" option it might be feasible to create an exclusive class which would be eligible for a non-copayment option. Further opinions are needed to determine whether lifestyle factors are legitimate bases upon which to create special classes (e.g., for safety belt users)

HMOs may have little interest in offering, or even legal ability to offer, a premium discount or benefit increase to enrollees who use safety belt and child restraints. However, the HMO as an institution is midway between the employer and the typical insurer in terms of personal contact, membership, group identity, and the possibility of capturing the benefits of reduced losses. If incentives in the form of rewards for commitment to wear belts were successful for HMOs, then HMOs would have discovered a method by which other preventive health programs could be promoted. If successful, HMOs would have also demonstrated some promising experience with incentives that could be utilized by traditional insurers. On the other hand, if rewards for commitment fail in the HMO context, it will indicate that traditional insurers may find the approach even less satisfactory.

If public funds were available for safety belt incentives experiments, the HMO environment would be a promising candidate for at least one experiment. Combining child restraint and safety belt education and incentives in a program where education is not labor-intensive and where the seat loan or giveaway is of a convertible infant seat (i.e., one that has four-year utility, rather than one-year) would be an experiment with appeal to HMOs that are struggling to make child restraint promotion more cost-effective. Such an experiment would build upon the HMOs' inost important efforts to date - their child restraint promotion activities - 
and engage the HMOs in greater safety belt promotion activities. It would at the saine time explore the hypothesis that new parents are an especially good target for safety-related behavior change. If voluntary safety belt use is to become a national habit within one generation, both infants and their parents must be reached. 
NOTES TO CHAPTER 4
$\begin{aligned} & \text { Conversation } \\ & \text { Development, GHAA. }\end{aligned}$

2. Hunter, Harold R. "Safety Bcit and Child Restraint Programs in Health Maintenance Organizations", GHAA, prepared for U.S. D.O.T. \#DTRS57-S2P0-80525, October, 1982.

3. Hunter, op.cit.

4. Maxicare Health Plans, Inc., "Cost Benefit Analysis of a Comprehensive Prenatal Health Education Program Within an HMO Setting", prepared for U.S. Department of Health and Human Services, \#f 282-800-080, July, 1982.

5. Maxicare, op.cit.

6. $\quad$ lbid., p. 12. 


\section{CHAPTER 5: THE HEALTH INSURANCE INDUSTRY}

\subsection{SUMMARY}

This chapter explains why indemnity health insurers, the vast majority of health insurers that pay a portion of fee-fol-service medical expenses, are reluctant to consider offering special premiums or increased benefits on the basis of enrollees' behavior. While the industry supports safety belt usage and now covers the provision of many preventive health services, it has serious practical and philosophical difficulties with any sort of discriminatory premiums or coverage that is based on the behavior of individuals. In general, this industry has not paid close attention to the costs of motor vehicle injuries, and with few exceptions has offered no incentives for safety belt use.

One exception is Blue Cross of Oregon's major experimental health promotion incentives program, Health Chec, which was introduced in 1982 for its employees. This program sets up a pool of contributions from the health insurance premiums of participating employces. Part of this contribution may be returned to program participants after one year if they are absent from work less than the average of all employers and accumulate a certain number of "wellness" points for specific good health practices. A few of these points may be achieved by making a commitment to wear safety belts. While safety belt wearing is only a small part of this experiment, the concept has proven successful in reducing both absenteeism and medical coverage costs, and thus is a good candidate for consideration by an employer interested in supplementing other safety belt promotion efforts.

As with life insurance, the large employer is in the strongest position to bargain for the provision of special safety belt benefits by the insurer. Other optional benefits besides the "wellness" type plan above include purchase credit for child safety scats, provision of driver safety education, and counseling. 


\subsection{HEALTH INSURANCE TYPES AND PURPOSES}

The purpose of health insurance is to provide protection against certain direct financial losses resulting from an illness or injury. Indemnity health insurance benefits reimburse the insured individual for some medical care costs. 1

Many different kinds of health insurance are offered. Insurance may be underwritten for individuals and groups, and it may pay for direct medical costs associated with injury or illness both on-the-job and off-the-job. Insurance may be sold directly to individual insureds or offered by employers as a benefit. Group health insurance is becoming increasingly popular; in 1980, 84 percent of all health insurance premium payments were made for group policies. 2 The major types of health insurance coverage are hospital, surgical, physician, major medical, disability, and dental. Table 5-1 lists the various types of health insurance with the number of Americans covered by each type of policy in 1980 .

TABLE 5-1

TYPES OF HEALTH INSURANCE ${ }^{3}$

TYPE

Hospital

Surgical

Physician

Major Medical

Disability

Dental
NUMBER OF AMERICANS

COVERED IN 1980

$186,000,000$

$175,000,000$

$167,000,000$

$154,000,000$

$86,000,000$

$81,000,000$

The specific contracts offered by various health insurers vary greatly due to competition in the industy. Benefits that may vary among different insurers include benefits for death, dismemberment, total disability, partial disability, elective idemnities, double compensation for certain conditions, premium waiver, and renewability. 4 


\subsubsection{SIZE AND NUMBER OF IFIRMS}

The several different type's of health insurance providers include commercial companies; hospital and medical service plans, such as Blue Cross and Blue Shield ( BC/BS); group medical plans that operate on a prepayment basis, such as health maintenance organizations; and the U.S. government. Table 5-2 lists the types of non-government health insurance available, with the corresponding numbers of Americans covered by such policies in 1980.

TABLE 5-2

THE PROVIDERS OF HEALTH INSURANCE 5

TYPE

All policies

Commercial Companies

$\mathrm{BC} / \mathrm{BS}$ and other medical service plans

Other Plans
NUMBER OF AMERICANS

COVERED IN 1980

$185,146,000$

$105,966,000$

$86,721,000$

$29,414,000$

The largest group of health insurance providers are the commercial (mutual or stock) insurance companies which operate on ai for-profit basis. In 1980, there were 1,031 insurance companies providing accident and health insurance. 6 These firms are discussed in more detail in section 5.1.4.

The second largest group of health insurance providers are the hospital and medical service non-profit plans that "contract with health care providers to exchange the cost of covered health care services in return for periodic payments by the subscribers."7 The most widely used of these plans is Blue Cross/Blue Shield.

$\mathrm{BC} / \mathrm{BS}$ associations coordinate the nation's 70 Blue Cross and 68 Blue Shield plans throughout the country. Blue Cross provides benefits for hospital services and Blue 
Shield reimburses members for physician services. The BC/BS market share varies dramatically, ranging from a low 6.4 percent of the population in one market area to a high of 85.4 percent in another.

The third group of health insurance providers is a residual group that includes group and individual plans, special purpose plans, and various health and dental plans. Also in this group are HMO's operated by BC/BS.

\subsubsection{COMPETITIVE FACTORS}

Before 1940, BC/BS dominated the health insurance industry, but private carriers began to grow in strength after that time as health insurance became a tool in collective bargaining. The ability of private carriers to serve nationwide groups and their willingress to set premiums on an "experience rating" basis facilitated this growth in market share.

However, two competitive advantages are enjoyed by BC/BS over the commercial underwriters which enable it to maintain a significant market share in many areas. The tax exempt status of BC/BS appears to give it a competitive edge over the profit-making firms. In addition, BC/BS generally is able to acquire hospital services at a discount for. its members. However, each local BC/BS plan is autonomous and affiliated only loosely with the national association, so there may be wide variations among the BC/BS plans offered throughout the country. The fact that BC/BS previously set its premiums on "community ratings," rather than the generally less costly group "experience ratings," negated part of its competitive advantage in the past. Today, BC/BS uses "experience rating" in setting rates for most of its members.

In the commercial sector, health insurance is a relatively new element in a traditional industry: the life insurance industry. Most commercial health insurance policies are held by life insurance companies. In 1980, U.S. life insurance companies collected health insurance premiums totalling $\$ 29.4$ billion, or 31 percent of the life insurance companies' total premiums. Commercial health insurance premiums included $\$ 22.3$ billion for group health, $\$ 6.4$ billion for 
individual health, and $\$ 0.7$ billion for credit (loan-related) health insurance. 9 The larger life insurance carriers dominate the commercial health insurance industry and control the majority of group business. The many small firms which manage to participate in the industry sell primarily individual health policies and income loss insurance.

The vast majority of health insurance is purchased by employers for their employees. 10 These consumers of group insurance policies tend to be better informed as to differences in premiums and benefits than individual consumers. Since employers assume most or all of the costs of these policies, there is a large incentive for the employer to locate the best plan for its employees. The individual employee tends to be removed from most health insurance consumption decisions and from the actual costs of health care. One major exception to this rule is the fact that most employers must, by law, give their employees the option to join an HMO if one is available in the area. Nevertheless, most people covered by group health insurance are almost completely separated from the competitive process, allowing a third party, the employer, to bargain for them in the marketplace.

\subsubsection{FINANCIAL INDICATORS}

In the U.S. during $1980, \$ 247.2$ billion, or about $\$ 1,067$ per person, was spent on health care. This represented 9.4 percent of the U.S gross national product. Of the $\$ 70$ billion in benefits that were paid by private health underwriters, over $\$ 37$ billion came from commercial insurance companies, and over $\$ 32$ billion was paid by $\mathrm{BC} / \mathrm{BS}$ and other hospital or medical plans. Annual health insurance premiums in 1980 reached $\$ 77$ billion, of which $\$ 43$ billion accrued to commercial insurers and $\$ 34$ billion accrued to hospital or medical plans. 11 About $\$ 170$ billion in medical expenses were paid by government programs or charities, or were not reimbursed. 
In general, the health insuranre industry claims not to earn much money from the underwriting side of the business. In 1979, the comenercial accident and health underwriters carned an underwriting profit of $\$ 63.9$ million. However, in 1980 , the commercial health insurers suffered an underwriting loss of $\$ 860.3$ million, or 2.9 percent of earned premiums. 12

\subsubsection{THE MAJOR HEALTH INSURANCE FIRMS}

As indicated above, health insurance is dominated in the commercial sector by the life insurance companies. In 1980, there were 1,031 companies that underwrote accident and health insurance, but 14 firms had a combined share of just over 50 percent of the market (sec Table 5-3).

TABLE 5-3

MARKET SHARES OF LEADING COMMERCIAL HEALTH INSURANCE COMPANIES 13

NUMBER OF
COMPANIES

10

14

50

300

1,031
COMBINED MARKET

SHARE

$43.9 \%$

$50.6 \%$

$74.9 \%$

$96.5 \%$

$100.0 \%$ 
Table 5-4 identifies the ten largest cornmercial health underwriters.

TABLE 5-4

THE MAJOR COMMERCIAL HEALTH INSURANCE FIRMS 14

\begin{tabular}{|c|c|c|}
\hline 1980 RANK & COMPANY & $\frac{\text { PREMIUMS WRITTEN, } 1980}{\text { (Millions of } \$ \text { ) }}$ \\
\hline 1 & Prudential & 2,809 \\
\hline 2 & Aetna Life & 1,726 \\
\hline 3 & Travelers & 1,696 \\
\hline 4 & $\begin{array}{l}\text { Metropolitan } \\
\text { Life }\end{array}$ & 1,272 \\
\hline 5 & $\begin{array}{l}\text { Mutual of } \\
\text { Omaha }\end{array}$ & 1,253 \\
\hline 6 & $\begin{array}{l}\text { Equitable } \\
\text { Life }\end{array}$ & 1,250 \\
\hline 7 & $\begin{array}{l}\text { Connecticut } \\
\text { General }\end{array}$ & 1,231 \\
\hline 8 & $\begin{array}{l}\text { Continental } \\
\text { Assurance }\end{array}$ & 629 \\
\hline 9 & $\begin{array}{l}\text { Occidental of } \\
\text { California }\end{array}$ & 573 \\
\hline 10 & $\begin{array}{l}\text { Provident Life } \\
\text { and Accident }\end{array}$ & 496 \\
\hline
\end{tabular}

\subsubsection{MAJOR HEALTH INSURANCE CUSTOMERS}

By the end of 1980 more than 186 million Americans, or 85 percent of the civilian non-institutionalized population, were protected by at least one type of private health insurance. Of these, 172 million were under 65 years of age and 14 million 
were older than 65. This indicates that 88 percent of those under age 65 were protected by private health insurance and 60 percent of the post-65 age group was covered in addition to Medicare benefits. 15

A major trend in the consumption of private health insurance has been toward group policies and away from individual or single-family plans. In 1980, there were $33,907,000$ individual or family health insurance plans in effect, while there were $95,070,000$ group policyholders. Group premiums in 1980 reached $\$ 36.8$ billion compared to only $\$ 6.9$ billion for individual and family policies. 16 Grcup coverage has increased for a number of reasons. First, health insurance as an employee benefit has bccome increasingly popular. Also, companies have designed group coverage such that it is now available for small groups which previously were unable to qualify. Finally, large increases in health care costs have required insurers to attempt to fund larger benefit levels. 17

As noted above, a very large portion of Americans currently are protected by some form of private health insurance. It is not easy to identify the unprotected but they are generally considered to be young adults, who represent approximately 11 percent of the general population but 20 percent of the unprotected group; the unemployed; and employed persons earning under $\$ 10,000$ annually. It appears that those groups who can least afford the expenses of an illness or accident are the ones generally without heal th coverage.

\subsubsection{THE REGULATORY ENVIRONMENT}

Private insurers are subject to laws designed to protect policyholders from unfair or antisocial measures. The insurance industry is the largest and most important interstate business still regulated almost entirely by the states. The principal aim of state regulation is to insure that the companies remain solvent. The private carriers are not subject to rate regulation; however, one purpose of regulation is to guarantee that premium rates are set at levels such that covered claims can be 
paid and that insolvency is unlikely. In some states, changes $i_{1} B C / B S$ premium rates are regulated by the state. It is of ten politically popular to deny or delay rate increase requests to pressure $\mathrm{BC} / \mathrm{BS}$ into resisting rising hospital costs. 18

Because of competition, the standard provisions of most health insurance policies vary considerably. However, some provisions are determined by state agencies to protect both the insurers and the policyholders. Provisions that are regulated to protect the policyholders include: policy changes, incontestability, the grace period for premium payments, reinstatement, and the change of beneficiary. State-regulated provisions that protect the insurer include: written notice of loss, proof of loss, the right to examine the insured, and the right to autopsy. 19

\subsubsection{RATE DETERMINATION}

As with any type of insurance, the insurance premium, or cost, is determined by calculating the probability of loss on the part of the policyholder, plus the cost of administration. There are two general methods for determining the probability of loss for health insurance purposes, "community rating" and "experience rating." "Community rating" is based upon the population at large of a particular geographical area and assumes that all within that area are of the same risk regardless of actual physical condition. "Experience rating" relies only on the health history of the particular group to be insured; lower rates are charged to lower risk groups.

In an experience rating system the probability of loss is based on a number of factors, including age, sex, occupation, and the cost of health care services in a particular geographic area. For group plans, other experience factors include the loss ratio of the group in previous years, the size of the group, the amount of employer contributions, and whether the group has been previously insured.

In recent years, a number of factors have contributed to increasing health care costs. These factors include inflation, demographic changes, advances in medical technology, changes in public attitudes toward the right to health care, and 
government regulation. One way that health insurers respond to these rising costs is by decreasing the effective benefits and coverage of their policies. The purchasers of large group policies also are beginning to consider the benefits of self-insurance, under which the third party (the insurance company) is climinated and the employer acts as the insurer for its own workers. Finally, the rising costs of health protection have highlighted the questions of equity and the "right" to health care. These questions inevitably lead to a discussion of national health insurance.

\subsection{TYPICAL HEALTH INSURANCE POLICIES: FEDERAL PLANS}

Federal employees are offered a choice of many health insurance plans. The plans offered include an Aetna group plan, a BC/BS plan, an array of employee organization plans, and several HMOs. This analysis compares plans representative of those offered to Federal government employees: Aetna; BC/BS; the Government Employees Hospital Association Benefits Plan (GEHA), an employee organization plan; and a HMO, the Harvard Community Health Plan (HCHP).

The government's (or employer's) annual contribution per subscriber for 1983, regardless of plan selected, is $\$ 553$ for self-only enrollment, and from $\$ 1,038$ to $\$ 1,236$ for a family enrollment. The employee pays the remainder of the premium through biweekly payroll deductions. Table 5-5 lists the total annual premium costs for each of the plans.

The two private plans, Aetna and BC/BS, which are traditional forms of health insurance and allow the patient to select physicians, are respectively the most and least expensive plans, depending on which option is chosen. HCHP, the HMO that requires patients to procure health care at its medical centers, is close in cost to the high option plans of the private insurers. GEHA is the least expensive of the plans studied, being close in cost to the low option coverage offered by Aetna and $\mathrm{BC} / \mathrm{BS}$. 
TABLE 5-5

ANNUAL PREMIUM COSTS FOR VARIOUS HEALTH INSURANCE PLANS* SELF ENROLLMENT

BC/BS (High Option)

$\$ 1212$

Aetna (High Option)

1041

$\mathrm{HCHP}$

847

GEHA

721

Actna (Low Option)

710

BC/BS (Low Option)

697

FAMIL Y ENROLLMENT

BC/BS (High Option \$2653

HCHP

2238

Aetna (High Option) 1935

BC/BS (Low Option) 1622

Aetna (Low Option) 1616

GEHA

1590

* Note: These plans of fer substantially different benefits.

There is no consistent relationship between premiums and benefits. Except for those offered by the HMO, most of the benefits are comparable with some differences in coverages and levels of deductible and copayment. Because economic differences among plans are difficult to decipher, a consumer's insurance purchasing decisions might be based on other considerations including the option of selecting one's own doctor, the perccived or actual quality of health care, the perceived or actual quality of administration, and general convenience.

\subsection{INDUSTRY EXPERIENCE WITH INSURANCE INCENTIVES}

\subsubsection{GENERAL EXPERIENCE}

The preventive medical services typically covered (at least in part) by health insurance are impurtant influences on the extent to which medical facilities are used. For example, The Surgeon General's Report On Health Promotion and Disease lists preventive services available for the normal infant, including counseling for accident avoidance behavior such as using child safety seats. By paying for the major part of these services, health insurance certainly is playing a constructive role in preventive medicine. However, financial incentives seldom 
have been used to influence preventive health behavior. Only one instance was found where preventive health counscling was being reinforced with tangible rewards or incentives. The provision of payment for a child or infant safety seats was not generally a part of accident/injury prevention activities except for a few HMOs.

Discussions with major associations serving the commercial health underwriters, the Health Insurance Association of America, the American Council on Life. Insurance, and the Health Insurance Institute, revealed that no insurance incentive programs currently exist. A number of reasons were offered as to why incentives programs do not exist, either in general or specifically targeted toward safety belt usage. These reasons include the following:

- Most health insurance is of fered on a group basis. Incentives designed to influence individual behavior are difficult to manage within a group framework.

o Questions of legal discrimination cloud the issue of offering favorable conditions to some, while denying these benefits to others.

o Since experience rating is used in determining most health insurance premiums, a natural incentive already exists to reduce risk.

o There are huge administrative and enforcement problems associated with individual incentive programs. There is no accurate method of determining whether policyholders with safety belt clauses actually use their safety belts.

- The actual dollar amount of benefits offered to the individual policy holder in exchange for the habitual use of safety belts is not likely to be substantial enough to motivate changes in behavior.

- There is a lack of valid data regarding the health care cost savings that health insurers can expect to result from higher rates of safety belt use. 
While the health irsurance associations were quick to state their support for the use of safety belts, they also implied that except for information programs, incentives to alter the behavior of policyholders were not within the scope of their business. The health insurers acknowledged that health care costs related to the failure to use safety belts of ten were paid by the health underwriters, but they believe that issues of driving safety, including the use of safety belts, should fall within the domain of the automobile insurance industry. In addition, it should be noted that there is some concern within the industry that any attempt to provide financial incentives to individuals through group insurance may in fact conflict with some of the underlying objectives for which group insurance programs were designed: group health insurance programs are intended to finance medical care for all employees and families in a group. 20

The Blue Cross and Blue Shield programs, which generally take an active role in encouraging healthful behavior, offer preventive medical services but do not provide direct incentives for preventive behavior. Many BC/BS plans have general campaigns to increase public awareness of automobile safety and other health issues such as smoking, weight loss, stress management, and high blood pressure. In addition, with the help of employers, BC/BS attempts to identify "multiple risk factors" that contribute to poor health, such as smoking and high blood pressure, and programs are devised to confront these problems. Programs are implemented with a great deal of publicity and encouragement to participate and, in some cases, the programs are offered during work hours, providing the incentive of a break from work for attending employees.

\subsubsection{BLUE CROSS OF OREGON'S "HEALTH CHEC" PROGRAM}

With one notable exception, BC/BS offers no direct incentive programs to encourage healthy behavior or the use of safety belts. The reasons offered for this were identical to those already listed above for commercial insurers. 
The exception is Blur Cross of Oregon, which currently is testing a program with its own employees that utilizes financial incentives to encourage healthy behavior. The program, entitled Health Chec, creates a pool of $\$ 400$ for each employee at the beginning of the year. In return, the employee signs a contract to take part in certain "wellness" activities of varying intensity throughout the year. As the year progresses, the health care expenses for each employee are deducted from the original $\$ 400$. At the end of the year, if the employee meets two conditions, the remainder of the original $\$ 400$ is given to the participant. The two conditions are that the participant meets the specifications agreed to in the contract by taking part in the specified "wellness" activities, and that the employee must have at least one less sick day than the group average.

As indicated above, the employee must participate in a series of "wellness" activities to qualify for a financial award at the end of the year. These "wellness" activities either aid the employee in achieving better health or guide the participant towards a lifestyle of good health maintenance activities. "Wellness" activities of the first type include no smoking classes, weight reduction programs, and exercise classes. The second type of "wellness" activities include defensive driving courses and the use of safety belts.

Exhibit 5-1 describes the Health Chec program and lists the "wellness" activities. Much of the program is operated on a honor system. Attendance at formal classes or programs is monitored, but many activities such as the use of safety belts are impossible to monitor. In these cases, the signed contract at the beginning of the year and the word of the participant are accepted as proof of participation.

Initially, 468 employees joined the Health Chec program, which was started in January, 1982. Results for the first nine months of the program include the following:

- Health Chec participants recorded an average of 3.1 sick days, as compared to an average of 4.1 sick days for non-participants.

o Program participants missed 937 fewer days of work due to illness than they did during the previous year. 


\section{HEALTH CHEC -}

\section{A REWARDING PROGRAM}

Because we are concerned with your good health - not just paying the bills to have it restored - we are introducing on a one-year trial basis a new type of benefit program for all of our active staff members who choose to participate and are eligible.

It's called Healtin Chec, and here's how it works. First, it includes all the benefits of our present group health plan, with payments made exactly as they are now.

\section{HERE'S WHATS NEW}

Under Health Chec, even if you have been "well" you and your family will receive benefits.

The new feature is that on January 1,1982 , a potential "reward" of $\$ 400$ will be established for each of our employees. Medical claims (not dental and vision claims) that are incurred will be deducted from this figure. Claims that exceed $\$ 400$ will still be paid in the normal manner.

\section{HERE'S HOW IT WORKS}

If you or your family have incurred bills that are less than $\$ 400$ from January 1, 1982 through December 31,1982 , you will receive a "health check" for any remaining unused portion of the $\$ 400$ (less taxes). To allow time for claims to be processed, December 31, 1982 will be the cut off date and you will receive your check during April of 1983.

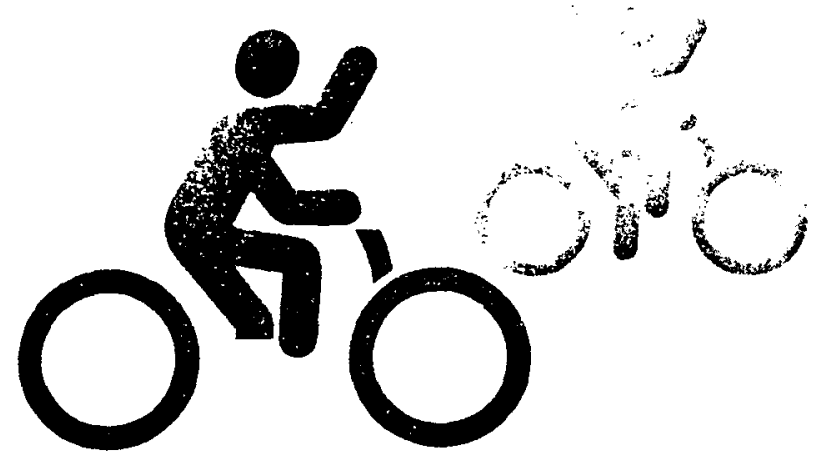

\section{HERE'S HOW YOU CAN PARTICIPATE IN THE PLAN}

If you or your enrolled lamily members don't have any claims at all, or receive less than $\$ 400$ in benefits in the benefit year, whatever is left in your personal "account" will be paid to you if:

1. You have been enrolled for the whole benefit year.

2. You take part in a formal "wellness" participation program.

3. You have one less sick day during the benefit year than the company average for the year (1981).

NOTE: You must be an active member of our group program for the entire calendar year. Retirees or those on leave of absence, for example, are not eligible to receive Health Chec payments.

\section{HERE'S HOW THE WELLNESS PARTICIPATION PROGRAM WORKS}

A recent study showed that long life and good health are significantly related to seven simple but basic health habits:

1. Three meals a day with no snacks;

2. Breakfast every day;

3. Moderate exercise three times per week;

4. Seven or eight hours of sleep each night;

5. No smoking

6. Moderate weight;

7. No alcohol or in moderation.

Using these guidelines and adding a few other basic health and safety activities, the following list has been prepared, with point values assigned to each. To be able to qualify for this part of Health Chec, you must earn " 10 points toward health" during the year.

You will note that certain key activities are worth ten points by themselves. If you do not choose to participate in one of these you must participate in at least one four-point activity and enough others to make up the required ten points.

You will be asked to sign an agreement stipulating your planned activities and then to attest to their completion at the year's end.

\begin{tabular}{|c|c|}
\hline WEIGHT/EXERCISE/NUTRITION & Points \\
\hline $\begin{array}{l}\text { Join Weight Watchers or similar organization } \\
\text { and participate for year }\end{array}$ & 10 \\
\hline Eat three meals each day - no snacks & 4 \\
\hline Always eat breakfast & 2 \\
\hline $\begin{array}{l}\text { Join organized fitness program ("Y" or } \\
\text { Community College) and participate } \\
\text { for year }\end{array}$ & 10 \\
\hline $\begin{array}{l}\text { Personal fitness program (long walk, bicycle } \\
\text { riding, swimming) two or three times per } \\
\text { week ïrough year }\end{array}$ & 4 \\
\hline Read "Food \& Fitness" & 2 \\
\hline Read "Feel Better" & 2 \\
\hline \multicolumn{2}{|l|}{ SUBSTANCE ABUSE } \\
\hline Quit smoking - maintain for year & 10 \\
\hline $\begin{array}{l}\text { Quit drinking (or join Alcoholics Anonymous } \\
\text { and participate for year) }\end{array}$ & 10 \\
\hline $\begin{array}{l}\text { Drink moderately (average no more than one } \\
\text { drink }-2 \text { oz. of alcohol-per day) }\end{array}$ & 4 \\
\hline Read "Alcoholism" & 2 \\
\hline \multicolumn{2}{|l|}{ GENERAL } \\
\hline Take Defensive Driving class & 4 \\
\hline Take stress management class & 4 \\
\hline Have blood pressure checked once a year & 2 \\
\hline Have Pap smear done annually (if over 25 ) & 2 \\
\hline Do breast self-examination monthly & 2 \\
\hline Wear seat belts at all times & 2 \\
\hline Get seven to eight hours sleep each night & 2 \\
\hline Read "Stress" & 2 \\
\hline
\end{tabular}

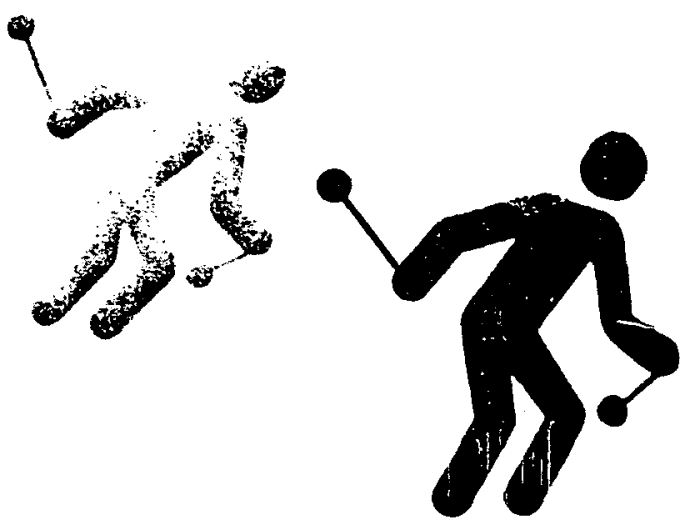


- This decrease in sick time resulted in a savings of $\$ 45,000$ ( $\$ 96$ per participant) for the employer.

- Of the 468 participants, 165 promised to wear their safety belts at all times. This promise provided two of the ten points necessary for a participant to be eligible for a refund at the end of the year.

- Prospective year-end refunds average $\$ 200-\$ 250$ per participant.

These results have convinced $\mathrm{BC}$ of Oregon to continue the program. In addition, beyond offering it to their own employees, they are now beginning to offer Health Chec to groups within its coverage area.

\subsection{CONCLUSIONS}

The health insurance industry has not used incentives to encourage the use of safety belts, and the potential for implementing such incentives is questionable. Health insurers have considered the provision of financial incentives, but directing such incentives at the individual consurner of health insurance is believed to be impractible by the health insurance industry for the following reasons: the burdensome level of monitoring and administration that would be created by targeting incentives at individuals; the separation of most individuals from the health insurance buying process, since most allow their employers to make this consumption decision for them; and the fact that the financial incentive offered to the individual would most likely be too small to encourage the habitual use of safety belts. In addition, the lack of valid data regarding health care cost savings that insurers could expect from safety belt users is seen as a major problem.

An incentive program designed to increase safety belt usage is more practical for groups than for individuals. The major consumers of health insurance are group administrators who more easily can identify the benefits gained through preventive measures such as safety belt use. The reduced premiums offered by an incentive program would be of interest to large groups, and the burden of administration and monitoring can be shared by the insurer and the employer. 
The key to implementing a safety belt usage incentive plan appears to lie with the employer. Most health insurance is purchased for groups and most groups are administered by employers. Although insurance companies tend not to compete aggressively for individual hedth policies, large financial stakes are associated with the more profitable group policies. The competitive process is aided by the fact that the employer has a large financial incentive to procure the most costeffective policy for its employees. In addition, the employer has a direct financial stake in healthy employees: large amounts of money are involved in the claims filed by its employces; sick leave for off-the-job motor vehicle injuries comes directly out of the employer's pocke:t; and lost productivity due to disruption from absences related to motor vehicle injuries of the employee or members of his/her family produces an additional financial burden. Therefore, it is in an employer's interest to procure a health insurance program that not only is cost-effective in providing medical care but also attends to preventive measures, such as safety belt usage.

Apart from the industry's major ethical questions regarding discriminatory pricing of health insurance policies, the major problem in a health insurance program using incentives to encourage the use of safety belts is the question of monitoring. As indicated above, Health Chec (Blue Cross of Oregon) uses an honor system in their program, but in this case safety belt usage is only one small element within a comprehensive program. In a program where safety belt usage was a more substantial component, the monitoring aspect would need to be more formal. 


\section{NOTES TO CHAPTER 5}

1. Bickelhaupt David L. and John, H. Magec. General Insurance, Richard D. Irwin, Homewood, Illinois, 1970, F. 755.

2. Health Insurance Association ol America (HIAA), Source Book of Health Insurance Data, Washington, D.C., 1981-1982, p. 13.

3. HIAA, P. 12.

4. Bickelhaupt and Magee, p. 770.

5. HIAA, p. 13.

6. Best's Review, November, 1981, p. 50.

7. Morrow, Carol Klapperman. Health Care Guidance, Praegers Publishers, N.Y., 1976, p. 5.

8. Krizay, John and Andrew Wilson. The Patient as Consumer, Lexington Books, Lexington, MA, 1974, p. 40.

9. Krizay and Wilson, p. 39.

10. Langwell, Kathryn $M$. Research on Competition in the Financing and Delivery of Heal th Services: A Summary of Policy Issues, U.S. Department of Health and Human Services, National Center for Health Services Research, October, 1982, p. 5.

11. HIAA, pp. 23, 29.

12. Best's Review, p. 52.

13. Ibid., p. 50.

15. HIAA, p. 19.

16. Ibid., p. 27.

17. Ibid., p. 27.

18. Krizay and Wilson, pp. 43, 44.

19. Bickelhaupt and Magee, p. 774.

20. Levy, Dr. Leslie. "Insurance Incentives and Disincentives," in "Health Education and Promotion: Agenda for the 1980's," Health Insurance Association of America and American Council of Life Insurance, p. 48. 
CHAPTER 6: LIFE INSURANCE INDUSTRY

\subsection{SUMMARY}

This chapter explores the potential for life insurance companies to provide either a premium discount or additional motor vehicle accidental death benefit for those policyholders who habitually wear safety belts. No-smoking life insurance premium discounts are highlighted as an example of how life insurance incentives can be developed, given sufficient actuarial data and potential consumer demand. As derived in Section 6.5.2, if the expected loss payout for an unbelted driver was $\$ 14.00$ on a $\$ 100,000$ policy, the payout for a belted driver would be only $\$ 6.00$. Under these assumptions, a belt wearer buying $\$ 100,000$ of life insurance could expect to pay $\$ 8.00$ less on the annual premium (or to receive an additional $\$ 130,000$ in a special auto accident death benefit) than a non-belt wearer.

Recognizing the very low likelihood that a safety belt wearer will die in a motor vehicle accident, a few auto insurers recently have added special $\$ 10,000$ accidental death benefits to their automobile policies at little or no charge. (The estimated additional annual loss payout for this benefit is less than $\$ 0.60$ per belt wearer.)

It is unlikely that life insurers themselves will initiate policies recognizing the mortality differences related to belt-wearing behavior because these differences and the potential market are relatively small, especially when compared to those for smoking behavior. However, it seems quite possible that a company wishing to acquire a safety belt discount or extra accidental death benefit for its employees could do so at very little cost. An employer who is successful in increasing employee belt use rates actually could enjoy both the special benefit plus lower average annual premiums. 
Nevertheless, since there is no evidence that even the 50 percent premium discounts for non-smoking term insurance actually have changed smokers' behavior, it is not clear that a special ADB benefit for safety belts would be effective as an incentive to belt wearing except as a supplement to other more direct employer efforts to increase belt usage.

\subsection{GENERAL DESCRIPTION: LIFE INSURANCE TYPES}

Life insurance was created to protect the insured's family, creditors, or other beneficiaries against financial loss caused by the death of the insured. With a life insurance policy, a person creates an sstate, or adds to one, and the future of the estate is protected as the insurance policy is kept over the years.

The average amount of life insurance in force in the U.S. in 1981 was $\$ 45,700$ per family, and $\$ 53,200$ for insured families. ${ }^{1}$ Life insurance policies usually provide the payment of proceeds in installments or in some manner other than a lump sum. This is the so-called "settlement option" and is chosen either by the insured or the beneficiary.

The purchase and service of individual life insurance policies are handled exclusively by insurance brokers and agents. Insurance companies can maintain their own agents, rely on independent insurance brokers, or choose a mixture of the two to market their products. Four categories of life insurance are available: ordinary life insurance; industrial life insurance; group life insurance; and credit life insurance. ${ }^{2}$ For group life and credit insurance, life insurance companies usually sell directly to the employers or to lending institutions.

Ordinary life insurance is the most widely used form of insurance protection, accounting for 50 percent of all life insurance in force in the U.S. at the end of 1980.3 This type of insurance typically is distributed through life insurance agents and issued as individual policies having face amounts of $\$ 1,000$ or more, with $\$ 5,000$ a common minimum. 4 Life insurance can be further classified into two basic types of protection, whole life (permanent) and term insurance: 
Whole Life Insurance: In addition to offering protection from financial losses resulting from the death of the insured, whole life insurance also builds cash value. This is achieved by investing part of the premium collected during the early years in a reserve. This reserve, together with the interest earned and the later premium payments, assures that sufficient funds will be available to cover the increased future risks. Cash values can help families meet financial emergencies, pay for special needs, or provide retirement income.

Term Insurance: These policies provide life protection only and do not accumulate cash values. In general, the premiums are lower than those for whole life policies of equal protection (i.e., face amount), but they increase with each renewal of the term policy, reflecting higher mortality rates at older ages.

Group life insurance is the most recent and fastest growing major class of life insurance. It differs from ordinary life insurance in that the coverage is extended to a group of people instead of an individual. Most group plans are sold to employers for their employees, but are also sold to associations, trusts, unions and creditors. Nearly all of them are term insurance plans. Currently, group life insurance is a nearly universal employee benefit in this country that can be purchased through employers and often is subsidized by them. Other forms of group insurance include group mortgage insurance and group survivor benefits (usually to surviving spouse and/or dependent children).

At the end of 1980, group life insurance outstanding in the United States totaled $\$ 1,599.4$ billion, which represented an 11.3 percent increase during the year and was nearly three times the amount in force at the end of 1970 . Total group coverage amounted to $\mathbf{4 4 . 6}$ percent of life insurance in force in the United States at the end of 1980.5 


\subsection{LIFE INSURANCE INDUSTRY}

\subsubsection{SIZE OF INDUSTRY}

At the end of 1980, the number of U.S. legal reserve life insurance companies (not including fraternal benefit societies) was estimated at $1,948.6$ For those companies in business at mid-1980, a total of 1,796 (93 percent) were owried by stockholders, while the remaining 135 were mutual companies. 7 Mutual companies, which generally are older and lalrger than stockholder-owned companies, hold three-quarters of the assets of U.S. life companies and account for 50 percent of life insurance in force. 8 In 1981 , total life insurance in force reached $\$ 4.064$ trillion.

\subsubsection{SIZE AND RANK OF LIFE INSURANCE COMPANIES}

Life insurance companies usually are ranked by two measures: life insurance in force, which measures the maximum potential claim against the insurer; and premium income, which is proportional to the average risk assumed by the life insurer. The ranking of the top 15 life insurance companies by their respective premium income and insurance in force is presented in Table 6-1.

\subsubsection{INCOME OF LIFE INSURANCE COMPANIES}

Life insurance companies receive their income from two major sources: premiums paid by policyholders, and investment earnings. Part of each premium is invested, and the anticipated earnings from the investment are taken into account in calculating the insurance premium. Of the total $\$ 132.5$ billion in life insurance company income in 1980, 71 percent was from premium receipts and 26 percent from investment earnings. 9 Table 6-2 provides a breakdown of various categories of life insurance company premium receipts in 1980. 
TABLE 6-1

1981 RANKING OF U.S. LIFE INSURANCE COMPANIES

BY PREMIUM INCOME (TOP 15) AND INSURANCE IN FORCE

\begin{tabular}{|c|c|c|c|c|}
\hline \multirow[b]{2}{*}{ COMPANY } & \multicolumn{2}{|c|}{ PREMIUMS } & \multicolumn{2}{|c|}{ INSURANCE IN FORCE } \\
\hline & RANK & BILLION $\$$ & RANK & BILLION $\$$ \\
\hline Prudential & 1 & 9.9 & 1 & 456.2 \\
\hline Metropolitan & 2 & 5.4 & 2 & 393.6 \\
\hline Aetna Life & 3 & 4.4 & 4 & 163.9 \\
\hline Travelers & 4 & 4.4 & 8 & 116.5 \\
\hline Connecticut Genl. & 5 & 2.8 & 9 & 90.1 \\
\hline New York Life & 6 & 2.6 & 6 & 137.5 \\
\hline John Hancock Mutual & 7 & 2.4 & 5 & 145.6 \\
\hline Equitable Life & 8 & 2.4 & 3 & 223.9 \\
\hline Cologne Life & 9 & 1.9 & 37 & 31.2 \\
\hline Teachers & 10 & 1.8 & 106 & 9.1 \\
\hline Transamerica & 11 & 1.6 & $\therefore 7$ & 123.6 \\
\hline Bankers Life & 12 & 1.5 & 22 & 42.7 \\
\hline Great-Western & 13 & 1.4 & 16 & 64.1 \\
\hline Mutual of Omaha & 14 & 1.4 & 34 & 32.5 \\
\hline Capital Life & 15 & 1.3 & 82 & 11.6 \\
\hline
\end{tabular}

SOURCE: "National Underwriter", Life and Health Edition, Part I (May 29, 1982, p. 27-28) and Part II (June 12, 1982, p. 11). 
TABLE 6-2

PREMIUM RECEIPTS:

U.S. LIFE INSURANCE COMPANIES

( $\$$ in Millions)

Amount

LIFE INSURANCE PREMIUMS

Ordinary

Group

Industrial

Credit

Total

ANNUIT Y CONSIDERATIONS

Individual

Group

Total

HEALTH INSURANCE PREM!UMS

Individual

Group

Credit

Total

TOTAL PREMIUM

RECEIPTS

\begin{tabular}{c|r}
$\$ 29,463$ & 72 \\
8,508 & 21 \\
1,323 & 3 \\
1,535 & $4 \frac{4}{3}$ \\
40,829 &
\end{tabular}

$\$ 6,504$

$\frac{17,526}{24,030}$

24,030

27

$\frac{73}{26}$

$\$ 6,366$

22,262

$29, \frac{738}{366}$

22

76

$3 \frac{2}{1}$

$\$ 94,225$

\section{Percent}

72

21

3
$\frac{4}{3}$

NOTE: Credit life insurance is limited to insurance on loans of 10 years or less. 


\subsubsection{LIFE INSURANCIE INCOME AND EXPENDIT URES}

The financial transactions of life insurance companies may be illustrated in terms of a single dollar received and expended. This composite dollar represents the totals for the life insurance business as a whole; the proportions will vary from company to company. Table 6-3 illustrates the breakdown of life insurance income and expenditures for 1980.10

\section{TABLE 6-3}

U.S. LIFE INSURANCE COMPANY DOLLAR, 1980

\section{INCOME}

Premiums

$73.0 \xi$

Net Investment Earnings and Other Income 27.0 $1 \overline{00.0 \xi}$

\section{HOW USED}

Benefit Payments and Additions to $F$ unds for

Policyholders and Beneficiaries Benefit Payments in Year $49.4 c$

Additions to Policy

Reserve Funds

28.0

Additions to Special

Reserves and Surplus

Funds

Operating Expenses

Commissions to

Agents

Home and Field Office Expenses

$$
\frac{9.5}{15.2}
$$

Taxes

$$
3.4
$$

Dividends to Stockholders

$$
\frac{1.1}{100.0 \xi}
$$




\subsubsection{REGULATOR Y ENVIRONMENT}

The general purpose of insurance regulation is to protect the public against insolvency or unfair treatment by insurers. The value of life insurance contracts depends on the ability of insurers to carry out promises to the public, sometimes many years after the issuance of a policy.

The power to regulate the life insurance industry rasts with the insurance commissioner in each state. The commissioner's wide authority includes licensing insurers and agents, approving rates and forms, examining insurers' records, and investigating complaints. Periodically, detailed examinations are conducted on insurers according to state law. This involves checking assets, liabilities, and reserves, as well as reviewing nearly all underwriting, investment, and claim practices of the insurers. A zone system is used in cooperation with the National Association of Insurance Commissioners (NAIC) to avoid duplicate examinations. 11

The National Association of Insurance Commissioners (NAIC) is a voluntary association of top state insurance administrators. In addition to the zone examination practices, it also influences the uniformity of insurance laws in various states.

In most states, the insurance commissioner has the power to determine whether insurers are meeting statutory requirements. The commissioner has free access to insurers' records and books, and conducts hearings on matters such as rate violations and unfair trade practices. As a result of such investigations, the commissioner may issue administrative rulings or advisory opinions on the insurers or their agents. In some extreme cases, the commissioner has the power to refuse to renew the license as well as the power of suspension or revocation.

The insurance department with which insurance commissioners conduct their duties may vary from a few persons in some small states to well over 700 employees in New York State. 12 


\subsubsection{RATE DETERMINATION}

The premium level of each life insurance policy is determined by the insureors age at issue, sex, and medical history, which traditionally have been considered to be the most important factors affecting life expectancy. A lower premium may be applied to preferred risks, while a surcharge may be added for above-average risks. To qualify for the preferred risk premium, the insurance applicant must meet more stringent medical standards and have a favorable family health history.

\subsection{EXISTING LIFE INSURANCE INCENTIVES: NON-SMOKING}

Life insurance policy premiums are calculated on the basis of mortality. To provide insurance incentives to the insureds, usually in terms of premium discounts, justification is based on either improved mortality or on marketing considerations. Premium discounts are offered by various life insurance companies. The motivations for offering these insurance incentives are to attract "preferred risk" applicants or to protect a company's market share from industry competition. The promotion of desirable lifestyle habits among insureds, such as non-smoking and regular physical exercise, is a secondary consideration. The most widespread life insurance discount is that of fered to non-smokers.

\subsubsection{DESCRIPTION OF NON-SMOKERS' DISCOUNTS}

The non-smoker discounts recognize that individuals who do not smoke have a much lower mortality level than those who do. The savings usually are in the form of discounts from the standard premium rates on most permanent and term insurance plans. They are generally available to adult men and women (ages 20 through 65) who have not smoked cigarettes within the past twelve months. Discounts have been offered to non-smokers by approximately 400 U.S. insurance companies. 
Three months after the first Surgeon General's Report on Smoking and Health in 1964, the State Mutual of America Insurance Company of Worcester, Massachusetts, became the first major life insurance company to study mortality differences between smokers and non-smokers and to offer lower rates to noncigarette smokers. Their experiment with a non-smoker discount program has been widely adopted throughout the life insurance industry.13 For this reason, the following description of a non-smoking discount is derived primarily from State Mutual's 15-year experience with this program.

For insurance purposes, a non-smoker is defined as a person who has not smoked cigarettes in the immediate past twelve months. (Pipe and cigar smoking are permissible.) The applicants' non-smoking statements are made as part of the insurance application, but to qualify for non-smoker discounts, some life insurance companies additionally require a minimum policy purchase. State Mutual has no minimum policy purchase requirement specifically tied to its no-smoking discount, and guarantees that the company will not subsequently change the product or price even if the policyholder returns to (or starts) smoking after buying the policy.

From 1964 through 1979, State Mutual sold 105,000 non-smoking life insurance policies, for an insurance amount of $\$ 3.4$ billion; approximately 80 percent of these policies are still in force. Between 1964 and 1979, sales of non-smoking policies amounted to approximately two-thirds of the company's total new individual adult life policy sales. 14,15 The average face value of an individual non-smoker permanent policy in 1980 was $\$ 55,000$, which was substantially larger than the industry average $(\$ 40,000-\$ 45,000)$ and the State Mutual average $(\$ 30,000)$.

Based on various mortality studies (principally from the United States, Canada, and Britain) for the general population and for certain subgroups, the Surgeon General's 1964 report indicated that, relative to non-smokers, cigarette smokers account for 70 percent higher age-specific death rates for major demographic subgroups of the population. The Surgeon General's updated report of 1979 , based on data from over 24,000 studies, revealed that smoking is even more dangerous than it initially was thought to be. 16 
At about the same time (1979), State Mutual reviewed its own mortality experience with smokers and non-smokers. 17 The study was limited to standard policies issued at ages 20 and over with insurance amount of at least $\$ 10,000$ and included the experience spanning policy anniversaries from 1973 to 1978. As demonstrated in Table 6-4, which compares the number of actual deaths with the number expected based on actuarial tables, the difference between smoker and nonsmoker mortality is substantial and is larger for insureds who obtained coverage at an earlier age. 18 
TABLE 6-4

STATE MUTUAL MORTALITY EXPERIENCE BY AGE AT ISSUE

(Dollars in Thousands)

\section{SMOKERS}

$\begin{array}{ll}\text { AGES AT } & \text { AMOUNT } \\ \text { EXPOSED } \\ \text { ISSUE } & \text { TO RISK }\end{array}$

NONSMOKERS

$\begin{array}{lll}\text { EXPECTED } & \text { MOR- } & \text { AMOUNT } \\ \text { DEATH } & \text { TALITY } & \text { EXPOSED } \\ \text { PAYOUT } & \text { RATIO } & \text { TORISK }\end{array}$

ACTUAL
DEATHS
AND PAYOUT

\section{$\$ 461$}

$180 \% \quad \$ 874,081:$

2,031

$2051,985,563$

3,994

2,638

$1221,900,021$

$92 \quad 726,496$

674

105

84,576

$1,091(29)$

4,162(102)

$4,766(80)$

$790(23)$
$132 \% \$ 5,570,737 \quad \$ 11,004(240)$

\section{EXPECTED MOR-}

DEATIT - TALITY COMBINED

PAYOUT RATIO MORTALIT

$\$ 195(6)$

60

75

20 and

over

$\$ 2,722,663$

$\$ 12,972(340) \quad \$ 9,798$

$\$ 20,648$

$53 \%$

$79 \%$

Standard medically examined issues of 1964-77; experience between 1973 and 1978 anniversaries; male and female lives--policy years $1-15$ combined; permanent plans--policies with face amounts of $\$ 10,000$ and higher expected deaths based on 1965-70 select basic tables. 


\subsubsection{NON-SMOKING PLAN EXAMPLE: STATE MUTUAL OF AMERICA}

State Mutual offers both lower premiurns and higher dividends to non-smoking insureds on their new life insurance policies. The annual premium savings for male non-smokers are greater than for females and the premium savings for both sexes are greater at age 45 than at age 35. The lower savings for females at age 35 relative to males are due to females' lower expected mortality which results in lower surplus premium needed to cover future risks. Table 6-5 contains premium information related to this plan.

TABLE 6-5

COMPARISON OF SMOKER AND NONSMOKER PREMIUMS: STATE MUTUAL LIFE (\$25,000 Whole Life Policy)

$\begin{array}{lccc} & \frac{\text { SMOKER }}{\text { PREMIUM }} & \frac{\text { NONSMOKER }}{\text { PREMIUMS }} & \frac{\frac{\text { ANNUAL }}{\text { PREMIUM }}}{\frac{\text { SAVINGS }}{\$ 411.25}} \\ \text { MALE (Age 35) } & \$ 440.50 & 622.25 & \$ 29.25 \\ \text { MALE (Age 45) } & 668.00 & 389.25 & 45.75 \\ \text { FEMALE (Age 35) } & 404.00 & 588.25 & 14.75 \\ \text { FEMALE (Age 45) } & 608.50 & 20.25\end{array}$

In general, for whole life policies the nonsmokers discount savings range from six percent to 15 percent, while the annual premium savings for term insurance range from 16 to more than 50 percent (see, for example, Table 6-6). This is because most of the premium for a whole life policy goes to an annuity, rather to insurance per se. 
sc. The premium discounts vary according to the company, age at issue, and the exact nature of the policy. In general, the savings are larger for policies issued at ages 30 through 45 than at other ages.

TABLE 6-6

COMPARISON OF INITIAL PREMIUMS BET WEEN NONSMOKERS AND SMOKERS ON TERM INSURANCE ISSUED BY SAVINGS BANK LIFE INSURANCE

$(\$ 50,000$ Coverage)

\begin{tabular}{|c|c|c|c|}
\hline $\begin{array}{l}\text { Issue } \\
\text { Age }\end{array}$ & $\begin{array}{l}\text { Non-smokers } \\
\text { One Year } \\
\text { Renewal Term Insurance: }\end{array}$ & $\begin{array}{l}\text { Smokers } \\
\text { Five Year } \\
\text { Renewal Term }\end{array}$ & $\begin{array}{l}\text { Percent } \\
\text { Savings }\end{array}$ \\
\hline 25 & 79.00 & 99.00 & 25 \\
\hline 35 & 84.00 & 119.00 & 29 \\
\hline 40 & 132.00 & 179.00 & 26 \\
\hline 45 & 192.50 & 239.00 & 20 \\
\hline 55 & 493.50 & 619.50 & 20 \\
\hline 60 & 813.00 & 969.00 & 16 \\
\hline
\end{tabular}

Sources:

(1) "Reduced Rate Non-S mokers Policy", Savings Bank Life Insurance.

(2) "Savings Bank Life Insurance - Rates and Information", Savings Bank Life Insurance. 


\subsubsection{NON-SMOKER PROGRAM IMPLEMENTATION}

The administration and marketing of non-smoking discounts as practiced by State Mutual are similar to general company procedures employed for other types of business. The company, however, uses a number of methods to safeguard against possible improper application of non-smoking premium discounts to cigarette smokers. These include routine life insurance medical examinations (these may include a chest $X$-ray or nicotine test, if necessary); credit reports (which can be requested to study the potential insureds' financial and health history for life insurance protection of $\$ 100,000$ and over); and observations by company agents (who may observe the insurance applicants during their first and subsequent visits when the company believes that smoking habits usually become evident). In addition, the company looks to indicators such as significant deviations in the nonsmoking portion of its new business from the non-smoking population norm as warnings of possible problems in policing the insurance applicants.

\subsubsection{NON-SMOKING DISCOUNT PROGRAM EVALUATION}

The responses from policyholders, insurance agents, and insurance commissioners towards the non-smoker discounts are generally favorable. These discounts are now well-received by insurance agents because the lower premiums allowed by nonsinoker discounts offer competitive advantages over other life company policies. When the non-smoker discounts were first introduced in the 1960s, certain life companies watched the non-smoker discounts with suspicion, and some even considered them as "gimmicks" to win new business.

As a rule, new plans or modifications to existing insurance policies are subject to revicw by the insurance commissioners of the states where the insurance companies conduct business. In most states, the approvals of non-smoking premiums discounts were only a formality since this was not considered a sensitive issue. 
Life insurance companies are reluctant to estimate whether they have gained a greater share of the life insurance market as a result of non-smoker discounts. State Mutual feels that in the past five years it has not picked up additional business by offering non-srnoker discounts; this statement is supported by the fact that 400 life companies currently offer various non-smoking discounts. 19 As the competition becornes keen and the market nears saturation, the gain of additional business becomes increasingly difficult. State Mutual's impression is that they may have gained a slight edge in market share during the 1960s because of their early entry into the non-smoking business; however, that edge apparently is no longer there today.

Non-smoking policies comprise the majority of business for those firms offering such discounts. For three representative firms, it was found that the percentage of insurance sales by face amount accounted for by non-smoker policies was in the 60 to 70 percent range, but the percentage of business as measured by the number of policies was substantially lower (see Appendix 6-1).

Several factors have contributed to the growing popularity of non-smoker policies. First, the proportion of non-smokers in the general population has changed from approximately one-third in the 1960s to approximately two-thirds in 1980 . This has expanded the potential customer base for non-smoker policies. In addition, during the last 15 years the non-smoker discounts have spread from a few policies to many of the more popular policies (e.g., State Mutual has applied non-smoker discounts to all invididual life insurance policies except those in the pension series).

The life insurance companies contacted for this study apparently have not conducted internal studies on the profitability of non-smoking business. The companies assert that it is difficult even to speculate about how much standard (or smoker) life insurance business actually has been displaced by the non-smoking business, and about how much new business has been gained from non-smokers. State Mutual believes that it did gain additional profits due to the conservative estimates of non-smokers mortality. 20 This view can be supported by the data in 
Table 6-4. This table illustrates that the mortality for non-smokers is two-thirds the average mortality for the population as a whole (smokers and non-smokers), and one-third the mortality for smokers alone. The profitability of non-smoker policies also is enhanced because of the larger average size of non-smoking policies (\$55,000 for State Mutual and $\$ 70,000$ for Phoenix Mutual).

State Mutual's study on the causes of death found that smokers carry with them predominately higher mortality rates in several categories that have not been commonly associated with smoker mortality, including motor vehicle accidents, suicide, homicide, accidents, and all other causes of death. For instance, the study indicated that a smoker is 2.6 times as likely as a non-smoker to be involved in a fatal motor vehicle accident. From this, State Mutual concludes that the use of smoking as an underwriting criterion is, in reality, a proxy for lifestyle: people with a riskier lifestyle have a greater inclination toward smoking, so their higher mortality is due in part to their overall lifestyle rather than to smoking habits alone.

The lower mortality rates of non-smokers are due in part to their less-risky life style. Desirable driving habits, perhaps including the wearing of safety belts, may already contribute to the size of the "non-smoker" discount. This might somewhat dilute the viability of using additional life insurance discounts as a means of promoting safety belt use.

\subsubsection{IMPACT ON THE PUBLIC'S SMOKING PATTERNS}

Generally, those insurance companies interviewed were reluctant to estimate whether the introduction of non-smoker life insurance policies has influenced the smoking patterns of the public or their insureds. In part, this reluctance is caused by the lack of specific studies related to the issue.21 However, State Mutual considered the non-smoker discount insurance program to have had a negligible impact in changing the public's smoking patterns. State Mutual did. feel that the 
publicity gained from the promotion of non-smoking insurance discounts over the years at least might have reinforced the public's awareness that it pays to stay healthy by not smoking cigarettes. 22

\subsection{EXISTING LIFE INSURANCE INCENTIVES: PHYSICAL FITNESS}

\subsubsection{DESCRIPTION OF PHYSICAL FITNESS DISCOUNTS}

A "physical fitness" discount obstensibly is based on the knowledge that those who protect their fitness with a regular exercise program are excellent risks for life insurance. To qualify for this discount, the applicant must have participated in an organized physical fitness or exercise program, or performed acrobic-type exercises regularly during the year. This is usually stated in the insurance application form. Certain companies require purchase of a minimum insurance amount; others allow the purchase of insurance coverage up to a predetermined amount without medical examination. At the present time, only a few life insurance companies offer "physical fitness" discounts. The Manhattan Life Insurance Company's program is examined in this section.

The relevance of physical fitness discounts to safety belt incentives is strong since these discounts exemplify the role of premium discounting as a marketing technique able to capture, or hold, customers who believe they exhibit behavior that entitles them to lower rates. Compared to the non-smoking premium discounts, the physical fitness discounts are based on much less actuarial data and are directed at a much smaller proportion of the population. The fitness discounts also are noteworthy in that the burden of proof and commitment to rigorous exercise is no greater than one might expect in a safety belt user policy; basically, they rely on an honor system whereby the customer's assertion of compliance is sufficient. Premiums for policies with discounts for physical fitness, however, are not significantly lower than the premiums of standard policies offered by other firms. 


\subsubsection{EXAMPLE OF PHYSICAL FITNESS DISCOUNT: MANHATTAN LIFE}

The Manhattan Life Insurance Company offers two types of fitness-related insurance discounts, Health Awareness and Physical Fitness. The plans differ slightly with respect to maximum insurance limits and availability. These programs are designed especially for health-oriented, physically-fit insurance applicants and are similar to those of fered by other firms. (See Appendix 6-2 for a description of Unity Mutual's "Fit Person" discount plan.) Potential life insurance applicants can qualify for this insurance discount if they are in good health and are "health-oriented" individuals or regular participants in a physical fitness or exercise program.23 For the purposes of the Health Awarenes's discount, Manhattan Life defines health-oriented individuals as "those who can submit proof of at least two complete annual physical examinations, the last examination within the past twelve months." Individuals qualifying for the physical fitness discount are those "who regularly participate in organized physical fitness or exercise programs, or who perform aerobic-type exercises for a minimum of 20 minutes a day, four days a week" (statements required in application). 24

Both discount plans were first implemented in 1981. Today, policies with Health A wareness and Physical Fitness (HA/PFI) discounts account for about 15 percent of the company's total life insurance coverage. The mortality data used by Manhattan Life for the development of HA/PFI were derived largely from various medical clinic data, such as the Passenberger Study conducted by the Harvard University Medical School.25

The response to these plans from policyholders and insurance agents generally is favorable. The company believes this program will enable them to gain market share and improve profits. These new plans were approved by New York State Insurance Department in a routine manner, and the implementation of those discount plans encountered no obvious problem. At this time, the only method for policing potential applicants rests upon the statements provided in the application form. 
A comparison of premiums of fered under a standard life plan and HA/PFI plan for a few selected policies is illustrated in Table 6-7.

TABLE 6-7

\section{COMPARISON OF PREMIUMS BET WEEN STANDARD AND HA/PFI PLANS \\ BASED ON $\$ 100,000$ FACE AMOUNT POLICY, MALE}

POLICY \&

AGE

ART $-70 * \$ 309$

A GE 40

ART -70

AGE 45

$\$ 500$

GPL** $\$ 1,025$

AGE 40

GPL $\quad \$ 1,276$

AGE 45

STANDARD HA/PFI HA/PFI

PREMIUM PREMIUM SAVING (\%)

HA/PFI/ NONSMOKER

DISCOUNT
ADDITIONAL NONSMOKER'S SAVING (\%)

*ART: Annual Renewal Term Insurance, with guaranteed renewal to age 70.

* *PL: Graded Premium Life, which provides permanent insurance coverage with an initial premium that increases annually for 10 years.

SOURCE: Manhattan Life Insurance Company, "Health A wareness/Physical Fitness Insurance," New York, NY. 


\subsection{POTENTIAL LIFE INSURANCE INCENTIVES FOR ENCOURAGING SAFETY BELT USAGE}

\subsubsection{METHODS FOR PROVIDING INSURANCE INCENTIVES}

In theory, life insurance incentives could be :rovided through either premium discounts or coverage extensions. With respect to premium discounts, the idea is that the expected reduction in mortality will be translated into dollar savings. To effectively encourage safety belt usage, the premium reduction will have to be large enough to make a meaningful impact. However, any substantial reduction in premiums must be supported by mortality improvements. Arbitrary reduction of premiums in large amounts may result in insufficient reserve funds available to cover future risks. The improved mortality experience exhibited by one subgroup may not be sizable enough to make an significant impact on overall mortality; one mortality subgroup, such as "autornobile fatalities," represents only one of many causes of deaths associated with the aggregate mortality.

The alternative to premium discounts is to extend additional insurance coverage to the insureds or their beneficaries. It is common to attach optional insurance riders that provide extra coverage to basic (usually permanent) policies. Rider insurance is low-cost insurance protection which "rides" with the basic policy. Some of the more popular riders are the accidental death benefit (ADB) and the waiver of premium. The "accidental death benefit" is the life insurance provision for paying additional protection (double or triple that offered by the basic policy) in the event of accidental death. Under the "waiver of premium" benefit, if the insured becomes totally and permanently disabled by bodily injuries or diesase, the payment of subsequent premiums is waived by the insurer. Other examples are rider life insurance for a spouse or children.

The relatively low cost of riders is made possible by their relatively low risks and the convenience of servicing them. Even though additional premiums are required for rider insurance, these payments are consolidated with the premiums for the 
basic policies, thus simplifying the policy's administration. For these reasons, it is possible to extend insurance coverage through riders such as ADB to provide incentives for the use of safety belts without highly credible mortality experience. Depending on the mortality findings, extra protection for safety belt wearers could be provided through riders at little or no increase in the overall premiums. A nother advantage of this method is that it stands a good chance of theing approved by the state insurance department because combining this feature with an existing benefit, such as ADB, makes it less controversial.

\subsubsection{PRELIMINARY EXPLORATION OF MORTALITY ASSOCIATED WITH SAFETY BELT USE BY PASSENGER AUTOMOBILE DRIVERS}

To determine the amount by which life insurance loss payouts can be reduced by increasing belt use rates, the differences in mortality between belted and unbelted motor vehicle occupants must be estimated. Two methods of estimating this mortality difference are explored in this section. One uses FARS data on passenger car drivers killed in automobile accidents, while the other relies directly on NHTSA's estimate of 56 percent safety belt effectiveness derived from NASS and NCSS data.

From 1975 through 1980, a total of 104,049 passenger car drivers died in U.S. automobile crashes. Among those, 75,720 were known to be unbelted, and only 2,377 were belted. 26 . For 25,944 , the belt usage information is unknown. To determine an upper bound for potential life insurance premium savings, those motor vehicle deaths with unknown belt use were distributed to "belted and unbelted" in the same proportion as the known belt use data. This averages out to 16,811 unbelted and 529 belted drivers killed each year. Over the same period, there was an average annual driver population of approximately 131.4 million, of whorn 11 percent were believed to be safety belt users. 27 This translates into a belt use estimate of 14.5 million generally belted drivers and 116.9 million generally unbelted drivers. 
Under these assumptions, the probability of dying in an automobile accident during an average year is 3.6 deaths per 100,000 belted driver population ( 529 divided by 14.5 million), which is equivalent to an expected insurance payout of $\$ 3.60$ per year for $\$ 100,000$ of insurance coverage. For unbel ted drivers, the probability of having a fatal automobile injury is 14.4 deaths per 100,000 unbelted driver population (16,811 divided by 116.9 million), or equivalent to an expected insurance payout of $\$ 14.40$ per year for $\$ 100,000$ insurance coverage. The $\$ 10.80$ difference represents the upper bound of life insurance loss payout reductions generated by safety belt use. If applied to the purchase of additional coverage, this could provide an additional $\$ 300,000$ in special automobile accidental death benefits to be paid only if the insured dies while wearing a safety belt. (These computations are based on insurance payouts before the allocation of overhead and related expenses.)

Using the more refined and conservative NHTSA estimate of the effectiveness of safety belts in reducing fatalities, the difference between the expected loss payouts for belted and unbelted fatalities is smaller. 28 If safety belt effectiveness is 56 percent, then the loss payout for belted drivers would be 44 percent that for unbelted drivers. The expected payout on a $\$ 100,000$ insurance policy for a belted driver is about $\$ 6.30$ (44 percent of $\$ 14.40$ ), which saves the insurer about $\$ 8.00$ each year in loss payouts. This $\$ 8.00$ could be used to provide a special accidental death benefit of about $\$ 130,000$.

\subsubsection{INDIVIDUAL VS. GROUP LIFE INSURANCE POLICIES}

Both premium discounts and extended coverages could be applied to individual or group life insurance policies. With regard to safety belt incentives, a group approach through employers may be the most promising. As discussed in Chapter 2 , employers are in a unique position to require mandatory on-the-job safety belt use and to encourage voluntary off-the-job belt usage through incentive programs. The group approach provides a more a favorable environment for program evaluation, enforcement, and making mid-course adjustments. In addition, group policies generally are more cost-effective to manage than individual policies. 
Finally, employers are in a stronger position to negotiate the premiums and benefits of employee plans with life insurance companies, and in a better position to realize the savings in overall life insurance costs if they are successful in increasing the group's safety belt usage.

An employer who negotiates for an extra safety belt death benefit could expect the average premium to increase unless there is an improvement in the employees' safety belt usage rate. For example, if a $\$ 30,000$ term policy has an average annual premium of $\$ 100$ and an employer wished to have an additional $\$ 30,000$ provided as an ADB for belt wearers, than the average premium would have to increase by about 11 cents (assuming the employees' initial belt usage was 10 percent and not counting administrative overhead). The premium increase covers the expected cost of paying out $\$ 60,000$ instead of $\$ 30,000$ to any employee who might be killed while wearing a safety belt (see Appendix 6-3).

However, if an employer could raise the belt use rate to 50 percent, then the average premium could be lowered to $\$ 99.50$. This premium reduction opportunity reflects the lower expected mortality of safety belt wearers. Thus, for a very small cost (or potential cost savings, if employees increase their safety belt usage rate an employer can provide a significant special insurance benefit for those employeers who die in motor vehicle accidents while wearing safety belts.

\subsubsection{SAFETY BELT ACCIDENTAL DEATH BENEFIT}

In November, 1982, the Motors Insurance Corporation (MIC), an affliate of General Motors, announced a new policy feature that will pay $\$ 10,000$ to the estate of any insured occupant of a motor vehicle who is killed in a motor vehicle accident while wearing a safety belt. 29 The coverage is provided as an accidental death provision of the MIC automobile bodily injury and property damage insurance policies for GM employees in Indiana. It is also available as a rider to an accidental death and dismemberment policy through MIC's subsidiary, MIC Life.

Under the MIC's automobile policy, this $\$ 10,000$ protection can be purchased for $\$ 2.00$ a year. For MIC Life, the coverage is available as a rider to an accidental 
indemnity policy at four cents per month for each $\$ 1,000$ of protection or $\$ 4.80$ per year for $\$ 10,000$ protection (maximum coverage).

MIC claims the goal of the program to be an increase in safety belt usage, and believe their $\$ 10,000$ death benefit will be a substantial incentive to use safety belts. The plan covers the driver and all occupants of the car jwned by the policyholder, provided they use safety belts. This feature will be offered to General Motors employees in Indiana and Ohio.

Early in 1983, two other automobile insurance companies decided to offer a $\$ 10,000$ ADB for safety belt wearers. Nationwide decided to make this additional benefit available at no charge to all its individual customers, and is filing for state approvals (see Section 3.7.1). State Farm also has begun to offer a \$10,000 ADB at no charge for safety belt wearers. These initiatives by automobile insurers demonstrate the practical opportunity for special safety belt death benefits to be offered at little or no cost.

\subsubsection{OBSTACLES TO IMPLEMENTATION}

One problem in implementing safety belt insurance incentives is the burden of proof. The additional insurance proceeds can be collected by a beneficiary only if it can be proved that the policyholder or the insured did wear safety belts while the automobile accident occurred. The perceived value of insurance incentives would be diluted if the public judges their burden of proof to be overwhelming. Police reports could be used for this purpose, but the information reported through this channel is not always complete since it is not their major concern in dealing with fatal accidents. Another course might be to rely upon coroner's reports. A viable and reliable method for resolving the burden of proof problem must be developed to assure the success of this plan.

A nother problem may be obtaining approvals from state insurance commissions. It is necessary for auto and life insurance companies to obtain approvals for new insurance policies or modifications of existing ones from insurance departments in the states where the companies conduct business. For auto insurers, the regulatory 
responsibilities include those listed in Section 3.6 and relate primalrily to concerns that special benefits tend to confuse the consumer. While state insurance regulators are more receptive to insurance innovations agreed to by major employers, most states do not allow employer-offered group auto insurance. Life insurers are likely to have less trouble in obtaining state approvals, especially with group benefit plans, but also will have to provide some credible actuarial evidence that the discount is warranted.

\subsection{RECOMMENDATIONS}

For reasons stated in Section 6.5, the following recommendation is made for a pilot safety belt insurance incentive plan: As a demonstration program, employers should be encouraged to work with their life insurers to establish additional safety belt benefits. Group life plans provide much more flexibility for both the employer and the life insurance companies to negotiate terms, conditions, and premiums of proposed policies because they allow risk to be spread among members of a group. Employers may be willing to pick up a part or even all of the any additional premiums, since encouraging safety belt use represents an especially attractive investment given the many employer costs related to employee motor vehicle injuries. The accumulated experience of group plans eventually could be extended to individual life policies.

In terms of effectiveness, it is likely that the life insurance benefits realized in this way will be most useful as a supplement to more direct employer incentives for safety belt use. 


\section{APPENDIX 6-1}

PERCENTAGE OF :3USINESS ISSUED TO NONSMOKERS BY STATE MUTUAL LIFE, PHOENIX MUTUAL LIFE, AND HOME LIFE INSURANCE COMPANIES

STATE MUTUAL LIFE

YEAR OF ISSUE

PERCENTAGE NONSMOKER

BYFACE AMOUNT

1960's

1979

$40 \%$

$67 \%$

1980-82

$70 \%$

PHOENIX MUTUAL LIFE

YEAR OF

ISSUE

BY FACE AMOUNT

PERCENTAGE NONSMOKER

1968

1979

19

60

BY NUMBER

6

30

HOME LIFE

(Excluding Plans With No Nonsmoker Premium Class)

YEAR OF

PERCENTAGE NONSMOKER

ISSUE

\section{BY FACE AMOUNT BY NUMBER}

1976

1977

1978

1979

49

59

66

69
28

41

49

52 


\section{APPENDI $\times$ 6-2}

\section{UNITY MUTUAL'S "FIT PERSON" DISCOUNT PLAN}

The "Fit Person Discount" plan is designed to reduce premiums for prospective insureds whose anticipated mortality is better than average. The one requirement that an insurance applicant must meet "is engaging in a strenous physical activity such as running, tennis, swimming or cycling on a regular basis." However, to be eligible for the discount, one must acculmulate enough underwriting credits from the cxercise requirement and other underwriting factors such as a good family health history, frequent physical examinations, and abstinence from cigarette smoking. Once the policy is issued, tre fit person discount classification continues for the duration of the policy, regatrdless of the future activities, health, or physical condition.

The company applies the fit person discount only to permanent insurance plans with a minimum face amount of $\$ 25,000$, issued to insureds who are between ages of 25 and 70. Once a policy is issued with the fit person discount, the premiums are guaranteed to stay the same. As a mutual company, Unity Life pays dividends to policyholders in addition to the discounts. The same cash values and loan values are allowed as on standard plans.

The Fit Person Discount was first introduced in 1978. Currently, the fit person discount plan accounts to about 50 percent of the company's life insurance coverage. The company did not experience any obvious difficulty in implementing this plan. The responses of agents, policyholders, and the state insurance department are considered favorable. Some publicity for the fit person discount has been engaged in by the company, including local advertising and sponsoring television sports events, tennis tournaments, and foot races. The company says that it is difficult to estimate the impact of this plan on the company's profit picture, but they believe that it has helped to retain some of their customers. 
The company relies on the statements in the application form to police the potential applicants. However, the company may investigate in doubtful cases and may even reduce the amount of proceeds paid out for the more dubious cases.

The Fit Person Discount is a fixed dollar amount: for the Executive Whole Life Insurance Policy (premiums payable until death), if a male aged 45 purchases $\$ 50,000$ insurance protection, the standard premium per thousand dollars of insurance is $\$ 29.26$. The Fit Person Discount for that age and plan is $\$ 2.60$ per thousand, a saving of 8.9 percent. For the issue age of 50 , the standard premium is $\$ 36.06$ per thousand and the discount is $\$ 3.23$ per thousand, a saving of nine percent. 
APPENDIX 6-3

\section{PREMIUMS FOR A SAFETY BELT-RELATED ACCIDENTAL DEATH BENEFIT}

The purpose of this exercise is to calculate the amount of premium that would be required to provide a special insurance benefit paid only to insureds who die in motor vehicle accidents while wearing safety belts.

Let $\mathbf{P}=$ Total premium for all insureds related to motor vehicle accidental fatalities

$b_{i}=$ Insurance face amount payable in case of a motor vehicle accident $b_{s}=$ Amount to be paid, if a belt is worn

$b_{n}=$ Amount to be paid, if a belt is not worn

$\mathrm{P}_{\mathbf{i}}=$ Probability of a motor vehicle acciden fatality

$P_{s}=$ Probability of motor vehicie accident fatality, if a belt is worn

$\mathrm{P}_{\mathrm{n}}=$ Probability of motor vehicle accident fatality, if a belt is not worn

$A=$ Percent of insureds wearing safety belts

$N=$ Total number of insured persons

$\mathrm{P} / \mathrm{N}=$ Total premium per policy holder for motor vehicle accidental death

Then $P=P_{s} \times b_{s} \times A N+P_{n} \times b_{n} \times(1-A) N$, and

$$
P / N=P_{s} \times b_{s} \times A+P_{n} \times b_{n} \times(1-A)
$$

\section{Example 1}

With no special benefit:

$$
\begin{aligned}
b_{s} & =b_{n}=\$ 30,000 \\
P_{s} & =.000036 \\
P_{n} & =.000144 \\
A & =0.1 \\
P / N & =30,000 \times 0.000036 \times 0.1+30,000 \times .000144 \times 0.9=\$ 4.00
\end{aligned}
$$


With special additional benefit of $\$ 30,000$ for those who die in rnotor vehicle accidents while belted:

$$
\begin{aligned}
& b_{S}=\$ 60,000 \\
& \text { So, } P / N=\$ 4.11
\end{aligned}
$$

Thus, the change in the premium per policy to provide the additional $\$ 30,000$ special benefit (exclusive of administrative overhead charges)

$=\$ 4.11-\$ 4.00$

$=\$ 0.11$.

\section{Example 2}

If belt use rises (for example, as a result of the increased benefits) to $A=0.5$, then $\mathrm{P} / \mathrm{N}=60,000 \times .000036 \times 0.5+30,000 \times .000144 \times 0.5=\$ 3.24$

Thus, there is a net reduction in premium per policy of $\$ 0.76$ as belt use increases to 50 percent among insureds:

$$
\left(P / N-P^{\prime \prime} / N=4.00-3.24=\$ 0.76\right) \text {. }
$$




\section{NOTES TO CHAPTER 6}

1. 1982 Life Insurance Fact Book, (Washington, D.C.: American Council of Life Insurance), p. 5.

2. Bickelhupt, David L. General Insurance, (Illinois: Richard D. Irwin, 1974), p. 258 .

3. 1981 Life Insurance Fact Book, (Washington, DC: American Council of Life Insurance), p. 26-27.

4. Ibid., p. 26.

5. Ibid., pp. 29-30.

6. Ibid., p. 37.

7. Ibid.

8. National Underwriter - Life and Health Edition, May 29, 1982, No. 22, pp. $27-$ 28 .

9. Ibid.; p. 56.

10. Ibid., p. 26.

11. Bicklehaupt, op. cit., pp. 203-205.

12. Ibid., p. 203.

13. State Mutual of America Insurance Company, "If You Haven't Smoked for One Year, We'll Give You a Better Rate on Your Insurance," SK-19, Rev. $3 / 81$, p. 5.

14. Cowell, Michael J. and Brian L. Hirst. "Mortality differences Between Smokers and Non-Smokers," 1980 Transactions of Society of Actuary, Vol. 32, p. 193.

15. State Mutual, op. cit., p. 8.

16. "Report on Smoking and Health," U.S. Department of Health, Education and Welfare, Office of the Surgeon General.

17. Codwell \& Hirst, op. cit., p. 194.

18. Ibid.

19. Phoenix Mutual Life Insurance Company corroborated many of the statements made by State Mutual. 
20. Codwell \& Hirst, op. cit.

21. Telephone conversations with leading anti-smoking agencies such as the U.S. Department of Health and Human Services (Office on Smoking and Health) and the American Lung Assoclation indicated that they had never carried out efforts to promote non-smiking insurance discounts, and never have conducted any studies to evdluate if the public's smoking habits have been influenced by the availability 'of non-smoking discounts.

22. Phoenix Mutual Life Insurance Company corroborated many of the staternents made by State Mutual.

23. "Health Awareness/Physical Fitness Insurance," Manhattan Life Insurance Company, New York, NY, pp. 1.

24. Ibid., p. 2

25. Telephone conversation with Mr. Sibigtroth, Vice President, Actuarial Department, Manhattan Life Insurance, November 17, 1982.

26. TSC special tablulation on drivers involved in passenger automobile accidents. Derived from FARS data, 1975-1980.

27. Felrice, Barry. "Safety Belt Usage Summary Report," NHTSA Internal Memo, A ugust 23, 1982.

28. Telephone conversation with Stephen O'T oole, Government Relations, Motors Insurance Corporation. 


\section{CHAPTER 7: WORKERS' COMPENSATION INSURANCE}

\subsection{SUMMARY}

This chapter reviews the potential for workers' compensation insurance to offer incentives for safety belt use. It considers the relationship of employers' loss experience to the premiums paid for workers' compensation insurance, and concludes that for the larger employers, who employ 80 percent of the nation's workers, there is a very direct relationship. In other words, the large employer who reduces a company's loss experience can expect reduced workers' compensation premiums. For the fleet operator, the potential cost savings may be considerable. For example, a inotor carrier may save up to $\$ 200$ annually in workers' compensation claims costs alone for every driver converted to regular belt use. While there are both regulatory and practical barriers making it most unlikely that a commitment by an employer to adopt a safety belt program could produce up-front premium reductions, for large firms the results of a successful safety belt program should yield savings in future workers' compensation premiums.

It is legally possible in some states to deny workers' compensation benefits to those whose injuries were caused through their failure to use available safety equipment. In Vermont, this has led to an announced policy asserting that safety belt use would be a factor considered in determining benefits for state employees injured in vehicle accidents while on state business. Although a follow-up education program by the Vermont Department of Education has warned workers that they may lose their compensation if they are injured while not wearing safety belts, in practice workers' compensation benefits have not been reduced even in those cases where it has been determined conclusively that belts were not worn when employees were injured. Denial of workers.- compensation benefits is widely perceived as too severe a measure for furthering safety belt use.

The most promising means of increasing safety belt use through workers' compensation lies in encouraging the participation of insurers in industry-wide safety belt programs that have a high probability of achieving dramatic loss 
reductions. The experience of workers' compensation insurers with driver safety programs and their access to detailed records of motor vehicle injury claims would help convince employers that workers' compensation premiums are not a fixed cost, but can be reduced substantially through effective fleet driver safety programs in which safety belt use is emphasized. Workers' compensation insurers also are wellinformed about the role that reduced injury losses can play in a firm's overall profitability, due to both lower workers' compensation premiums and to much larger indirect cost savings. The ATA/MVMA/NHTSA motor carrier safety belt program is an example of a program where workers' compensation insurer participation has yielded valuable data on the high costs of on-the-job motor vehicle injuries to the employer. It is recommended that workers' compensation in'surers be encouraged to participate in industry-specific efforts to increase on-the-job safety belt usage.

\subsection{BACKGROUND}

\subsubsection{WORKERS' COMPENSATION INSURANCE TYPES AND PURPOSES}

Workers' compensation insurance is designed to provide for the expenses of medical care, rehabilitation, and lost wages for injured employees and death benefits for the dependents of persons killed in work-related accidents. It is the oldest social insurance program in the United States; the first law was passed in 1908 to provide cash and medical benefits for work-related disability and death. 1

Workers' compensation is based on the idea that the cost of occupational injuries and many diseases is to be charged directly to the employer regardless of liability. Each state has its own workers' compensation laws but all provide for the basic benefits of medical expenses, income, and rehabilitation expenses. Employers finance the system, which cost $\$ 26$ billion dollars in 1981 , through insurance plans. Most public and industrial employees are covered under workers compensation insurance plans, as are about two-thirds of all private employees (with agricultural, domestic, and casual labor generally exempted). In 1979, 78.6 million workers, or 89 percent of all wage and salary workers, were covered by workers' compensation. 2 
An employer's statutory obligation to provide workers' compensation insurance may be fulfilled in one of several ways. In six states (Ohio, West Virgnia, Nevada, North Dakota, Wyoming, and Washington), workers' compensation insurance is provided only through a "monopolistic" state fund (i.e., private insurers are not allowed to write any workers' compensation insurance for risks in these states). In 12 states (including the large industrial states of California, Pennsylvania, Illinois, Texas, and Michigan), both state funds and private insurers may write workers' compensation insurance. Only private insurance is available in the remaining 32 states. $^{3}$

In all states except North Dakota, Wyoming, and Texas, any private company able to demonstrate proof of financial ability to carry its own risk may self-insure. This practice generally is limited to large employers (usually with current premium volume in one state of at least $\$ 200,000)$. States must approve an employer's plan to self-insure; appropriate bonds may have to be posted to guarantee financial solvency. Group self-insurance, under which a number of small employers band together to pool their risks and their assets, is an option available to employers in some states (although it is limited to government agencies in California, Illinois, Minnesota, and Texas). ${ }^{4}$

\subsubsection{SIZE OF THE INDUSTRY AND NUMBER OF FIRMS}

Generally, insurers writing workers' compensation insurance in a particular state belong to a rating organization. The largest of these organizations, the National Council on Compensation Insurance (NCCI), has over 600 members nationwide. Private insurers write the majority of workers' compensation insurance, accounting for 63 percent of the approximately $\$ 26$ billion market in 1981. Table 7-1 shows the breakdown of the workers' compensation insurance market for 1981 . 
TABLE 7-1

1981 WORKERS' COMPENSATION INSURANCE MARKET

\begin{tabular}{lc:c} 
SOURCE & $\begin{array}{l}\text { 1981 } \\
\text { PREMIUMS } \\
\text { (\$ in Billions) }\end{array}$ & $\begin{array}{c}\text { SHARE OF } \\
\text { MARKET } \\
(\%)\end{array}$ \\
\hline Private Insurers & $\$ 16.2$ & $\underline{6}$ \\
State Funds & 1.3 & 13 \\
Self-Insurance* & $\underline{6.2}$ & $\underline{24}$ \\
& $\$ 25.7$ & 100
\end{tabular}

*Imputed premiums. Group self-insurance accounts for about 20 percent of this figure, or about four percent of the total workers' compensation insurance market.

SOURCE: "Workers' Compensation Marketing - 1981," Best's Insurance Management Reports, Statistical Studies, Property/Casualty, Release No. 17, September 6, 1982.

\subsubsection{MAJOR FIRMS}

The largest single private carrier of workers compensation insurance is Liberty Mutual, with $\$ 1.2$ billion in direct premiums in 1981 , a 7.8 percent share of the private workers' compensation insurance market. The top ten private carriers represented 44 percent of the private market in 1981; the top 20 firms covered 64 percent of the market. Table 7-2 shows the leading insurers and their share of the private workers' compensation insurance market in 1981. 
TABLE 7-2

LEADING WRITERS OF WORKERS' COMPENSATION INSURANCE, 1981

\author{
1981 DIRECT \\ PREMIUMS \\ (\$ in Millions)
}

SHARE OF

PRIVATE INSURANCE

MARKET (\%)

$\underline{\text { FIRM }}$

$\begin{array}{lrl}\text { Liberty Mutual } & 1,265 & 7.8 \\ \text { Actna Life } & & \\ \text { and Casualty } & 902 & 5.6 \\ \text { Travelers } & 886 & 5.5 \\ \text { INA } & 834 & 5.2 \\ \text { Hartford } & 665 & 4.1 \\ \text { Fireman's Fund } & 596 & 3.7 \\ \text { Home } & 515 & 3.2 \\ \text { Wausau Companies } & 515 & 3.2 \\ \text { Crum and Forster } & 465 & 2.9 \\ \text { AlG } & 447 & 2.8 \\ \text { Kemper } & 440 & 2.7 \\ \text { U.S.F.\&G. } & 439 & 2.7 \\ \text { CNA } & 412 & 2.6 \\ \text { Continental } & 410 & 2.5 \\ \text { Comml. Union } & 336 & 2.1 \\ \text { Teledyne Group } & 300 & 1.9 \\ \text { Royal } & 245 & 1.5 \\ \text { American Financial } & 243 & 1.5 \\ \text { Texas Employer's } & 240 & 1.5 \\ \text { Mission Group } & 222 & 1.4\end{array}$

SOURCE: "Workers' Compensation Marketing - 1981," Best's Insurance Management Reports, Statistical Studies, Property/Casualty, Release No. 17, September 6, 1982. 


\subsubsection{MAJOR CUSTOMERS}

In 1981, the five states of California, Texas, Pennsylvania, New York, and Illinois together accounted for 44 percent of all workers' compensation insurance. State funds are the largest writers in California (\$450 million in state-written insurance) and New York (\$396 million), and the second largest writer in Pennsylvania (\$51 million). ${ }^{5}$

Because of the statutory nature of workers' compensation, all firms are customers to some extent. However, over the past decade more firms who can afford to finance their risk exposure internally have chosen self-insurance. This does not mean that self-insurers are removed from the workers' compensation insurance market entirely. Even those firms choosing self-insurance usually must purchase some form of excess or catastrophe insurance protection from an outside insurer; this coverage is designed to limit the insured's risk of loss for any given claim or policy year. ${ }^{6}$ In addition, many self-insurers contract with outside firms to provide. services such as claims administration.

\subsubsection{MAJOR ASSOCIATIONS}

The two major workers' compensation insurance-related associations are the National Association of Insurance Commissioners (NAIC) and the National Council on Compensation Insurance (NCCI). The NAIC is an organization of state insurance commissioners working to promote uniformity in state supervision of insurance matters, and to recommend legislation in the various state legislatures. The NCCI develops and administers rating plans and classification systems for workers' compensation insurance which are used as the basis for setting workers' compensation rates in most states. 7

\subsection{ANAL YSIS OF TYPICAL POLICY AND BENEFITS}

The specifics of workers' compensation and employers' liability policies vary by state, but by custom a standard form is almost universally accepted by most workers' compensation insurers. There are four basic parts to the typical workers' compensation policy: 
Declarations, which provide the basic data necessary to underwrite the policy, such as the name of the insured, states of operation, premium basis, rates, and classification of operations;

0

Insuring agreements, which identify coverage, define terms, and set the policy duration;

- Exclusions, which avoid duplicate coverage, exempt certain types of employment, and set liability limits; and

- Conditions, which specify the rights of the insurer, the insured, and employees. 8

Benefit levels are determined by each state's workers' compensation statute, which specifies the income/medical breakdown of benefits, the duration of compensation, and minimum and maximum payment levels. All states now cover unlimited medical expenses for work-related injuries. Although income and disability benefits differ by state, they follow a general pattern. Schedules of income benefits are provided for different types of disability. Payment usually is provided on a weekly basis, although a lump-sum payment may be made in lieu of weekly benefits for specific injuries such as the loss of a limb or an eye. Payments vary widely among states for the same injury; for example, Vermont schedules 168 weeks of payments for the loss of an arm, while the same injury is scheduled for up to 500 weeks in Wisconsin. 9 These variations are due to political, social, and economic factors such as the types of industries in the state and average per capita income.

Benefits usually are set as a percentage of the injured employee's weekly wage within some minimum and maximum state guidelines. Through 1979, 24 states had set the maximum compensation rate at 100 percent of the state's average weekly wage, and four states (Alaska, Illinois, lowa, and Maine) have exceeded that level. All but two states now are setting an employee compensation rate of at least $662 / 3$ percent of the employee's average weekly wage. ${ }^{10}$ The maximum total payment usually is set in terms of either an amount or some multiple of weekly benefits, ranging from 6-10 weeks to lifetime. Different benefits are specified for temporary disability, permanent disability, and fatal accidents. The duration of payments differs for workers, widows/widowers, and dependents. 
It should be noted that most laws provide for a "waiting period" (usually between three and seven days) before compensation is provided. This helps to minimize administrative expenses and, in effect, acts as a "deductible." 11 Also, most major employers have sick leave policies to cover short-term absences due to injury or illness.

\subsection{RATE DETERMINATION}

The pricing of workers' compensation insurance, which affects its potential for safety belt use incentives, is controlled by the rules through which risk classifications, rates, and premiums are determined. The dominant factor in setting these rules, and therefore in determining workers' compensation insurance premium rates, is the Basic Manual for Workers' Compensation and Employers' Liability Insurance. This Manual, developed by the $\mathrm{NCCl}$, is used in about 40 states, and even in the remaining states there is a general similarity to its rules and rates. (Note that it is not used in the six monopolistic fund states and in four of the states where private insurance is available.) A new basic manual was adopted on July 1, 1980, in which the rules were modified to adjust for contemporary business conditions. ${ }^{12}$

The first step in determining the premium paid by an insured is to apply the appropriate "basic manual rate" by assigning a company to its appropriate classification according to a rating manual. Average rates are derived first from total industry group statistics. The industry groups then are divided into 700 classifications of industrial products or processes for which the basic manual premium rates are set. These rates are set with respect to payroll, ranging (in 1974) from a few cents per $\$ 100$ of payroll for low-risk classifications such as office workers to over $\$ 30$ per $\$ 100$ for high-risk occupations such as steeplejadcks. 13

The next step is to determine the "standard premium" by applying the appropriate experience modification factors (which have been developed according to approved experience rating plans). ${ }^{14}$ Application of experience rating plans is mandatory in all states. These plans are based on the past loss experience of the individual 
employer, typically over the past one to three years (i.e., from four years past to one year past). This affects how soon a company feels the impact of reduced losses on premium charges. The smaller the company, the less (in terms of percentage) the influence of past experience. This is because, in theory, past experience is of less statistical validity for a small company. Experience modification factors are expressed as a percentage of the basic manual rate. A credit (i.e., a percentage reduction) is applied to the basic rate if an employer's record shows a better-thanaverage loss history; for a below-average loss history, the new adjusted rate will be higher. Large employers tend to be "self-rated risks," because as the size of an insured increases, the statistical reliability and predictablity of its loss experience improve. Thus, the insured's own experience, rather than that of its class, is the major determinant of the premium charge. 15

Premium discounts are then applied. These discounts give credit for expenses which do not increase proportionally as premium size increases, and result in.a premium lower than that which would accrue if the standard rate was applied to the entire payroll. 16

On top of this basic rating program, an insured may be able to benefit from a retrospective rating plan, under which the premium is computed according to the losses actually occurring during the current policy period. The premium charge is estimated at the beginning of the policy period; the actual premium paid varies between some upper and lower bounds (the "maximum retrospective premium" and the "minimum retrospective premium"). Five types of retrospective rating plans are available. These plans have similar structures but vary in specifics, primarily with regard to the minimum and maximum premiums. ${ }^{17}$ Four of the retrospective rating plans are uniform across states and apply only to workers' compensation insurance; the fifth, which also may apply to other types of liability insurance, is actually a set of formulas and factors used to tailor a plan for an individual insured that may include other lines of insurance in addition to workers' compensation. 18 


\subsection{FINANCIAL INDICATORS}

The scope of workers' compensation insurance coverage has broadened considerably in recent years, largely because of changes in state laws to meet performance standards recornmended in 1972 by the National Commission on State Workmen's Compensation Laws. The combination of higher benefits and more inclusive concepts of what constitutes compensable injury and disability adopted by courts and state workers' compensation administrators have led to substantial increases in the costs of workers' compensation insurance. ${ }^{19}$ Premium volume has more than quadrupled since 1970, but premium growth in 1981 was significantly slower than in previous years (up 10 percent in 1980, 18 percent in 1979, and more than 20 percent in 1977 and 1978). ${ }^{20}$ However, this slowdown in premium growth was not matched by a slowdown in losses, and the industry suffered in underwriting loss of $\$ 292$ million in 1981 as the adjusted loss ratio worsened by 1.4 points to 71.8 percent and the combined loss and expense ratio hit 101.8 percent. $^{21}$ During the $1976-1980$ period, the industry had an underwriting loss, after dividends, of more than $\$ 3$ billion. $^{22}$ Table 7-3 estimates the payouts for workers' compensation losses in 1979 at more than $\$ 11$ billion.

\subsection{COMPETITIVE FACTORS ${ }^{23}$}

The primary competitive faytors related to workers compensation insurance are price and services. The basic workers' compensation insurance product - the payment of statutory benefits to injured workers - is uniform among insurers, as is the basic pricing structure. However, the net cost to employers can vary widely, as can the "product" offered by various insurance writers. In addition, private insurers and state funds must compete with the self-insurance option available to large firms.

Insurers see a shift in recent years from an emphasis on competitive loss prevention and control services to price competition. Many employers treat the purchase of workers' compensation insurance like the purchase of any business necessity, with price as the most important factor in choosing an insurance carrier. A price 
differential of 10-15 percent has been cited as sufficient to stimulate a change of carrier, but that factor could vary with the length of the relationship between the employer and the insurer and with premium size.

Price competition focuses on the medium and large accounts, which represent fewer than 20 percent of the accounts but over 80 percent of the premium dollars. The smaller employers (those with premiums under $\$ 5,000$ ) have little leverage in negotiating the final cost of workers' compensation insurance, so the premiums charged to them tend to be uniform. In addition, most small employers do not require some of the more sophisticated services used by the larger employers. However, they do receive some indirect benefits of the competition for the larger employers, such as the opportunity to join safety groups, which can result in lower net premium costs.

Insurers can utilize a number of cost-reducing options which result in a lower net premium cost to the insured. These include dividend plans, retro'spective rating plans, "account pricing," cash-flow plans, and participation in safety groups. Under dividend plans, insurers share any earned surplus with the insured based on reduced expenses, overall insurer profitability, losses of the insured, or some combination of these factors. The choice of a retrospective rating plan will influence final premium cost. With account pricing, insurers may make price concessions on other lines of insurance to make the purchase of workers' compensation insurance more attractive. Cash-flow plans are premium payment plans that delay remittances and yield a different net cost to the insured based on the time value of money. The formation of safety groups is a method of combining small risks, usually trade association members representing a particular hazard in a particular rating classification, into larger, more cost-effective accounts. These groups may be offered loss-sensitive dividends that can range up to 30 percent or more of premiums. 
TABLE 7-3

ESTIMATES OF WORKERS' COMPENSATION PAYMENTS

BY TYPE OF BENEFITS, 1979 AND 1978

\begin{tabular}{|c|c|c|c|}
\hline \multirow[b]{2}{*}{ TYPE OF BENEFIT } & \multicolumn{2}{|c|}{ ( $\$$ in Millions) } & \multirow[b]{2}{*}{$\begin{array}{l}\text { PERCENTAGE } \\
\text { CHANGE }\end{array}$} \\
\hline & $\underline{1979}$ & 1978 & \\
\hline $\begin{array}{l}\text { Total } \\
\text { Regular } \\
\text { Black lung }\end{array}$ & $\begin{array}{r}\$ 11,872 \\
10,160 \\
1,712\end{array}$ & $\begin{array}{r}\$ 9,735 \\
8,712 \\
1,023\end{array}$ & $\begin{array}{l}22.0 \\
16.6 \\
67.4\end{array}$ \\
\hline $\begin{array}{l}\text { Medical and Hospitalization } \\
\text { Compensation } \\
\text { Regular } \\
\text { Black lung }\end{array}$ & $\begin{array}{l}3,470^{*} \\
8,402 \\
6,704 \\
1,698\end{array}$ & $\begin{array}{l}2,960^{*} \\
6,775 \\
5,754 \\
1,021\end{array}$ & $\begin{array}{l}17.2 \\
24.0 \\
16.5 \\
66.3\end{array}$ \\
\hline $\begin{array}{l}\text { Disability } \\
\text { Regular } \\
\text { Black lung }\end{array}$ & $\begin{array}{l}7,137 \\
6,104 \\
1,033\end{array}$ & $\begin{array}{r}5,815 \\
5,223 \\
592\end{array}$ & $\begin{array}{l}22.7 \\
16.9 \\
74.5\end{array}$ \\
\hline $\begin{array}{l}\text { Survivor } \\
\text { Regular } \\
\text { Black lung }\end{array}$ & $\begin{array}{r}1,265 \\
600 \\
665\end{array}$ & $\begin{array}{l}960 \\
531 \\
429\end{array}$ & $\begin{array}{l}31.8 \\
13.0 \\
55.0\end{array}$ \\
\hline
\end{tabular}

* Includes $\$ 1.7$ million in 1978 and $\$ 13.9$ million in 1979 paid for medical services under the black lung program.

SOURCE: Price, Daniel N.. "Worker's Compensation: Coverage, Benefits, and Costs, 1979," Social Security Bulletin, Vol. 44, No. 9, September 1981, page 9. 


\subsection{REGIJLATOR Y ENVIRONMENT}

Workers' compensation statutes generally are administered by special state commissions that supervise the administration of the compensation act and have the power to make rules and reguiations related to carrying out the provisions of the

laws. In line with the increasing concern about rising costs, interest has been stimulated among the commissions in finding ways to "deregulate" workers' compensation insurance in the hopes of making the workers' compensation system more cost-effective.

One such "deregulation" method is to adopt a competitive rating system. The intent is to allow competitive market forces to determine the price of property and liability insurance, including workers' ${ }^{\prime}$ compensation. Under competitive or open rating systems, rate setting is freed from reliance on the $\mathrm{NCCl}$ 's basic manual; this gives insurance writers a great deal more flexibility in setting premium costs. A number of states, including Michigan, Minnesota, and Arkansas, already have adopted open rating. The NAIC supports the open rating idea and has designed a bill to establish it for workers' compensation insurance. ${ }^{24}$ It is possible that some insurers may reduce services, including safety-related services, under an open rating system, but many may choose to continue these services since they benefit both the insured and the insurer.

The move toward open rating systerns is not likely to significantly reduce the number of large employers choosing to self-insure because the long-range underwriting environment is unlikely to make it financially attractive to transfer risks to outside insurers. However, the growth of group self-insurance may slow, as competitive rating laws will allow greater flexibility in rates and marketing plans which could make individual private insurance more attractive to firms in this market. 25

The ability of open rating to have a real impact on reducing the net costs of workers' compensation insurance is unclear. At least one observer believes that small insureds are unlikely to see an increase in availability or a break in rates under 
open rating; that large insureds will not feel much of an impact because they already play a large part in setting their own rates; and that medium-sized insureds will be pressured to purchase multiple-line insurance packages. "(Open rating will be seen as) another failed government attempt to thwart the economics of the marketplace, for, with or without open rating, the insurers will gravitate toward operations which seem to be profitable." 26

\subsection{MAJOR PUBLIC POLICY CONCERNS}

The major workers' compensation public policy concerns are the related questions of coverage and cost control. The coverage issue has become more important in recent years as the concepts of compensable injury and occupational disease have broadened. As coverage expands, the increase in loss exposure leads inevitably to increased costs. The NCCI sees occupational diseases, defined as those particular to certain occupations and due to causes in excess of ordinary employment hazards, as the most serious potential source of compensable losses over the coming years. In addition, the progressive and recurring nature of many occupational diseases raises complex questions of when compensable liability begins and of responsibility for the liability. 27

With regard to cost control, in recent years legislation has been considered by many states to improve the operation and administration of workers' compensation laws. Possibly the most significant single piece of legislation is known as the Florida wage loss law. The Florida law is seen as an attempt to return to the basic philosophy underlying workers' compensation by compensating the injured employee only for the actual wages lost as the result of an injury. This is in sharp contrast to most state workers' compensation laws, under which compensation for a particular injury is based on a scheduled payment or disability rating irrespective of economic loss. Enactment of this legislation scems to have had a positive impact on controlling costs: rates have been cut significantly, and the improvement in loss experience has heightened competition in this market. ${ }^{28}$ Whether the cost reduction reflects a gain in the efficiency of the system or a reduction in the overall package of employee benefits is a matter of some debate. 


\subsection{GENERAL INDUSTRY VIEW OF INSURANCE INCENTIVES}

The overall orcupational death rate has been reduced by two-thirds over the past 25 years (down from 39 to 13 per 100,0.00 workers), largely as the result of preventive measures taken to reduce occupational hazards. In many instances, workers' compensation insurers have taken the lead in recommending installation, modification, and utilization of protective equipment and procedures which have been effectively reduced employer losses and insurance costs. The emphasis of loss prevention efforts, safety literature, regulations, and training has been on reducing industrial hazards. Less attention has been paid to reducing on-the-job motor vehicle injuries, despite the fact that employees whose work involves the operation of motor vehicles face a considerably higher risk of fatal injury than do industrial workers. Recent studies estimate that car and truck accidents account for up to one-third of all injury-related worker deaths, while only 14 percent of such deaths occur in manufacturing. ${ }^{29}$ It is clear that not as much attention has been focused by workers' compensation insurers on promoting the use of safety belts and other safety driving measures as on reducing other industrial accidents.

Under the present system of workers' compensation insurance, there is no easy way to provide incentives, in the form of premium discounts, for good future behavior. Premium credits (and surcharges) are based on past loss experience. Therefore, even if a company implemented a safety belt use program and promised 100 percent on-the-job belt use by its employees, no credit could be given for such an effort until time had passed and a demonstrable reduction in losses was achieved. Under a retrospective rating plan, credit may be given for lower-than-expected losses during the current policy year, but there is no means to promote actions that may cut losses by providing advance discounts.

In a few states, such as Illinois and Rhode Island, some discretionary pricing is possible. The underwriter can raise or lower the premium rate by up to 25 percent on top of the experience modification by considering whether or not the insured's loss history accurately reflects the exposure to risk. It may be possible, therefore, 
to envision a pricing system which could reflect an underwriter's expectations of future loss reductions, such as those which could occur under a strong employer safety belt use program. 30

It is generally accepted that the workers' compensation system should provide economic incentives to encourage saftety. Using experience modification factors to lower the costs of workers' compensation insurance to firms with superior safety records encourages safety as well as providing the economic benefit of a strengthened competitive position relative to similar firms with less outstanding records.

A large company can expect to realize a significant cut in premium costs from a decrease in compensable losses, but smaller companies (e.g., those with less than \$5 million per year in business) will find it much harifer to reap such financial rewards. The incentive value of the experience modification factor on. employer safety efforts varies with the size of the insured. One study concluded that except for particularly hazardous industries, "incentives provided small firms are so slight as to be negligible... while incentives facing large firms closely approximate those that would be available through self-insurance." 31 Experience rating may be a significant incentive only for the top 20 percent of insured employers (but these employers cover 80 percent of employees); an analysis by the California rating organization found that over 80 percent of employers are essentially too small for their loss experience to have statistical validity. ${ }^{32}$

\subsection{WORKERS' COMPENSATION COST REDUCTIONS: MOTOR CARRIERS}

A inajor workers' compensation insurance company, Liberty Mutual, has compiled claims data over a 12-month policy year (beginning during 1981) for six for-hire trucking fleets (see Table 7-4). These fleets represent all geographic areas of the country and primarily operate tractor-trailers. Both line-haul and city operations are conducted by each fleet. The total number of employees for these firms was 8,050 , of which 6,199 were drivers. Only accidents for which there were both 
medical expenses and lost time were included. The study found that while injuries incurred by truck occupants during the actual operation of a vehicle represented only seven percent of the clairns, threy represented almost one-third of the total dollar losses. While the average costs for all workirs' compensation claims was under $\$ 5,000$, the average for vehicle accident-related claims was more than four times higher. $\$ 1,994,000$ was paid out for the vehicle accident-related injuries alone, an average of nearly $\$ 23,000$ per claim, or $\$ 322$ per year for every driver in the fleet. In other words, a truck fleet with 800 drivers could expect to pay out nearly $\$ 250,000$ each year for injuries which could be substantially avoided through safety belt use. Estimates of safety beit effectiveness in heavy trucks are still far from definitive, but there is some data that suggests belts may reduce fatalities by about 40 percent and serious injuries by up to 60 percent. 33

This can be illustrated using the motor carrier industry as an example, with figures provided by Liberty Mutual officials: The workers' compensation insurance rates for motor carriers, prior to experience modifications, range from about two percent to about 18 percent of payroll depending on the state, with the average around seven or eight percent. For larger trucking companies (those doing \$5-50 million in business per year), these costs could be cut in half with very good experience or doubled with bad safety records (i.e., a nominal eight percent rate could become an effective rate of anywhere from four percent to 16 percent, depending on the experience modification factor). For a company in which payroll represents 25 percent of revenue, when workers' compensation insurance costs are set at eight percent of payroll, these costs are equivalent to two percent of revenue. A company with a poor loss record may have its workers' compensation rate set at 16 percent of payroll, which is equivalent to four percent of revenue, while a company with good loss experience has its rate set at only four percent of payroll, or one percent of revenue. This differential can have considerable impact on the size of profits: when a company is operating on a two percent profit margin, by cutting workers' compensation costs in half the company can increase its profit margin to three percent, a 50 percent increase. At a one percent margin, halving workers' compensation costs can double a company's profits. Thus, all trucking companies 
TABLE 7-4

\section{WOR KERS' COMPENSATION CLAIMS OF SIX MOTOR CARRIER FLEETS*}

\section{Total Claims Experience}

\begin{tabular}{|c|c|c|c|c|}
\hline \multirow[b]{2}{*}{ Number of Claims } & \multicolumn{2}{|c|}{ All Claims } & \multicolumn{2}{|c|}{$\begin{array}{c}\text { Motor Vehicle } \\
\text { Accident } \\
\text { Claims Only }\end{array}$} \\
\hline & & 1,289 & & 88 \\
\hline Cost of Claims & & 33,427 & & 993,812 \\
\hline A verage Cost Per Claim & $\$$ & 4,758 & $\$$ & 22,657 \\
\hline$\%$ Total Claims & & -- & & 6.8 \\
\hline \% Total Claims \$ & & --- & ; & 32.5 \\
\hline
\end{tabular}

\section{Experience by Fleet}

\begin{tabular}{|c|c|c|c|c|c|}
\hline \multirow[b]{2}{*}{ Fleet } & \multirow[b]{2}{*}{$\begin{array}{l}\text { No. of } \\
\text { Drivers } \\
\end{array}$} & \multicolumn{2}{|c|}{ Vehicle Accidents } & \multicolumn{2}{|c|}{ Average Cost Per Claim } \\
\hline & & $\begin{array}{l}\% \text { Total } \\
\text { Claims }\end{array}$ & $\begin{array}{l}\% \$ \\
\text { Cost }\end{array}$ & All & Vehicle Accident \\
\hline $\begin{array}{l}A \\
B \\
C \\
D \\
E \\
F\end{array}$ & $\begin{array}{r}600 \\
1,600 \\
1,968 \\
208 \\
1,004 \\
819\end{array}$ & $\begin{array}{r}12.2 \\
20.0 \\
3.4 \\
21.4 \\
4.8 \\
10.9\end{array}$ & $\begin{array}{l}47.5 \\
35.8 \\
34.6 \\
60.6 \\
12.9 \\
29.3\end{array}$ & $\begin{array}{r}\$ 6,180 \\
9,484 \\
2,625 \\
6,723 \\
4,100 \\
11,307\end{array}$ & $\begin{array}{r}\$ 35,838 \\
16,993 \\
27,128 \\
19,009 \\
10,979 \\
30,526\end{array}$ \\
\hline
\end{tabular}

*NOTE:

1. Claims for 12-month policy year beginning during calendar 1981 .

2. Covers only claims with both lost time and medical expenses.

3. Motor vehicle accident claims relate only to injuries incurred during actual vehicle operation (e.g., does not include injuries from falls while entering a truck or cargo loading related injuries).

SOURCE: Liberty Mutual Insurance. 
may pay the same for fucl, wages, interest, and equipment, but the ones with supcrior loss records may hold a substantial competitive advantage due to lower workers' compensation costs.

\subsection{REDUCTION OF WORKERS' COMPENSATION BENEFITS DUE TO FAILURE TO WEAR SAFETY BELTS}

On March 23, 1981, Governor Richard Snelling directed that his cabinet take steps to ensure that operators and passengers traveling in vehicles on state business use their safety belts at all times. On July 31, 1981, the Vermont Board on State Employees' Benefits notified all Vermont agency and department heads that the board would "henceforth consider as a factor in determining benefits, whether employecs injured in vehicle accidents on state business were wearing their seat belts at all times." The memo asserted the following:

"Under Vermont's Workers' Compensation Act, an employer can contest a claim for compensation on the grounds that the employee did not make use of a safety device provided for his or her use. In these cases, the burden is on the employer to demonstrate that the device was available, that the employee failed to use it, and that such failure caused or aggravated the injury."

In December, 1981, the Vermont Commissioner of Education launched an in-service safety belt education program for state employees. In a 90-minute safety belt education program, workers were informed about the efficacy of belts and the governor's directive that they be worn at all times when traveling on state business. The program also strongly implied that employees violating the directive would have trouble collecting workers' compensation benefits for a motor vehicle injury that occurred when they were not wearing belts.

However, according to Vermont's Workers' Compensation Insurance Coordinator, through January, 1983 no Vermont state employee has had any benefits denied due to failure to wear belts, even though in at least two cases there was clear evidence that injuries were sustained because belts were not worn. Apparently, the custom 
of paying workers' compensation regardless of employecs' negligence in using all available safety equipment is still stronger than the desire to use available legal means to deny employees benefits for failing to wear belts.

\subsection{RECOMMENDATIONS FOR SAFET Y BELT INCENTIVE PROGRAM}

Workers' compensation insurers should be encouraged to develop data on the efficacy of safety belts in decreasing loss experience. This could be accomplished by gaining their participation in industry-specific safety belt programs. The loss data developed by Liberty Mutual for use by the joint American Trucking Associations/Motor Vehicle Manufacturers Association/National Highway Traffic Safety Administration truck program is a good example of how insurers can provide data that are useful in motivating employers to expand their safety belt efforts. Workers' compensation insurers generally believe that a commitment to safety belt use is not by itself likely to be successful in improving belt use rates, nor to have much of an impact on loss experience. Rather, safety belt promotion by employers must be an integral part of a comprehensive, long-term, professionally-managed overall driver safety effort. Armed with data and knowledge of a successful industry-specific driver safety program which they have helped to develop, workers' compensation insurers then could be expected to encourage an emphasis on safety belt use as part of driver safety efforts. While smaller firms will not be the first to benefit from industry-specific successes in increasing safety belt usage, they should eventually receive the benefits of reduced industry-wide loss experience in the firm of lower base premium rates. Despite the lag in workers' compensation premium reductions, smaller firms may be interested in adopting effective safety belt programs since these firms are particularly sensitive to the indirect costs (e.g., productivity, insurance costs, customer losses, etc.) of avoidable motor vehicle injuries.

Insurers could sell such programs to employers not only as a means of reducing workers' compensation premium costs but also as a way of realizing direct and indirect cost savings which have the potential to be translated into either 
competitive advantage or profit increases. The direct compensable costs of each employee fatality have been estimated at $\$ 120,000$ in direct payments by an employer for wages, inedical and rehabilitation expenses, survivor benefits, and property damage. 35 Not included in that figure are the many indirect costs associated with employee deaths and injuries, including productivity losses and the extra efforts needed to cope with the temporary or permanent loss of an employee. These indirect costs have been estimated at up to ten times as great as the direct costs. 


\section{NOTES TO CHAPTER 7}

1. Price, Daniel N. "Workers' Compensation: Coverage, Benefits, and Costs, 1979," Social Security Bulletin, Vol. 44, No. 9, September 1981, p. 9.

2. Bicklehaupt, David L. General Insurance (Richard D. Irwin: Homewood, IL), 1974, pp. 622-623.

3. Ibid., p. 631 .

4. Workers' Compensation Insurance Rate Régulatory Study (WCIRRS), Conducted by Risk Planning Group, Inc., and Independent Actuarial Services, Inc., February 1982, pp. I-2, I-75 - I-76.

5. "Workers' Compensation Marketing - 1981." Best's Insurance Management Reports, Statistical Studies, Property/Casualty, Release No. 17, September 6, 1982.

6. "Financing Workers' Compensation," Risk Management Reports, Volume IX, No. 3, May/June 1982, p. 33.

7. "Insurance F acts, 1981-82 Edition," Insurance Information Institute, p. 82.

8. Bicklehaupt, pp. 622, 633-640.

9. "Workers' Compensation Benefit Levels by State," Liberty Mutual Insurance Company, September 1981.

10. O'Brien, Edward D., Sr. "National Trends in Workers' Compensation Benefits," Workers' Compensation: Perspective for the Eighties, Society of Chartered Property and Casualty Underwriters (CPCU), F all 1981, Pp. 49-50.

11. Bicklehaupt, pp. 626-627.

12. Gentile, Willard J." "The New Workers' Compensation Manual," Workers' Compensation: Perspective for the Eighties, p. 41 .

13. Bicklehaupt, p. 630 .

14. WCIRRS, Pp. $1-34-1-39$.

15. Conversation!s with Liberty Mutual officials.

16. Bicklehaupt, p. 641 .

17. Ibid., p. 643.

18. WCIRRS, PP. $1-69-1-70$. 
19. Insurance Facts, p. 26.

20. "Workers' Compensation Marketing - 1981."

21. Ibid.

22. Keys, Robert W., "Outlook for Price and Availability of Workers' Compensation Insurance in the 1980s," Workers' Compensation: Perspective for the Eighties, P. 4.

23. Discussion in this section is based on WCIRRS, pp. I-67 - I-77.

24. "Workers' Compensation Marketing - 1981." Best's Insurance Management Reports, Statistical Studies, Property/Casualty, Release No. 17, September 6, 1982.

25. Best's review, pp. 136-137.

26. Keys, op. cit., p. 9.

27. "Workers' Compensation Marketing - 1981." Best's Insurance Management Reports, Statistical Studies, Property/Casualty, Release No. 17, September 6, 1982.

28. Inman, Jack C., "Wage Loss in Florida; Workers' Compensation: Perspective for the Eighties, pp. 67-76.

29. Baker, Susan P, Judith S. Samkoff, Russell S. Fisher, and Carol B. Van Buren, "Fatal Occupational Injuries," Journal of the American Medical Association, August 13, 1982, cited in The Highway Loss Reduction Status Report, Insurance Institute for Highway Safety, Vol. 17, No. 11, August 12, 1982.

30. Conversations with Liberty Mutual officials.

31. Russell, Louise B. "Safety Incentives in Workmen's Compensation Insurance," The Journal of Human Resources, Volume IX, 1974, in WCCIRS, p. 1-86.

32. Workers' Compensation Insurance Rating Bureau of California, "How Important is the Classification system to the Employer," April 10, 1981, mimeo, in WCIRRS, pp. I-79-86.

33. TSC estimate derived from data in the following:

Mergel, Joseph, "Heavy Truck Occupant Crash Protection," Transportation Systems Center, December 1982;

Clarke, Robert M. and Mergel, Joseph, "Heavy Truck Occupant Crash Protection - A Plan for Investigating Ways to Improve It, SAE Technical Paper, 1982; and 
Ranney, Thomas $\Lambda_{.,}$"Injury Causation and Heavy Truck Occupant Crash Protection," in 26th Annual Procecdings, American Association for Automotive Medicine, October 1982, pp. 149-165.

34. "The Profit in Safety Belts: A View for Employers," Pabon, Sims, Smith and Associates, Inc. for the National Highway Traffic Safety Administration, U.S. Department of Transportation. 